Linköping Studies in Arts and Sciences No. 787

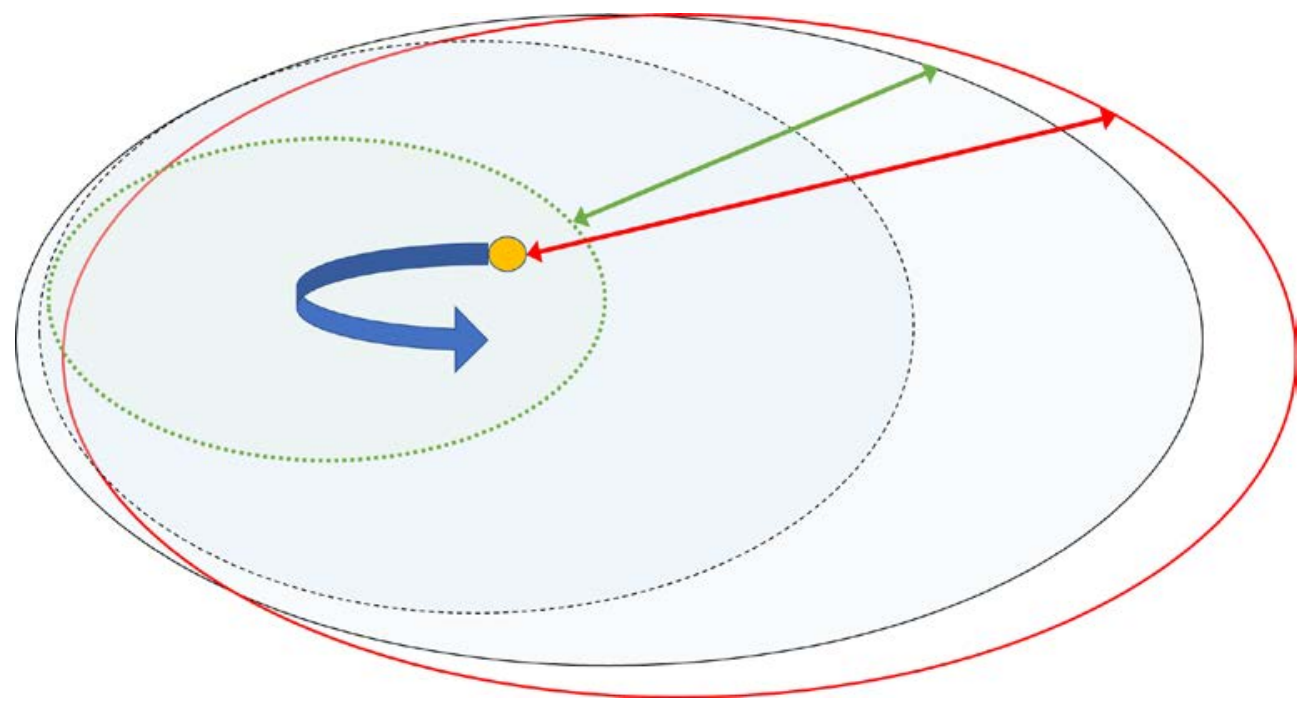

\title{
Adaptive behaviour in traffic: An individual road user perspective
}

\section{Sara Nygårdhs}

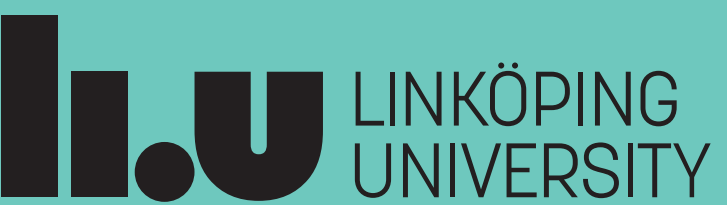




\title{
Adaptive behaviour in traffic:
}

\section{An individual road user perspective}

\author{
Sara Nygårdhs
}

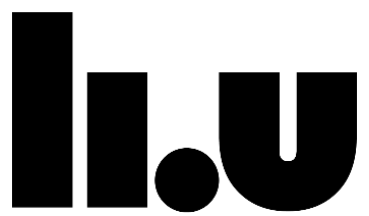

LINKÖPING UNIVERSITY

Linköping Studies in Arts and Sciences No. 787

Faculty of Arts and Sciences

Linköping 2020 
Linköping Studies in Arts and Sciences • No. 787

At the Faculty of Arts and Sciences at Linköping University, research and doctoral studies are carried out within broad problem areas. Research is organized in interdisciplinary research environments and doctoral studies mainly in graduate schools. Jointly, they publish the series Linköping Studies in Arts and Sciences. This thesis comes from the Division for Human-Centered Systems (HCS) at the Department of Computer and Information Science.

Distributed by:

Department of Computer and Information Science Linköping University

58183 Linköping

Sara Nygårdhs

Adaptive behaviour in traffic:

An individual road user perspective

Edition 1:1

ISBN 978-91-7929-857-9

ISSN 0282-9800

CSara Nygårdhs

Department of Computer and Information Science 2020

Published papers have been reprinted with permission from the respective copyright holder

Printed by LiU-Tryck, Linköping 2020

URL: https://urn.kb.se/resolve?urn=urn:nbn:se:liu:diva-164952 


\section{ABSTRACT}

Road-user adaptation is a prerequisite for traffic to run smoothly. By adaptation, the road user aims to ensure a feeling of comfort according to his or her present state and capability. In this thesis, adaptive behaviour of car drivers and cyclists in response to different factors is explored, using the individual perspective of the road user. The research focuses on investigating how adaptation in the road traffic environment can be described, and what adaptations road users make in traffic in response to static and dynamic infrastructure, additional tasks and other road users.

One simulator study and three field studies in real traffic were carried out. The study results implied that the current road-user role and the preconditions for that role, in terms of vehicle and infrastructure, affect adaptive behaviour. The results also showed that in non-complex situations, there is a certain level of visual guidance above which more detailed information does not have any effect on speed adaptation. Detailed information that allows road users to improve their predictions to take action to ensure a feeling of comfort, is however preferred. Under increased situational demands, vehicle speed can be reduced to maintain the safety margins. It was found that there are individual strategies concerning what degree of complexity for interaction with an additional task is acceptable.

A conceptual model of adaptation in relation to the environment and subjective perceptions of safety and a feeling of comfort is proposed and applied to different traffic situations. For future transport system designs it is advised that adaptive behaviours of road users are supported. 


\section{ACKNOWLEDGEMENTS}

While working on this thesis, I have exceeded my comfort zone many times. Thanks to a lot of people, adaptation has however been possible.

First of all, I would like to thank all the study participants for making it possible to do relevant research. Without your effort, there would be nothing.

Thank you also to everyone who contributed in one way or another to the work. There are more of you than can be mentioned here.

Björn Johansson, my main supervisor, thank you for taking me on and pushing me further. Your knowledge, readiness to read and comment on drafts (and there have been many!) as well as your rationality have been very helpful.

Katja Kircher, thank you for sharing your expertise, for your creativity and ability to seek solutions and for working together in the field studies.

Katja Kircher and Björn Johansson together, thank you for your different perspectives and interesting discussions at our supervisory meetings.

Jan Andersson, thank you for making me take the step to start with a PhD. Your belief in me made it so much easier.

Nils Dahlbäck, thank you for your enthusiasm and interest in my progress along the way and a thousand ideas.

Esso Lundkvist, thank you for the fun when working with you and for always being there when I need to ask something.

Joakim Dahlman, thank you for your valuable and nice comments at the $60 \%$ seminar.

Oliver Carsten, thank you for being a nice discussant and for your comments and suggestions at the final seminar.

Christer Ahlström, thank you for all your help, data analyses, nice figures and, sometimes frustrating but always helpful, comments.

Carina Fors, thank you for taking interest although we did not work together in this, and for our collaborative writing of the first scientific paper I ever published.

Anna Anund, thank you for reading and commenting on Paper III and on an early version of the kappa.

Åsa Forsman, thank you for patiently explaining statistical models to me.

Birgitta Thorslund, thank you for being such a good friend with whom most aspects of life can be discussed, even work.

Thank you to the other nice people at VTI for your support, and especially Jonas Ihlström, Ignacio Solís Marcos and Erik Kjellman for your work in relation to the studies.

The whole COIN group, thank you for your feedback and for being a group at the university to which I could belong throughout the PhD years. I would especially like to thank Mattias Forsblad for being a fellow $\mathrm{PhD}$ student and a friendly face at the university from the start, and Sam Thellman for being the same at the end. 
Anne Moe, thank you for all your help (and that sums up to a lot) in administrative issues at the university.

Arjan Stuiver and Joke van Dijken, thank you for your invaluable help conducting the study in the Netherlands.

Gabriel Helmers, thank you for your involvement when planning the road delineator study.

Erik Hollnagel, thank you for your kind permission to use the ECOM figure every time I asked.

I would also like to express my gratitude to friends and family for your support in varying ways. It means a lot to be able to let some frustration out or to celebrate some steps on the way or to simply be occupied with other things than the thesis.

Gunilla Nygårdhs, thank you also for your constant language support, and for proof-reading papers I and II, as well as a late version of the kappa.

Rolf Jonsson, thank you for being all the things that you are, funny, loving, honest and always on my side.

Axel and Tilda Nygårdhs, thank you for only caring about me, not about the thesis.

\section{Sara Nygårdhs}

Linköping, April 2020 


\section{LIST OF ABBREVIATIONS}

ADAS - Advanced Driver Assistance Systems

ANOVA - Analysis of Variance

CDT - Countdown Timer

COCOM - Contextual Control Model

DiC - Driver in Control

ECOM - Extended Control Model

ETTO - Efficiency-Thoroughness Trade-Off

FOT - Field Operational Test

JCS - Joint Cognitive System

MiRA - Minimum Required Attention

NASA-TLX - National Aeronautics and Space Administration - Task Load Index

NASA-RTLX - National Aeronautics and Space Administration - Raw Task Load Index

OECD - the Organisation for Economic Co-operation and Development

RSME - Rating Scale Mental Effort

SMS - Short Message Service

SWAT - Subjective Workload Assessment Technique

TPB - Theory of Planned Behaviour

TOTE - Test-Operate-Test-Exit

VRU - Vulnerable Road User 


\section{INDEX}

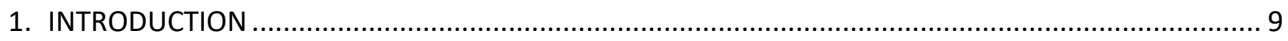

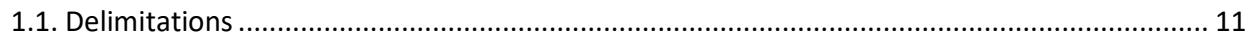

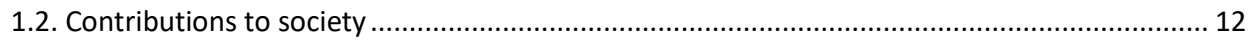

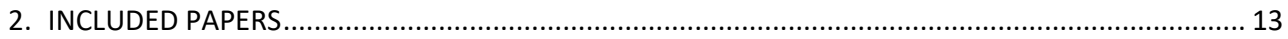

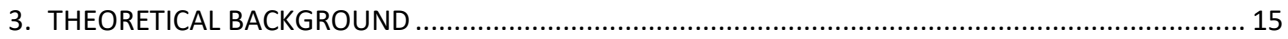

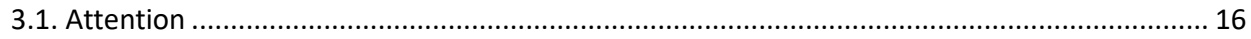

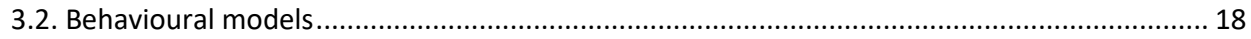

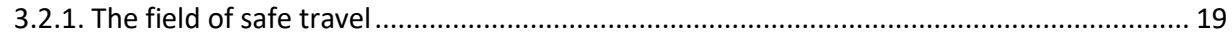

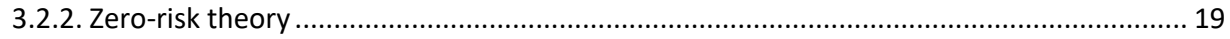

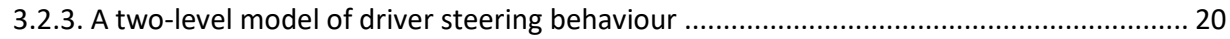

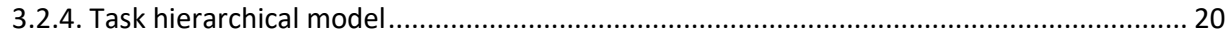

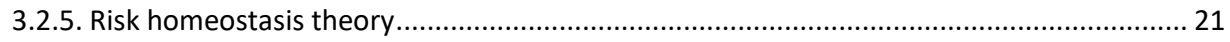

3.2.6. Task-capability interface model and task difficulty homeostasis theory ............................. 21

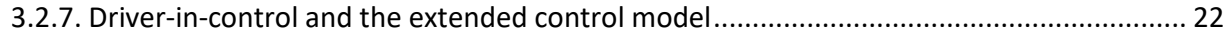

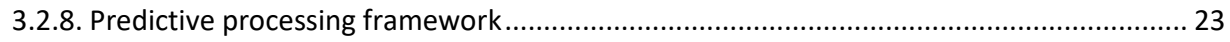

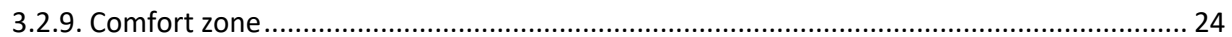

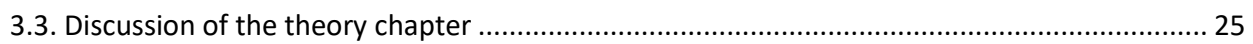

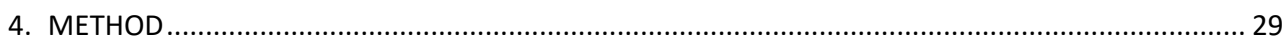

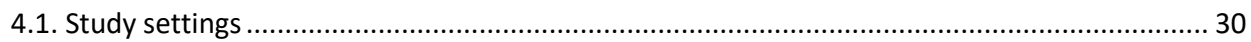

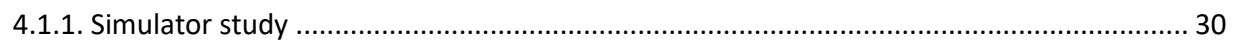

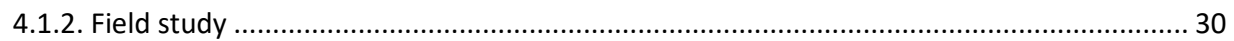

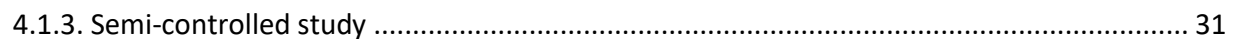

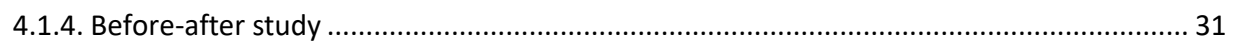

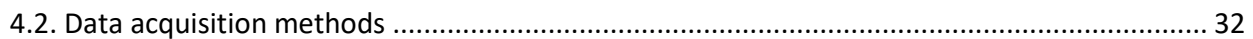

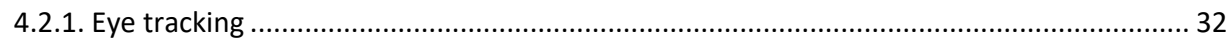

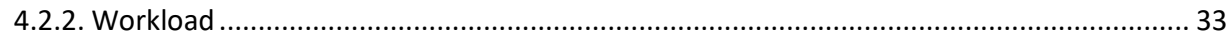

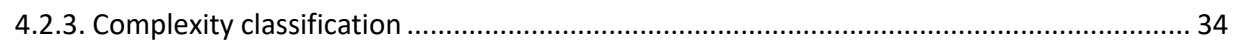

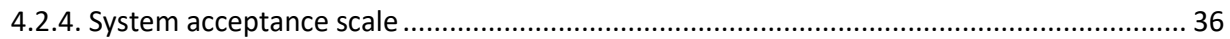

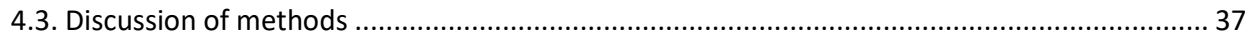

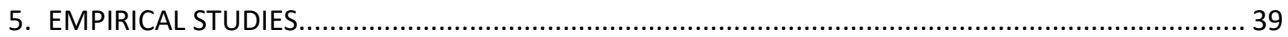

5.1. Paper I. The effect of different delineator post configurations on driver speed in night-time

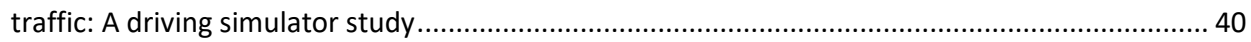

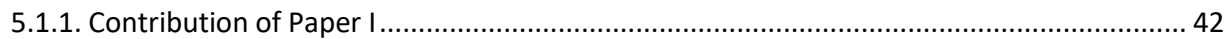

5.2. Paper II. Bicyclists' adaptation strategies when interacting with text messages in urban environments 
5.2.1. Contribution of Paper II

5.3. Paper III. Trade-offs in traffic: does being mainly a car driver or a cyclist affect adaptive behaviour while driving and cycling?

5.3.1. Contribution of Paper III.

5.4. Paper IV. Cyclists' adaptation to a countdown timer to green traffic light: a before-after field study. 46

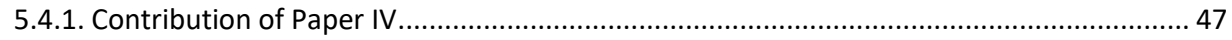

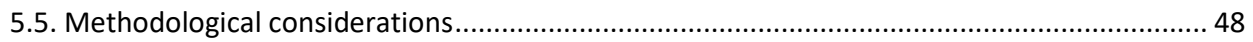

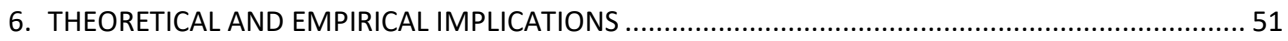

6.1. Road-user adaptation in response to static infrastructure ...................................................... 54

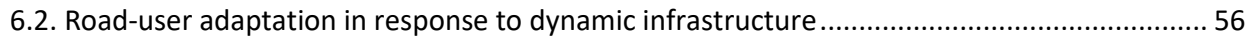

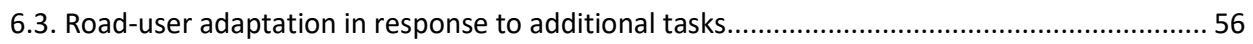

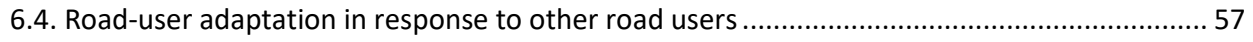

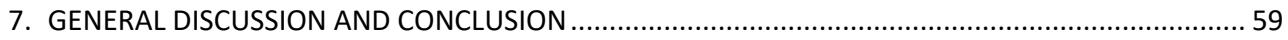

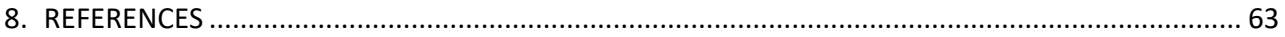




\section{INTRODUCTION}

Essentially everyone is a road user on an everyday basis. To go to school, kindergarten or work, to run errands, to visit friends and family, for exercise and for recreational purposes people become part of the traffic system in diverse ways. Whether it is by walking, riding a bike, going by bus, driving a car or some other means of transportation, they are still part of the same traffic system and try to make sure that the goal of their journey is achieved. What they are experiencing, both in terms of internal factors such as drowsiness, time pressure, anger etc., and external factors such as stressful traffic, text messages, road equipment, unexpected traffic manoeuvres from other road users etc., will affect their behaviour in different ways and also differently for different persons. Miscellaneous strategies are adopted to handle these internal and external factors in connection to transportation, with a constant trade-off between safety, the influencing factors and the other goals of the journey, striving for a general feeling of comfort. In this thesis, adaptation in the road traffic environment will be viewed as the road user setting the safety margins of the comfort zone according to his or her present state and capability. The comfort zone is where the road user experiences a feeling of comfort, with large enough subjective safety margins. These concepts will be further discussed within the text. The overall strategies and momentary adaptations are manifested by the behaviour of the road user. Identifying what kind of adaptations are made in certain situations, and why, contributes to understand road-user adaptations. This understanding forms a basis for a deeper knowledge of human behaviour in traffic. If the adaptations made are not adequate for the prevailing situation, the consequences can be severe, and knowledge about human behaviour in the traffic environment can potentially be used to take both proactive and reactive measures, mitigating the effects of inappropriate adaptation or preventing it. During the last couple of decades, the perspective on road safety has developed from focusing on the road user to the transport system overall, where all parts of the system should be considered to increase safety. For instance, in the Swedish Vision Zero the shared responsibility for traffic safety between those designing and those using the transport system is acknowledged (Swedish Transport Administration, n.d.). Since it is unfeasible to change the way that humans function, the system needs to be adapted to the humans for which it is made.

\section{The goal of this thesis is to increase and accumulate knowledge about road-user adaptation} in the traffic environment. This knowledge should aid in designing the traffic system in support of road users trying to achieve their goals.

For private individuals who are in control of their own locomotion, driving a car, riding a bicycle and walking are common means of transportation. The Swedish national travel survey of 2015-2016 showed that of all main trips (basically trips starting and ending at a person's home or workplace) undertaken, $27 \%$ were performed by bicycle or walking with an average travel distance of $3.2 \mathrm{~km}$, and 54\% by car with an average distance of $36 \mathrm{~km}$ (Trafikanalys, 2017). In this doctoral thesis, the focus is on driving and cycling, because of their prevalence and the speed associated with the vehicle, which reduces the time available for adapting to new situations compared to walking. Driving a car and cycling include many different, but also similar aspects. Similarities include that it is possible to decide at will (within constraints) when to travel and to choose your own way to get to your destination. In both driving and cycling you will have to attend to varying objects depending on the current traffic situation. The most salient feature distinguishing car drivers from cyclists is the degree of vulnerability. 
While a car driver is protected by the hard shell of the car, the seatbelt, air bag and other safety equipment in the car, a cyclist may wear a helmet but is otherwise unprotected in traffic. The room for manoeuvre is restricted for cars, because drivers are only allowed to drive within their own lane and it is not acceptable to stop the car unless there is a special place to do so. Although a bicycle also has a limited path on which to travel, a cyclist can slow down substantially or pull over at his or her own convenience, without disturbing other traffic in the same cycle path. The infrastructure is also different for cars on roads where rules and regulations apply that a driver must learn before applying for a driving licence. The infrastructure for bicycles is often more limited and cycle paths may not always lead the whole way to the destination. Although it is allowed to cycle along a rural road, it can be associated with danger for cyclists to do so, because the lateral clearance between a cyclist and an overtaking vehicle has been found to be less than $1.5 \mathrm{~m}$ in many cases (Dozza, Schindler, Bianchi-Piccinini, \& Karlsson, 2016). The room for mistakes or deviations is hence narrow for both road-user roles but the cyclist is more vulnerable if an accident occurs. Demography is another difference concerning who can use a certain means of transportation. While children can learn to ride a bicycle at an early age, guided by adults in their presence, there is an age requirement as well as practical and theoretical tests to pass before receiving a driving licence for a private car. Physical abilities limiting car driving include eyesight restrictions, while cycling on the other hand demands a certain degree of physical health. Social factors such as economic capacity also influence who can afford to apply for a driving licence and to buy a car.

Research has, over the years, developed a number of behavioural models that can be used to investigate road-user behaviour from different perspectives. Several of them have in common that the road user will try to keep his or her effort, or workload, at a comfortable level. Some of the models concern the individual road-user behaviour while other models are extended to include the vehicle as well. The behavioural models in turn illuminate different aspects of adaptive behaviour. In this thesis some of the most important models will be described and evaluated regarding their usefulness for understanding adaptive behaviour in traffic. The extended control model (Hollnagel \& Woods, 2005), ECOM, is chosen as an analytical framework. What makes ECOM appropriate is discussed later.

Behavioural models are however not enough for understanding adaptive behaviour in traffic, since adaptations are influenced by a number of important factors in the environment. Static infrastructure denotes components of the infrastructure perceived as constant by the road user from the moment they are detected until they are no longer perceivable. Examples include road delineators, static road signs etc. Dynamic infrastructure refers to infrastructure components that can change from the perspective of a single road user moving in traffic. Variable message signs, traffic signals and dynamic speed bumps are examples of these. Aspects of both static and dynamic infrastructure will be addressed in this thesis.

It is also important to realise that most people are not only focused on the traffic when driving, cycling etc. The term additional task is here used for a task that is not directly connected to the driving or cycling task. However, this does not mean that the task is not considered as important to the road user as moving in traffic. Some examples are changing radio channel and using a mobile phone. (The often-used term secondary task is not used because of its implication that one task is more relevant than another.) 
The term other road users refers to the presence and behaviour of other relevant road users as perceived or predicted by a specific road user. An example is when a cyclist going straight predicts that there might be a car coming from an obscured road to the right.

Research issues concerning road user adaptation in response to the factors stated above have been narrowed down to research questions. The investigation of the research questions has been operationalised by studies with participant drivers or cyclists or both and consists of one simulator study and three field studies. The research questions are as follows.

On a general level:

1. How can an adaptation in the road traffic environment be described in terms of comfort zone and safety margins?

In relation to static infrastructure:

2. How do drivers adapt their speed in response to different road delineator configurations?

3. How do drivers and cyclists adapt their behaviour in intersections?

In relation to dynamic infrastructure:

4. How do cyclists adapt their behaviour to a countdown timer to green traffic light for cyclists?

In relation to additional tasks:

5. How do cyclists adapt towards text messages received on their mobile phone?

6. How do drivers adapt their speed in connection to an additional task inside the car?

In relation to other road users:

7. How do drivers and cyclists adapt to other traffic in a mixed traffic intersection with stop rule and in a signalised intersection?

Research questions 2 and 6 are addressed in Study I, research question 5 is examined in Study II, research questions 3 and 7 are studied in Study III and research question 4 is investigated in Study IV. Research question 1 is mainly addressed by theoretical considerations and supported by the empirical studies.

Taken together, the research questions all have the same overall aim, i.e. to describe and understand adaptations in the road traffic environment from the perspective of individual road users. The intention is that the transport authorities can use this knowledge and be aided in planning and decision-making to facilitate for road users, especially in complex situations that are difficult to understand.

\subsection{Delimitations}

The means of transportation in focus for this thesis are driving a private car and cycling. Emphasis is placed on the human behaviour of the person driving or cycling, not on the specific vehicle. Professional drivers in general have more driving experience than the average driver which may lead to other ways of handling traffic situations. To minimize the heterogeneity and the number of aspects to consider, only non-professional drivers and adult cyclists are included. The non-professional drivers constitute the majority of people driving in 
traffic. The same reasoning can be applied for autonomous/self-driving cars, which are also excluded. Interaction between several road users is not examined here, other than from the individual perspective of a single road user, where other road users are perceived as factors affecting adaptation. Hence, the title of the dissertation. Additionally, environmental factors such as weather conditions are not specifically included in the thesis but are factors occurring naturally in field studies. Moreover, this thesis is not intended to evaluate the effects of different road safety measures, but instead to address how humans adapt their behaviour in traffic, to cope with a variety of challenges in traffic situations.

According to the definition by the Organisation for Economic Co-operation and Development (OECD) "behavioural adaptations are those behaviours which may occur following the introduction of changes to the road-vehicle-user system and which were not intended by the initiators of the change" and "behavioural adaptations occur as road users respond to changes in the road transport system" (OECD, 1990, p.23). Throughout this thesis, some characteristics differ from this definition, and need to be clarified: Here a micro perspective is used, and the timeframe is short. Additionally, the road traffic system, which includes pedestrians and vehicles on roads, is handled, in contrast to the road transport system which involves the act of transporting.

\subsection{Contributions to society}

While the focus in this dissertation is primarily on the scientific aspects of adaptive behaviour in traffic, the topics of the studies in this thesis have not only been chosen for their scientific relevance, but also because they address issues that can have direct or indirect consequences for society. All studies contribute by providing a knowledge base that can be used for designing road infrastructure to how road users behave; Study I contributes by increased knowledge about how people adapt in terms of speed to different road delineator configurations (one part leading to road authorities changing their regulations), Study II contributes to the knowledge about various ways for cyclists to adapt to incoming text messages, Study III provides increased knowledge about the interaction between car drivers and cyclists and what factors affect adaptation at intersections, whereas Study IV provides increased knowledge about what information cyclists use and how they adapt their behaviour to the information of a countdown sign. 


\section{INCLUDED PAPERS}

\section{Paper I}

Nygårdhs, S., Lundkvist, S.-O., Andersson, J., \& Dahlbäck, N. (2014): The effect of different delineator post configurations on driver speed in night-time traffic: A driving simulator study. Accident Analysis \& Prevention, 72, 341-350.:

- My contribution to paper: Participated in the planning of the study, data collection, analyses, authoring the paper.

- Co-authors' contributions: S.-O. Lundkvist led the planning of the study, Jan Andersson supervised the analyses and the writing of the paper and Nils Dahlbäck supervised the writing of the paper.

\section{Paper II}

Nygårdhs, S., Ahlström, C., Ihlström, J., \& Kircher, K. (2018). Bicyclists’ adaptation strategies when interacting with text messages in urban environments. Cognition, Technology \& Work, 20(3), 377-388.:

- My contribution to paper: Involved in planning, data collection, planning analyses together with colleagues, analysing (part of) data, main author of the paper.

- Co-authors' contributions: Christer Ahlström wrote the introduction and analysed part of data, Katja Kircher supervised the writing of the paper, Christer Ahlström, Jonas Ihlström and Katja Kircher were all involved in planning the study and collecting data.

\section{Paper III}

Nygårdhs, S., Kircher, K., \& Johansson, B.J.E. (2020). Trade-offs in traffic: does being mainly a car driver or a cyclist affect adaptive behaviour while driving and cycling? European Transport Research Review. Advance online publication. doi:10.1186/s12544-020-0396-y:

- My contribution to paper: Involved in planning and data collection, analysing and interpreting the data, authoring the paper.

- Co-authors' contributions: Katja Kircher took part in the data collection and data reduction process and added part of the discussion section, Björn J E Johansson supported the writing of the parts concerning the extended control model.

\section{Paper IV}

Nygårdhs, S. (submitted). Cyclists' adaptation to a countdown timer to green traffic light.:

- My contribution to paper: Involved in planning, all parts of data collection, analysing and interpreting the data, authoring the paper. 


\section{THEORETICAL BACKGROUND}

Adaptation has been described in many ways and differently in different disciplines. The term adaptive behaviour stems from biology and refers to behaviour that contributes to an individual's survival or reproductive success, i.e. natural selection. Behavioural adaptation denotes adapting to changing situations and changing environments (Carsten, 2013) and in the traffic area it has often been used for traffic behaviour in general regarding introduction of new road safety measures (Rudin-Brown \& Jamson, 2013).

Considering adaptation in the road traffic setting, terms such as compensatory behaviour, adaptive behaviour, behavioural adaptation and self-regulation have been used. The term compensatory behaviour has been used for self-selected added workload, e.g. in naturalistic driving to describe how drivers conversing on a hand-held mobile phone changed lanes less frequently and looked forward more (Fitch, Grove, Hanowski, \& Perez, 2014). In simulated driving, compensatory behaviour has been used for describing how drivers minimized cognitive workload from driving by reducing their speed to focus on an additional task (Son, Lee, \& Kim, 2011), and in cycling for terming behaviours such as speed reduction and choosing an appropriate location for performing additional tasks (Adell, Nilsson, \& Kircher, 2014). The term adaptive behaviour has been used for tactical compensation in traffic, such as speed adaptation and keeping distance from the car in front but also for anticipation to avoid accidents when cognitive or neuropsychological functions or both have declined (de Raedt \& Ponjaert-Kristoffersen, 2000). Adaptive behaviour has further been referred to in connection with for example road-crossing behaviour in a simulation study where pedestrian crossing time was adjusted to the time-to-arrival of a bike (te Velde, van der Kamp, Barela, \& Savelsbergh, 2005). The term behavioural adaptation has often been used in connection with safety measures, where introduction of a safety measure has other than the intended effects (Rudin-Brown \& Jamson, 2013), for example better visual guidance may lead to increased driving speeds (e.g. Kallberg, 1993). Self-regulation is a term typically used in connection with older drivers, where self-regulatory behaviours such as avoiding driving at night and in busy traffic are reported (Blanchard \& Myers, 2010; Charlton et al., 2006).

To summarize, compensatory behaviour and adaptive behaviour are terms that have been used more or less interchangeably concerning individual road-user behaviour in specific situations, although compensatory behaviour often includes the accommodation of an additional task and adaptive behaviour is more linked to situational changes. Furthermore, behavioural adaptation has been more connected to a population of road users reacting on road safety measures, whereas self-regulation has been used for road users reasoning about their own capabilities on a strategic level.

In this thesis the term adaptation is used to address the adjustments individual road users make to handle the demands of the current and in the near future expected road traffic situation, with respect to possible additional tasks. By individual I mean to investigate the individual perspective of a road user, with the aim to understand more global issues. The demands include static and dynamic infrastructure as well as other road users. Current refers to momentary, reactive, adaptations, while in the near future expected refers to proactive adaptations that are carried out in a time interval of a few seconds for urban areas but can be somewhat longer for rural areas. This is visualized in Figure 1. 


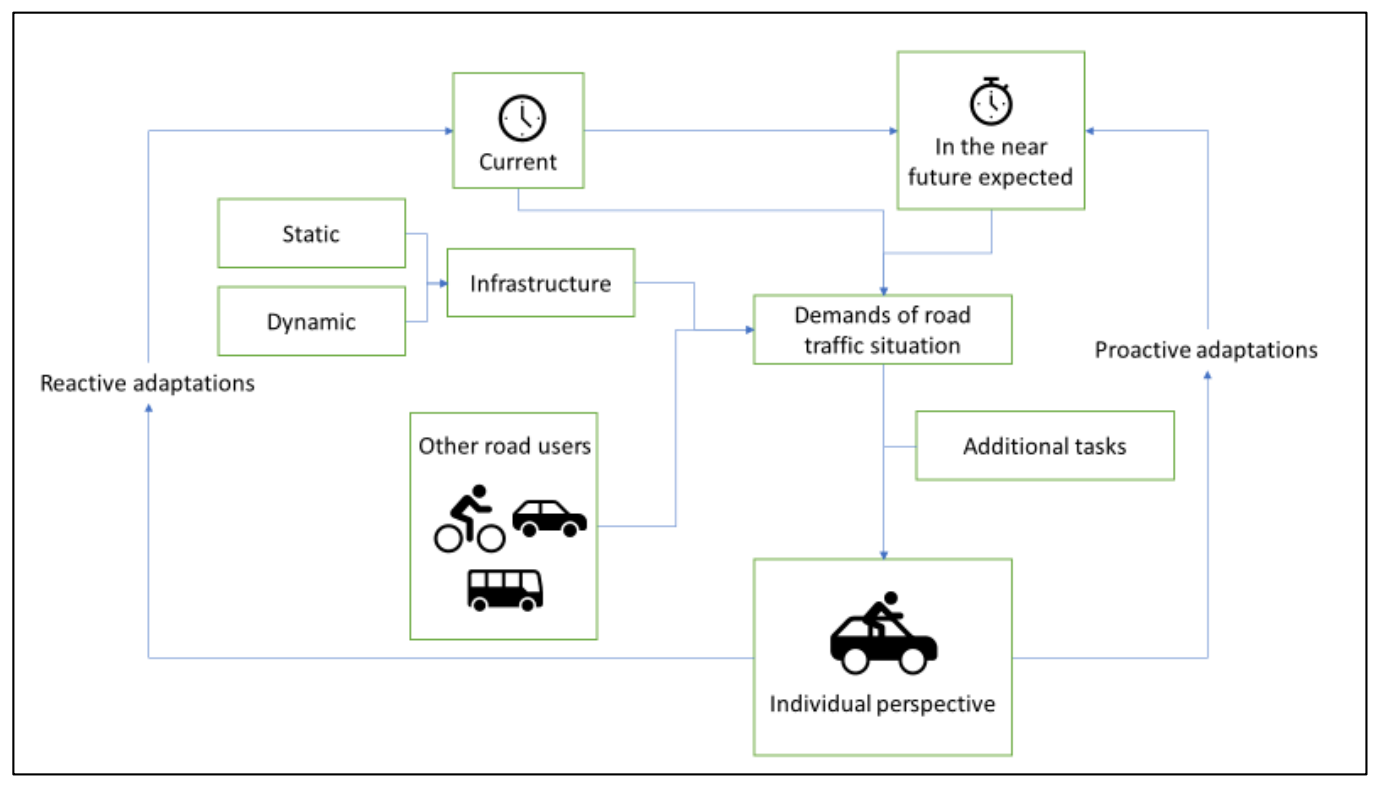

Figure 1. Adaptation from the individual perspective of a road user in this thesis.

One way of sorting adaptive behaviours is to discern between proactive and reactive adaptations. Proactive adaptations are made in relation to anticipated upcoming situational demands and are based on one's own prerequisites such as being in a hurry, more steady environmental features such as weather conditions, and self-paced activities such as initiating a phone call. Reactive adaptations are made as a reaction to the current traffic situation, including other road users and additional tasks that call for immediate attention, such as answering a phone call.

For an adaptation to take place, there must be something to adapt to, either at present or expected. For simplicity's sake this will hereafter be called an adaptation object, although it does not have to be a physical object but could also be more abstract things such as rules, goals and emotions. Knowing that there is a support system may initiate adaptation to it, for instance by not manually correcting for swerving inside the lane with a lane departure warning system. No adaptation can take place without attending to the adaptation object, whether consciously or not. The following section addresses attention in traffic.

\subsection{Attention}

Attention is understood on an intuitive level as the often-cited quote by William James (1890) states: "Every one [sic] knows what attention is. It is the taking possession by the mind, in clear and vivid form, of one out of what seem several simultaneously possible objects or trains ... of thought." A definition of attention has, however, not been agreed upon, although attempts have been made. Here the stance is taken on attention as a cognitive process that can use sensory input to confirm the current situation and to predict how the situation will emerge. Attention is used for selecting what input should be processed when the prediction is uncertain to increase knowledge of the situation. With such knowledge decisions can be made concerning whether an adaptation is necessary and if so, what kind of adaptation. 
In traffic, as in many other aspects of life, knowledge, expectations and goals guide our information intake to relevant parts of a scene (Corbetta \& Shulman, 2002; Land, 2006; Neisser, 1976; Yarbus, 1967). This top-down processing of the brain can however be interrupted by bottom-up information if new, unexpected, salient and possibly hazardous stimuli are detected (Corbetta \& Shulman, 2002; Itti \& Koch, 2001), such as other road users suddenly crossing the road ahead without previous notice. These stimuli can lead to reactive adaptive behaviours by avoidance manoeuvres. Attentional selectivity helps governing what people become aware of, and through attention a person selects subsets of the information he or she receives for further processing, while information that does not receive such further processing often fails to reach awareness (Hyman Jr, Sarb, \& Wise-Swanson, 2014; Most, Scholl, Clifford, \& Simons, 2005).

It is important to acknowledge that the mind does not consciously attend to (i.e. is subjectively aware of) everything that is presented to it, neither visually, auditorily nor through any of the other senses. On the other hand, as phrased by Koch: "When attending to something, the rest of the world doesn't disappear" (Koch, 2004, p. 171) and sensory input is continuously collected. Visualising attention by terms such as "a spotlight" (see for instance Findlay \& Gilchrist, 2003) could therefore be misleading. While haptic input can give sensory information about the state of the road surface, smell can give information about where (not) to go to avoid fumes, sound and vision can give information about the emerging situation. By hearing, information of approaching vehicles from behind can for instance lead cyclists to adapt to the situation by adjusting their speed before an intersection. However, the main information source used by attention in the traffic context is often vision.

Charlton and Starkey (2013) argue that for skilled performance, such as experienced driving, there are two processes involved. In the "operating process" attention to the task is conscious and intentional, whereas in the "monitoring process" nonconscious surveillance is performed where incoming stimuli are compared to earlier instances of driving. Conscious attention to the driving task is needed when the monitoring process detects an unfamiliar situation or stimuli related to loss of control or potential threats.

Previous experiences are indeed necessary for predicting the future, which is of high relevance in the traffic environment because it will guide our expectations. Neurological evidence states that when a person is not attending to a particular task, i.e. when no goaldirected attention is used, some parts of the brain, called the default mode network, increase their activity (Raichle, 2010) compared to when attention is needed for performance. The default mode network is important for the episodic memory (Snyder \& Raichle, 2012) in which personal experiences are stored and is hence input for the monitoring process described by Charlton and Starkey (2013). Outcomes of different alternatives in the past, including emotional responses (see the somatic marker hypothesis in Damasio, 1996), will guide decision-making in a certain situation and hence play a role in determining which adaptive behaviour should be performed when faced with an adaptation object.

Drivers have been observed to focus the fovea on places from which they need to obtain information (Land, 2006) and allocating attention to an object has processing advantages such as level of detail (Findlay \& Gilchrist, 2003). Visual sampling has been further explored by Kircher and Ahlstrom in studies with occlusion glasses (Kircher \& Ahlstrom, 2017a), eventually resulting in the theory of Minimum Required Attention (MiRA; Kircher \& 
Ahlstrom, 2017b). The MiRA theory states that as long as a driver samples sufficient information from relevant parts of the traffic environment at relevant points in time and with a sufficient enough frequency, he or she should not be perceived as inattentive, regardless of whether the driver is executing other tasks or not. Eye tracking is one way of assessing this information intake for visual sampling, which can be both foveal and peripheral.

Because of the vast amount of information in a visual scene, most visual sampling occurs without fixating individual objects (Wolfe, Dobres, Rosenholtz, \& Reimer, 2017). The point of fixation is not the only part of the visual field that is attended to, or that can be attended to, and peripheral vision plays a very important part here (Wolfe et al., 2017). Due to the fast information processing from peripheral vision to higher order understanding, it is enough with just a glance of the traffic scene to achieve a basic understanding of it (Wolfe et al., 2017). Whether an adaptation is needed and what type of adaptation will be carried out is based on the expectations that are associated with the traffic scene, in combination with other input. Apart from retaining information in driving, peripheral vision is also useful for guiding eye movements to interesting areas where more information needs to be sampled, and to facilitate perception of the world in absence of eye movements (Wolfe et al., 2017). It makes it possible to navigate the world safely without running into obstacles when conscious attention is directed elsewhere. This nonconscious adaptive behaviour of smooth navigation has been observed for people interacting with their mobile phone while avoiding to walk into branches of a tree with money attached to them, without observing the money (Hyman Jr et al., 2014).

Change blindness and inattentional blindness are phenomena that can clarify why adaptation to relevant information does not always occur, although the information seems to be acquired. Change blindness can be defined as the failure to attentionally experience changes to a scene, and inattentional blindness as the failure to attentionally experience the appearance of an object or an event (Rensink, 2009). These phenomena can explain why brake lights and traffic light changes are unnoticed, and why people fail to notice an object appearing right in front of their eyes when occupied with an attentionally demanding task (Most et al., 2005).

\subsection{Behavioural models}

Over the years, a number of behavioural models have been developed focusing on understanding, describing or predicting some aspect or aspects of human behaviour. By modelling, an aspect of behaviour is organised into its core parts, enhancing understanding and prediction of behaviour. Some examples of generic models for understanding human behaviour are the simple test-operate-test-exit unit (TOTE) which implicates a coordinated sequence of tests and actions until the preferred result is achieved (Miller, Galanter, \& Pribram, 1960), the perceptual cycle in which the perceiver constantly anticipates specific types of information and explores the world to achieve this information, directed by anticipatory schemata, which are in turn modified by the available information (Neisser, 1976), the theory of planned behaviour (TPB), which highlights the role of attitudes, subjective norms and perceived behavioural control in predicting behavioural intentions (Ajzen, 1985), the skill-, rule- and knowledge-based performance model (SRK) with three levels of performance (Rasmussen, 1983) and the contextual control model (COCOM), which is a cyclical model of human action, that describes action and control and where events modify the current understanding, leading to further actions which in turn influence events and feedback and so on (Hollnagel, 2003; Hollnagel, 2016a; Hollnagel \& Woods, 2005). Several theories and models have been used for understanding human behaviour in general 
and road-user behaviour in particular. In this section more road-user centred models are presented in chronological order, together with their implications for adaptation.

\subsubsection{The field of safe travel}

The field of safe travel suggested by Gibson and Crooks (1938) has had a large impact on visual perception theory. In their hypothesis the field of safe travel "consists, at any given moment, of the field of possible paths which the car may take unimpeded" (Gibson \& Crooks, 1938) (italics in original). The field is spatial and moves along with the vehicle. Lee (1980) acknowledged that the perceptual systems, especially vision, play a crucial role when moving through and interacting with the environment. He used the term optic flow field to recognise that visual stimuli change with time and space. That the optic flow affects speed perception has for instance been shown by Prokop, Schubert, and Berger (1997), where participants walking on a self-driven treadmill adjusted their speed to the optic flow although they were instructed to keep their walking speed constant. When presented with constant motion the visual system will, however, adapt to it and the impression of speed will eventually attenuate (Jagacinski \& Flach, 2003). This can have severe consequences in traffic, for instance when exiting a motorway at too high speed.

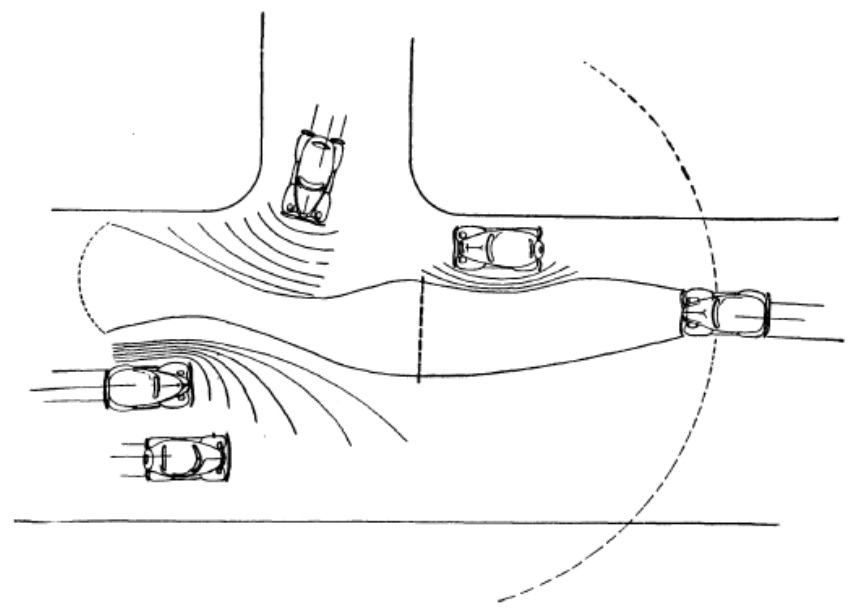

Figure 2. The field of safe travel of a driver in traffic. Reproduced from Gibson and Crooks (1938).

In models focused on the visual field, experienced speed affects adaptation. In the field of safe travel, adaptive behaviour can be seen in the adjustments made to stay within the unimpeded zone, where steering, accelerating and decelerating are the most obvious ones.

\subsubsection{Zero-risk theory}

The zero-risk theory, which was first proposed by Näätänen and Summala (1976) and further described by Summala (1988), entails that drivers are not adjusting risk but when they become more experienced they adapt to risk. Risk is controlled by maintaining safety margins, i.e. so that loss of control does not occur. According to this theory drivers are typically motivated to increase their speeds and if the traffic system offers opportunities to satisfy these motives, drivers tend to use them. Summala advocates speed limits as necessary for restricting drivers from adapting to greater risks in the traffic system. 
With zero-risk theory as a behavioural model, adaptation can be defined as the adjustments made to maintain safety margins. The zero-risk theory maintains that drivers use speed as an adaptation measure to handle the traffic system.

\subsubsection{A two-level model of driver steering behaviour}

Donges (1978) investigated driver behaviour in terms of steering and suggested a two-level model of driver steering behaviour, in which duality of information to the driver is a basis. This means that the visual field presented to the driver is one source of information, showing the current and future road ahead, for the driver to extrapolate for anticipation. The other source of information in the visual field contains static as well as dynamic cues, concerning deviation information between the path the vehicle is taking and the desired path. Donges's model contains an anticipatory open-loop control and a compensatory closed-loop control, both affecting the steering wheel angle. The steering behaviour, i.e. the adaptation in this model, is mainly affected by vehicle speed and road curvature.

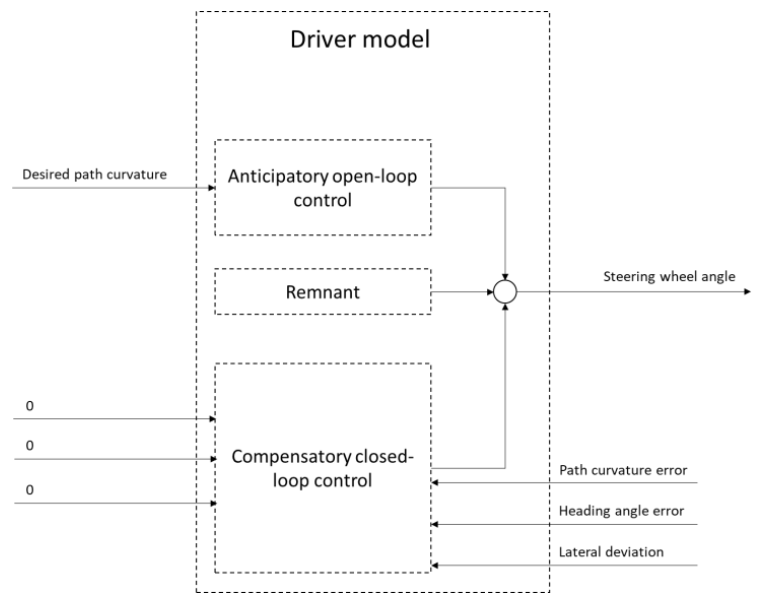

Figure 3. Block diagram of the two-level model of driver steering behaviour. Adapted from Donges (1978).

\subsubsection{Task hierarchical model}

Michon (1979; 1985) proposed three levels of skills and control in traffic. These are the strategic (planning), tactical (manoeuvring), and operational (control) levels. The strategic level concerns the planning of the trip, e.g. the goal of the trip, what means of transportation and what time of day should be chosen. At the tactical level decisions such as making a lane change to overtake a vehicle in front or slowing down is made, while the actual steering and speed adjustments are handled at the operational level. 


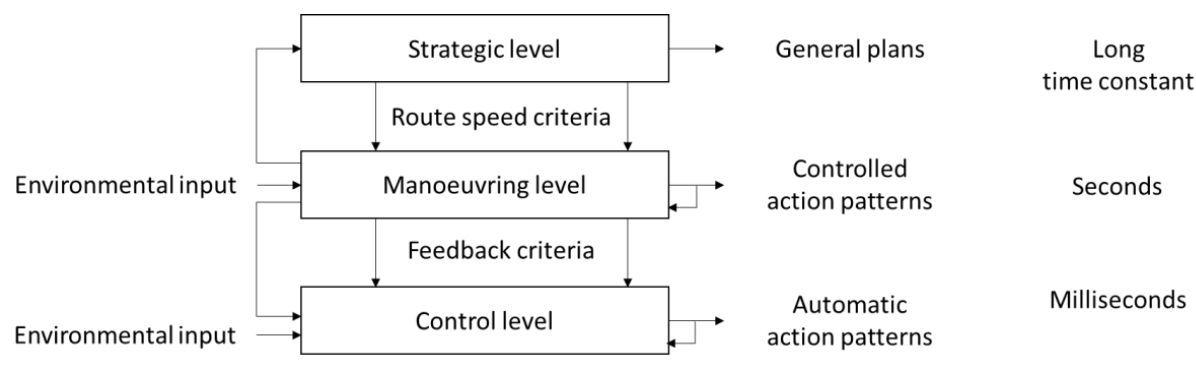

Figure 4. The hierarchical structure of the road-user task. Adapted from Michon (1985).

Taking this view, adaptation is carried out at the tactical level, where the decisions of carrying out adjustments are made, while the adaptations are operationalized at the operational level.

\subsubsection{Risk homeostasis theory}

In the risk homeostasis theory by Wilde $(1982 ; 2001)$, the target level of accident risk is determined by the expected benefits and costs associated with risky as well as with safe behaviour alternatives. The target level of traffic accident risk is the level of subjective accident risk at which the subjective difference between benefits and costs is maximized.

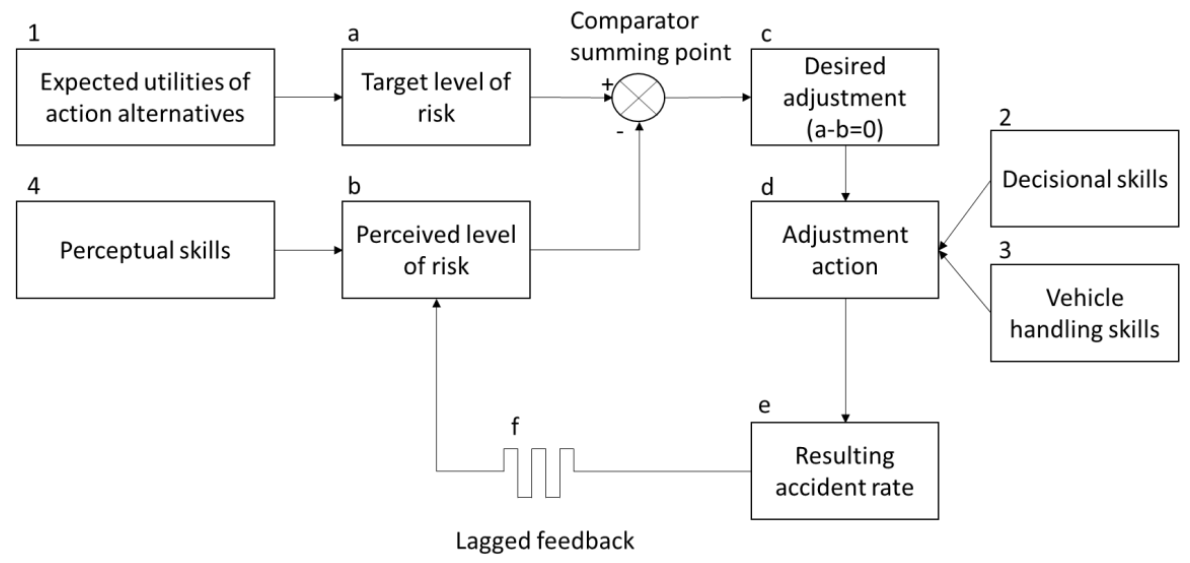

Figure 5. Homeostatic model relating accident rate to driver behaviour. Adapted from Wilde (1982).

Adaptation in the risk homeostasis theory is carried out considering benefits and costs in the future.

\subsubsection{Task-capability interface model and task difficulty homeostasis theory}

The task-capability interface model of driving (Fuller, 2000) includes the notion that task demands, such as environment, other road users, vehicle and speed were contrasted with the driver capability to achieve a safe outcome from competence and human factors at any given moment. The model was among other things based on the fact that drivers try to avoid collision. Later, Fuller carried out trials showing no correlation between subjective ratings of perceived risk and ratings of statistical risk (Fuller, 2005). This finding instead lead to the theory of task difficulty homeostasis which Fuller considers to be one of the sub-goals in driving and the main tool to manage task difficulty is that of speed choice (Fuller, 2005). 
Feelings of risk were proposed to motivate avoidance of too high a level of task difficulty (Fuller, McHugh, \& Pender, 2008). Ratings of risk were highly correlated with ratings of task difficulty in Fuller's trials (Fuller et al., 2008) but the data were all subjective ratings, which one should in general be careful to interpret.

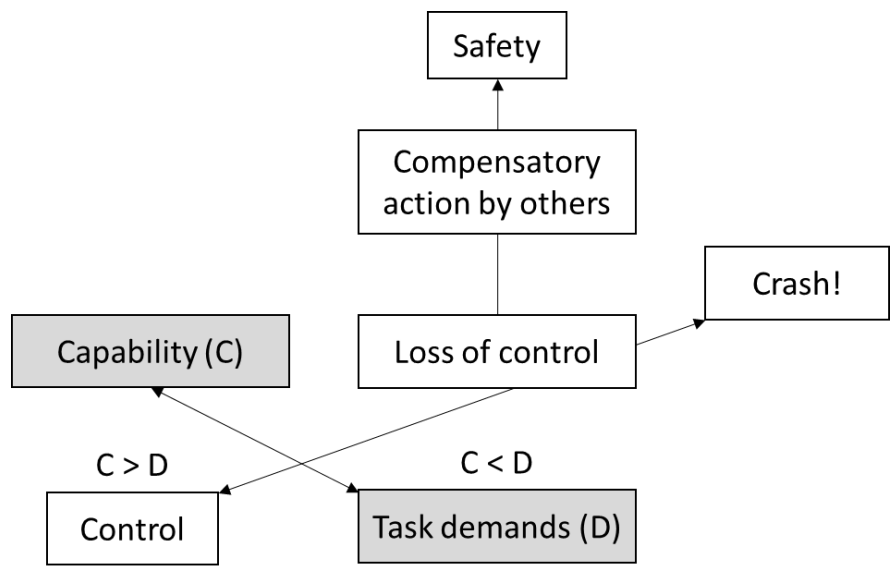

Figure 6. The task-capability interface model. Adapted from Fuller (2000).

In the task difficulty homeostasis theory, adaptation by choice of speed is used for handling the demands of the driving task.

\subsubsection{Driver-in-control and the extended control model}

Along the same line of models with different levels as Donges (1978), Michon (1979) and Rasmussen (1983), the researchers Hollnagel, Nåbo, and Lau (2003) propose a driver-incontrol model (DiC) with four levels. In the DiC model, the tracking level is considered to involve compensatory (feedback) control and being highly automated, e.g. maintaining speed, while the regulating level includes movement relative to other vehicles and anticipatory control (feedback and feedforward) and demands high attention at uncommon manoeuvres. Condition monitoring (feedback and feedforward) is involved at the monitoring level, e.g. traffic flow, whereas goal setting (feedforward) is at the targeting level with high demands to attention, mostly before the journey is started, e.g. choice of destination. Hence, all levels continuously communicate with each other and effective control is at hand if the joint drivervehicle system is in control at all levels simultaneously.

The driver-in-control model was developed into the more comprehensive extended control model (ECOM), which can be used for describing how the performance of a joint cognitive system, such as a driver and a vehicle, takes place on several layers of control at the same time; tracking, regulating, monitoring and targeting (Hollnagel, 2016b; Hollnagel et al., 2003; Hollnagel \& Woods, 2005), see Figure 7. At the tracking control layer, activities crucial for staying within a desired region of the time-space continuum are described. When applied to driving, such activities can be keeping an intended speed, lateral position on the road and distance from the car in front. In the regulating layer, goals and criteria for the tracking control layer are defined, involving positioning the vehicle in relation to other elements in traffic, e.g. avoiding obstacles and overtaking. Monitoring is concerned with the state of the joint driver-vehicle system relative to the driving environment and includes keeping track of 
traffic signs and signals. Targeting involves goal setting, typically in terms of destination, but also driving performance criteria, such as increasing speed if the driver thinks she or he will arrive late otherwise, or driving with extra caution if there is a person in the vehicle who needs to be handled with extra care.

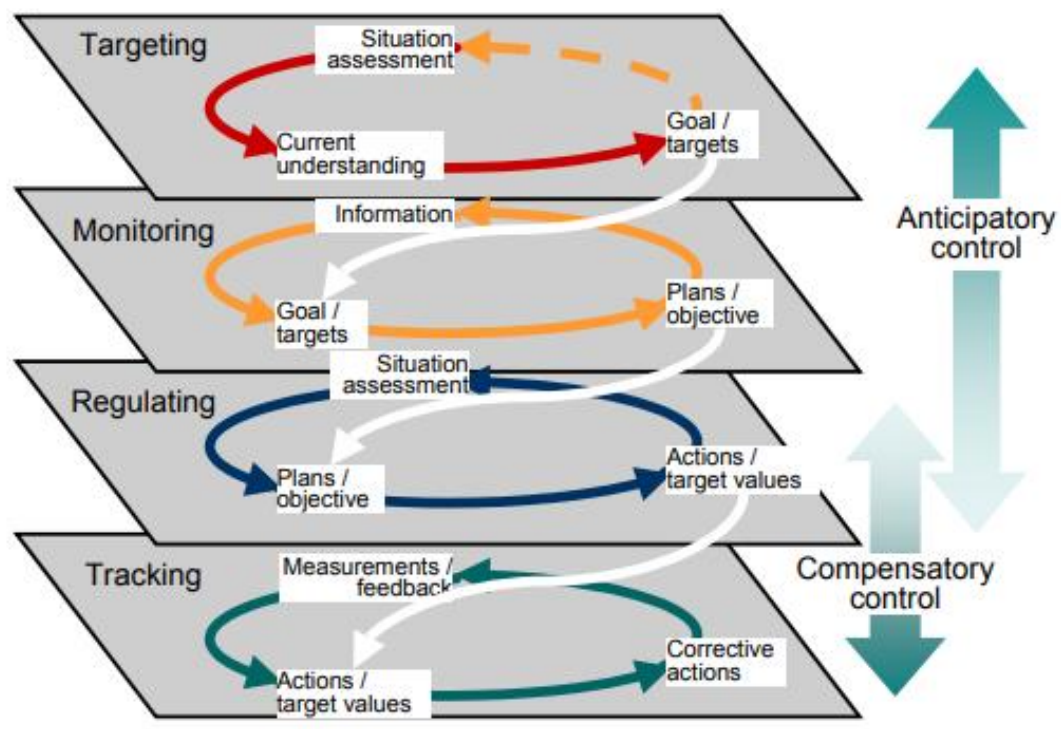

Figure 7. The extended control model. Retrieved from http://erikhollnagel.com/ideas/ecom.html Copyright 2016 by Erik Hollnagel. Reproduced with permission.

Adaptation in ECOM is most evident in the regulating layer but it is affected by information of the monitoring layer and operationalised in the tracking layer. Strategic adaptations such as selecting time of day and route to avoid challenging travel conditions and situations can be made in the targeting layer.

\subsubsection{Predictive processing framework}

Although ECOM can be used for describing road-user behaviour in traffic, it does not explicitly treat predictions made by road-users. Theory on prediction is however accounted for in the predictive processing framework (Clark, 2016; Lupyan \& Clark, 2015). According to the predictive processing framework, the brain constantly predicts the world and seeks information to confirm the prediction. If there are prediction errors, a new prediction will be made based on this information. Hence, the flow of processing in the brain is a mixture of topdown expectation and bottom-up error correction (see Figure 8). This suggests that prior beliefs, i.e. predictions or expectations, guide information intake, and that the difference between the prediction and the information intake leads to new, updated predictions, and so on. Actions taken to sample relevant information also alter the situation, and new predictions are made. Having an active top-down model will cause a person to discard some information and amplify other. The prior knowledge about the world hence greatly influences how the world is perceived, how signal is extracted from noise. 


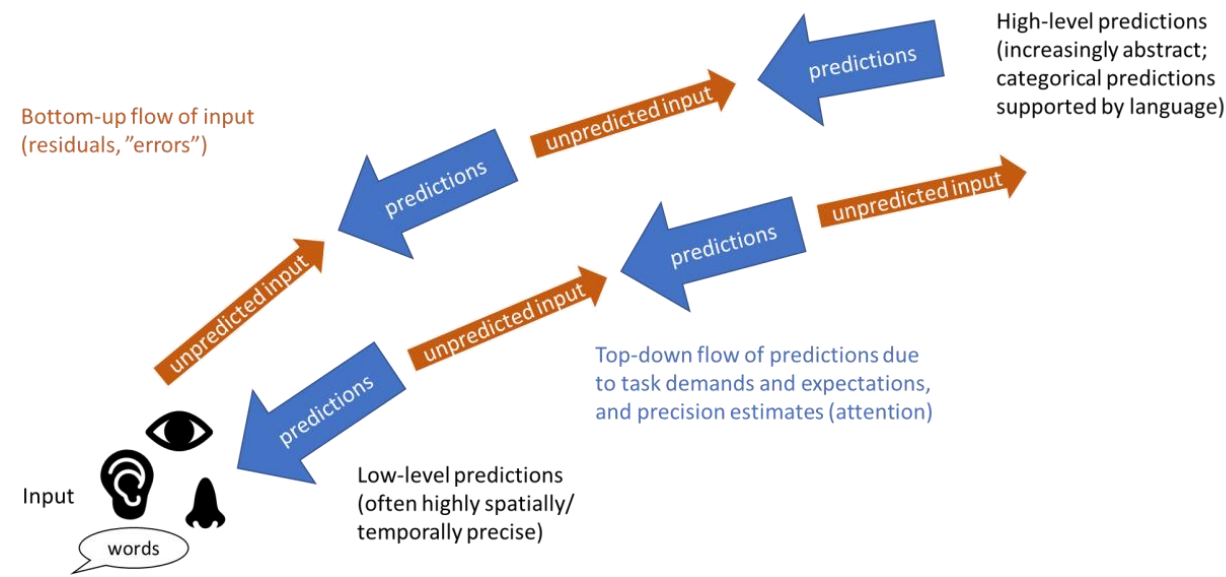

Figure 8. A schematised view of the predictive processing account of information transfer in the brain. Adapted from Lupyan and Clark (2015).

In the predictive processing framework, adaptation occurs when the prediction errors lead to new predictions.

\subsubsection{Comfort zone}

Since the introduction of the concept field of safe travel by Gibson and Crooks (1938), other fields and zones in traffic have been added. Often used in recent studies is the idea of a comfort zone, within which the road user experiences a subjective feeling of control (Bärgman, Smith, \& Werneke, 2015; Engstrom \& Ljung Aust, 2011; Ljung Aust \& Engström, 2011; Panero, 2018). The multiple comfort zone model was first proposed by Summala (2005) and further elaborated in (Summala, 2007). According to this model, several functional control variables must all be within an acceptable range, or above a certain threshold, for a driver to experience a general feeling of comfort and hence be in his or her comfort zone. If the acceptable range is exceeded (or the threshold not achieved) by some variable, there is a feeling of discomfort. The functional control variables include sufficient time and space margins to avoid a crash, to provide a smooth and comfortable travel, to avoid sanctions and to have an expected travel progress. When humans are presented with multiple goals like this, the choice mechanism satisficing (Simon, 1956) is often applied, by which goals are not individually optimised but rather all fulfilled to a satisfactory level. Summala (2007) means that at routine driving without arousal, tension or activation, the driver aims to keep within comfortable limits, where no feelings of risk, anxiety or discomfort are present. As long as the comfort zone boundary is not exceeded, the driver experiences a feeling of control and performance is experienced as good enough (i.e. satisficing is applied), and there is no need for corrective actions. If safety margins are breached, a subjective risk monitor is activated, and the driver senses a feeling of risk. Normally, this subjective risk feeling is reduced by driver behaviour such as making corrections of speed and steering. However, motives and goals, rules, social norms, vehicle characteristics and the road system are factors which can push drivers towards shorter safety margins (Summala, 2007). 


\subsection{Discussion of the theory chapter}

Among the theories and behavioural models for understanding road-user behaviour some are stimulus-driven, e.g. the field of safe travel, while others are goal-directed, e.g. zero-risk theory and risk homeostasis theory. At present it seems that the extended control model of ECOM is one of few that acknowledge that both bottom-up and top-down processing can occur simultaneously. Another is the predictive processing framework, which states that humans are in fact constantly predicting the world, i.e. top-down processing occurs, and that the prediction is also constantly modified by bottom-up processing. There is however no complete model for studying individual road user adaptation in traffic. Neither ECOM nor the predictive processing framework explicitly state internal factors such as emotions, feelings or capability. Considering that ECOM is a model with different performance layers interacting with and influencing each other all the time, i.e. bottom-up and top-down adaptations occur concurrently, ECOM is here chosen to be the basis for analyses.

With the discussion about comfort zone in mind while attempting to discern between adaptation and adaptive behaviour, adaptation can be viewed as setting the margins of the comfort zone according to the present individual state and capability. The individual state can affect performance but it does not have to do so, depending on whether the task difficulty has been adapted through adaptive behaviour, such as reducing speed while driving (de Waard, 1996). The adaptive behaviour is the instrument used for meeting the margins of the comfort zone.

In the behavioural models previously described, adaptation is handled in various ways. In some models, the adaptive behaviour is very specific, such as steering or altering speed, while other models perceive adaptation as the modifications made to maintain safety margins. The goal of maintaining safety margins is to stay within the comfort zone, where the demands of the task can be handled with subjectively experienced control.

Adaptation can hence be described as setting the safety margins of the comfort zone, whereas adaptive behaviour is shown in the adjustments made to stay within acceptable safety margins.

Adaptation in traffic implies two things - first that there is an adaptation object (e.g. a traffic sign, rule or an action by another road user), whether present or predicted, and second that the road user attends to the adaptation object, consciously or not. Therefore, the importance of expectations as well as of peripheral vision for directing attention in traffic should be acknowledged. Adaptation can be made both as top-down, with the road user skill and goals of the travel, and as bottom-up, where the specific situation, i.e. an external adaptation object, influences the adaptation. Bottom-up input however influences top-down processes in which the input is interpreted.

Even if there is an adaptation object at hand, and the road user attends to and adapts to it, there might be other relevant adaptation objects around that are not attended to. Sometimes the adaptation made by the road user to the attended adaptation object will aid in handling the other adaptation objects too, for instance increasing the comfort margins by reducing speed will give more time to detect and further act on other objects. If all relevant objects in a certain traffic situation are attended sufficiently to predict what will happen in the near future and choose an appropriate action, the road user can be considered attentive. 
When no adaptive behaviour can be noted, although there is an obvious adaptation object, the concept of inattentional blindness, where the mind is occupied elsewhere, could be useful. Together with change blindness this explains that adaptation does not always occur, although objectively, all the cues are there to make an adaptation. Other explanations for not adapting are that the individual does not interpret the adaptation object properly, for instance the intention of other road users, or that it is a calculated risk, where the individual deliberately wants to provoke something, and decreases his or her safety margins.

Table 1 shows a list of adaptive behaviours as mentioned above, together with the type of adaptation and in which situation the adaptation is carried out (present or prior to the journey). As can be seen, speed reduction and distance keeping from a vehicle in front can be both proactive and reactive adaptations. While an anticipating driver may reduce speed by letting go of the gas pedal in advance to keep the safety margins at a comfortable level, another driver may be surprised by traffic events and reduce speed by applying the brakes hard. While a proactive driver may keep the distance from a car in front anticipating irregular speed behaviour, another driver may experience that he or she must keep the distance to a car in front when performing an additional task.

Table 1. Type of adaptation, adaptation situation and examples of adaptive behaviour.

\begin{tabular}{|c|c|c|c|c|}
\hline \multicolumn{3}{|c|}{ Type of adaptation } & \multirow{2}{*}{$\begin{array}{l}\text { Adaptation } \\
\text { situation }\end{array}$} & \multirow{2}{*}{$\begin{array}{l}\text { Example of adaptive } \\
\text { behaviour }\end{array}$} \\
\hline Proactive/reactive & $\begin{array}{l}\text { Control layer } \\
\text { (ECOM) }\end{array}$ & $\begin{array}{l}\text { Task hierarchical } \\
\text { model }\end{array}$ & & \\
\hline Reactive & Regulating & Tactical & Present & $\begin{array}{l}\text { Reducing lane change } \\
\text { frequency }\end{array}$ \\
\hline Reactive & Tracking & Tactical & Present & Looking forward more \\
\hline Proactive/reactive & Regulating & Tactical & Present & Reducing speed \\
\hline Proactive/reactive & Regulating & Tactical & Present & $\begin{array}{l}\text { Keeping distance from } \\
\text { vehicle in front }\end{array}$ \\
\hline Proactive & Regulating & Tactical & Present & $\begin{array}{l}\text { Choosing appropriate } \\
\text { location for executing } \\
\text { additional task }\end{array}$ \\
\hline Proactive & Regulating & Tactical & Present & $\begin{array}{l}\text { Anticipation to avoid } \\
\text { accidents }\end{array}$ \\
\hline Proactive & Targeting & Strategical & Prior & $\begin{array}{l}\text { Avoiding challenging } \\
\text { driving conditions and } \\
\text { situations }\end{array}$ \\
\hline
\end{tabular}

While the behavioural models and theories contribute to ways of looking at road-user behaviour, the attention features are useful in understanding what the road user can adapt to. Recognising that adaptation can involve both top-down and bottom-up processes is crucial for understanding road-user adaptation.

In this thesis, individual road user behaviour in response to different adaptation objects in road traffic, namely static and dynamic infrastructure, additional tasks and other road users, is studied. The study results are used for theory development in the area of adaptation in the traffic environment from the perspective of individual road users. ECOM accounts for internal input in terms of strategies and goals but does not explicitly include emotions and feelings 
that may affect the comfort zone. Because of the relative comprehensiveness of ECOM, it is used for setting up testable hypotheses of observable adaptive behaviour in traffic. 


\section{METHOD}

Adaptation in traffic is a large and complex area to describe and analyse, which requires several methods to capture relevant data. Controlled studies can be appropriate for studying isolated phenomena while conducting semi-controlled studies is a way to come closer to the naturalistic setting that is present in real life of real road users accomplishing real tasks. Obviously, different data acquisition methods are needed depending on what kind of phenomenon is to be investigated. An overview of the studies included in this thesis together with the most important characteristics is given in Table 2.

Table 2. Overview of studies.

\begin{tabular}{|c|c|c|c|c|}
\hline & Study I & Study II & Study III & Study IV \\
\hline Sample size & 14 & 41 & 23 & 26 \\
\hline $\begin{array}{l}\text { Gender } \\
\text { (women/men) }\end{array}$ & $5 / 9$ & $19 / 22$ & $12 / 11$ & $11 / 15$ \\
\hline $\begin{array}{l}\text { Mean age } \pm S D \\
\text { (ys) }\end{array}$ & $42 \pm 15$ & $37 \pm 11$ & $39 \pm 14$ & $35 \pm 15^{1}$ \\
\hline Design & $\begin{array}{l}2 \times 7 \\
\text { (within-group) }\end{array}$ & $\begin{array}{l}2 \times 3 \times 2 \\
\text { (within-group) }\end{array}$ & $\begin{array}{l}2 \times 2 \\
\text { (mixed) }\end{array}$ & $\begin{array}{l}\text { before-after } \\
\text { (within-group) }\end{array}$ \\
\hline $\begin{array}{l}\text { Independent } \\
\text { factors }\end{array}$ & $\begin{array}{l}\text { - Distraction } \\
\text { task (2) } \\
\text { - Delineator } \\
\text { post } \\
\text { configuration } \\
\text { (7) }\end{array}$ & $\begin{array}{l}\text { - Music (2) } \\
\text { - Segment (3) } \\
\text { - Text message } \\
(2)\end{array}$ & $\begin{array}{l}\text { - Character role } \\
\text { (2) } \\
\text { - Condition (2) }\end{array}$ & $\begin{array}{l}\text { - CDT sign } \\
\text { (BL/TM) }\end{array}$ \\
\hline Setting & $\begin{array}{l}\text { Moving-base } \\
\text { simulator }\end{array}$ & Field study & Field study & Field study \\
\hline Scenario & $\begin{array}{l}\text { Driving on night- } \\
\text { time rural road }\end{array}$ & $\begin{array}{l}\text { Cycling in } \\
\text { daytime urban } \\
\text { real traffic }\end{array}$ & $\begin{array}{l}\text { Driving and } \\
\text { cycling in daytime } \\
\text { urban real traffic }\end{array}$ & $\begin{array}{l}\text { Cycling in } \\
\text { daytime urban } \\
\text { real traffic }\end{array}$ \\
\hline Measurements & Driving speed & $\begin{array}{l}\text { SMS interactions } \\
\text { MiRA fulfilment } \\
\text { NASA-RTLX } \\
\text { Glance behaviour } \\
\text { Complexity level }\end{array}$ & $\begin{array}{l}\text { Behaviour at } \\
\text { intersections } \\
\text { Glance behaviour } \\
\text { Complexity level } \\
\text { Pedalling } \\
\text { behaviour }\end{array}$ & $\begin{array}{l}\text { Behaviour at } \\
\text { intersection } \\
\text { MiRA fulfilment } \\
\text { Glance behaviour } \\
\text { Pedalling } \\
\text { behaviour } \\
\text { System } \\
\text { acceptance scale } \\
\text { Subjective } \\
\text { opinion of system }\end{array}$ \\
\hline
\end{tabular}

\footnotetext{
${ }^{1}$ Age at treatment

In the studies included, both the field in terms of the real world and a moving base passenger car simulator have been used as study settings. For data collection different methods and technical systems have been used, including eye tracking, NASA-TLX and complexity classification. Accumulating data from different sources, using different methods, allows for complementary angles in trying to understand the intricate area of adaptation in traffic. While an observer perspective makes it possible to look at more objective measures of action, subjective measures can be used to understand why certain actions occur. The studies were
} 
carried out in different ways and with different participants, from a controlled simulator study with car drivers to semi-controlled field studies with cyclists and car drivers. In this chapter, the methods used in the studies are summarized.

\subsection{Study settings}

There are several ways to investigate research questions but for understanding individual road-user behaviour, simulator studies and field studies are suitable, because of the opportunity to observe behaviour in action. A controlled simulator study as well as semicontrolled and quasi-experimental field studies have been carried out.

\subsubsection{Simulator study}

Study I was performed using a moving base passenger car simulator. Advantages of using a simulator for carrying out studies include the possibility to present all participants with the same traffic conditions and environments. There will be no differences in weather conditions, or the type of vehicle used. Randomizing condition order between participants is also easily done. Testing of behaviour in extreme or rare conditions such as high speed of own vehicle or odd or risky behaviour of other road users (e.g. a parked car suddenly driving out in the lane, a person running out in the street from behind a bus, or a vehicle break-down in front of one's own vehicle) can be accelerated. Obviously, a simulator can be used for simulating risky situations and for studying risky driving behaviour (e.g. Horberry, Anderson, Regan, Triggs, \& Brown, 2006; Åkerstedt, Peters, Anund, \& Kecklund, 2005). Adaptation towards certain adaptation objects in a simulator could therefore be studied without restricting driver behaviour to any greater extent.

Disadvantages include the fact that the participants know that they are safe and that if they behave inappropriately, they will not be harmed. This knowledge can lead to behaviour that is not in accordance with their normal behaviour, for instance in terms of speeding, lane keeping and overtaking. Another disadvantage is the occurrence of motion sickness (see e.g. Johnson, 2005; Kolasinski, 1995; McCauley, 1984; Stanney \& Kennedy, 2010). This can lead to situations where people who suffer from motion sickness adapt their behaviour to this by altering their normal driving behaviour (e.g. Helland et al., 2016; McCauley, 1984). People with known problems of motion sickness are frequently excluded from simulator studies, which leads to a biased population. Even people who normally do not experience problems with motion sickness, may do so in a simulator, e.g. in studies including sharp curves or hard braking or both. At present, all conditions in natural driving cannot be simulated. Especially lighting conditions such as glare from on-coming vehicles are hard to simulate.

\subsubsection{Field study}

Field studies have been used to a large extent for increasing external validity. Some example topics of field studies in the traffic environment are investigating driver behaviour in relation to additional tasks (e.g. Anttila \& Luoma, 2005), braking performance of experienced and novice motorcyclists (e.g. Vavryn \& Winkelbauer, 2004), the effect of variable message signs on driver behaviour (e.g. Erke, Sagberg, \& Hagman, 2007), pedestrians' behaviour at pedestrian crossings (e.g. Avineri, Shinar, \& Susilo, 2012) and driver aggression (e.g. Hennessy \& Wiesenthal, 1999). In addition, field operational tests, FOTs, have been conducted when performing long-term field tests, for instance to explore the effects of 
different advanced driver assistance systems (ADAS) (Benmimoun, Pütz, Zlocki, \& Eckstein, 2013).

Advantages with on-road field studies with car drivers and cyclists are that they include real conditions in terms of vehicle, infrastructure and potentially even other road users that must be taken into account as with normal driving or cycling, when not being part of a study. Hence, there is no margin for extra risky behaviour as in a simulator. The participants' ability to deal with external and internal demands, and consequently adaptation related to these, are better studied out in the field, where they naturally exist.

Disadvantages include that weather conditions and traffic conditions such as interactions with other road users are not the same between participants. This can make it hard to isolate the effect of a specific variable.

\subsubsection{Semi-controlled study}

In general, we know that what experimenters do and say affects the participants. When participants know that they are being observed, there is always risk of the observer effect, i.e. that they alter their behaviour because they know that they are monitored (e.g. McCambridge, Witton, \& Elbourne, 2014). Compliance due to being part of a study is a problem when aiming to explore natural behaviour, because the participant wants to do correct things.

While controlled studies in laboratory settings have been carried out due to their virtue of testing isolated phenomena, naturalistic studies have been used to study subjects' natural behaviour while affecting the subject to a minimum. Although naturalistic studies are seemingly preferable in theory, in practice this is proven difficult. Filming drivers inside a car in a field study or making cyclists in traffic wear eye tracking equipment without noticing and approving is not possible. Furthermore, to be able to study a certain phenomenon, naturalistic studies can often be time-consuming and it can be hard to make any causal inferences.

In the field studies reported in Paper II and Paper III within this thesis, a semi-controlled study approach (Kircher, Eriksson, Forsman, Vadeby, \& Ahlstrom, 2017) has been applied. A semi-controlled study is a combination of a controlled and a naturalistic study, where the researcher can decide which participants should be selected, which route should be driven or ridden, and what task should be carried out. (The task could be the act of driving or cycling as well as an additional task.) The participants are however given more freedom to decide if, when, where and how to perform the task. An advantage of using a semi-controlled method is that the adaptive behaviour when executing a task can be examined in a more naturalistic setting compared to in a controlled study. Disadvantages include reduced control and more complicated analyses.

\subsubsection{Before-after study}

A before-after study encompasses a quasi-experimental design, where the participants are not randomly assigned to an intervention. In this kind of study design, there are certain threats to internal validity that could provide alternative explanations for observed evaluation results. Common threats, or biases, in before-after studies such as the one described in Paper IV are (e.g. Ho et al., 2018):

- The history threat, which means that there might be other changes than the treatment in between the periods of measurement that could affect the results. 
- Regression-to-the-mean, which occurs when participants are chosen based on their extreme values and compared after an intervention when their values may have decreased or increased to the mean value quite naturally.

- Test performance bias, which involves that the first test could have an effect on the outcome of the second test, irrespective of intervention.

- The maturation effect, which occurs when psychological or physiological features change with age or experience or both.

- Dropout effects, which occur when the participants in the before study are not present for the after study for some reason or another.

In the before-after study conducted in Study IV, the history threat was noted since there were some changes in the infrastructure between the periods of measurement. These changes were not considered to influence the parameters examined in the study though. The effect of regression-to-the-mean was handled by not choosing participants based on any extreme criteria, such as red-light-violators or fast cyclists. The test performance bias was hard to assess in the study. There is a possibility that having performed the test in baseline might affect performance in treatment. However, because of the long period, 12 months, between the two tests, it seems unlikely that baseline participation would have affected adaptive behaviours in the treatment phase. The maturation effect was handled in Study IV by using adult participants only, who all had experience of both living in the city and cycling in the studied intersection. The dropout effect is a real problem in studies where participants should return several times for participation. In Study IV, this was handled by recruiting and using a number of participants in baseline that allowed for some dropouts.

\subsection{Data acquisition methods}

The selection of data capturing methods and the quality of the data achieved will affect what can be inferred and the certainty thereof. Objective measures include behaviour that can be observed, i.e. actions performed by the road user. It is however up to the observer to determine what behaviours are to be reported and to interpret these. To understand the underlying factors of the behaviour carried out, subjective measures such as interviews, rating scales or think-aloud protocols can be used. While interviews and rating scales concerning past behaviour are retrospective in nature, think-aloud protocols are intrusive and may affect behaviour (Hertzum, Hansen, \& Andersen, 2009). In this section, data acquisition methods for exploring road-user adaptive behaviour are discussed.

\subsubsection{Eye tracking}

In Study II, III and IV, eye tracking was used. Vision has an important role for input to attention in traffic, and hence for the discovery of possible adaptation objects and predictions of how the situation will evolve. Eye tracking is a method intended to capture visual aspects of attention.

Advantages with eye tracking include that it is possible to track where people direct their foveal vision. Hence, visual information intake can be traced, which indicates what the road user finds relevant.

Disadvantages are that the peripheral vision is not accounted for, and that it is not possible to discern between conscious and nonconscious attention. It is not certain that where a person looks is where conscious attention is paid and likewise, not fixating an object does not mean 
that conscious attention cannot be set to it. There are also technical limitations with the eye tracking system that was used in the studies, as there were some eyesight restrictions (vision could be corrected within the interval of \pm 4 diopters in steps of 0.5 dioptres, but no other correction could be made), that the view was somewhat impaired due to the frames of the eye tracking glasses, that calibration was needed for every participant, that the data analyses were time-consuming and that the tracking quality was sensitive to weather, mascara etc. However, use of eye tracking is one possible way to assess and evaluate if targets in traffic are attended to or neglected.

\subsubsection{Workload}

One of the aspects affecting the current situation and hence that sets the prerequisites for and needs of adaptive behaviour is workload. This aspect was assessed in Study II. Workload has been defined by de Waard and Lewis-Evans (2014) as the interaction between the task demands and the capacity, i.e. the capability of the operator to perform the task. Therefore, it is of interest to know if the traffic environment affects the perceived workload of the road user when performing an additional task.

There are many workload measures available, including physiological indices such as heart rate variability and electrical potential in the brain in response to events, but also subjective ratings such as the Bedford scale (Roscoe, 1984), the Rating Scale Mental Effort (RSME) (Zijlstra \& van Doorn, 1985), the Subjective Workload Assessment Technique (SWAT) (Reid \& Nygren, 1988) and the NASA Task Load Index (NASA-TLX) (Hart \& Staveland, 1988). Carsten (2014) states that although workload can be measured by operationalised subjective means, caution should be used when the values are used, since there is no absolute value. It can however be used for comparison between different conditions in within-subjects designs.

The NASA-Task Load Index (NASA-TLX) scale is a multidimensional rating scale of subjective workload-related factors that was developed by Hart and Staveland (1988). The scale consists of six factors with the endpoints low vs. high for the factors mental demand, physical demand, temporal demand, effort and frustration level, whereas the endpoints for the factor performance is good vs. poor. In its original form, the subjective importance of each factor for the specific task should be used as a weight for that factor. In Study II, where text message interaction while cycling was investigated, the NASA-TLX was adapted to cycling. The scale was used mainly because of its non-intrusiveness and multidimensionality, which led to information about mental as well as physical demand, experienced time pressure, selfrated performance, effort and frustration. Compared to SWAT, it is also more sensitive for low workload conditions (Nygren, 1991). Since equal weights of the scale were used, the scale in the study is the NASA-Raw Task Load Index (NASA-RTLX) (Hart, 2006). The disadvantage of not measuring workload momentarily must be balanced against the intrusiveness of doing so and the easy implementation of the NASA-RTLX scale. In addition, the filling out of the scale was carried out quickly by simply placing a mark on a continuous line for each of the six factors concerning the last segment cycled. The adapted NASA-RTLX was primarily used for investigating if there was any experienced difference between segments cycled in the study.

An obvious problem with the NASA-TLX or NASA-RTLX is that the scale is used for a segment of a road, but given after the segment was cycled, not continuously. In addition, the scale is subjective and there will be different outcomes for different persons. However, since 
the purpose of using the NASA-RTLX in Study II was to indicate whether there was any difference between cycling on a particular segment while e.g. receiving a text message or not in a within-subjects design, this was not considered crucial.

\subsubsection{Complexity classification}

In an everchanging traffic environment, it is apparent that the complexity of the current traffic environment affects the road user. Equating the same intersection and the same driver at separate occasions, once without traffic and once with a lot of traffic, is not correct. Several attempts have been made to rate complexity of a traffic scene in different ways and examples of these are presented in this section.

In a framework for task analysis by Fastenmeier and Gstalter (2007) a step-by-step procedure is performed that is derived from classifications of road traffic situations and a model of the drivers' information processing. The classification of road traffic situations includes road design (e.g. a two-lane rural road), road layout (e.g. a straight signalised junction with traffic lights) and traffic flow (e.g. bottlenecks and left turn). The driving task is divided into subtasks and behavioural requirements are organized into perception, expectations, judgement, memory, decision, driver action and errors. This is eventually used for calculating ratings of complexity. A high complexity task can consist of many requirements that have to be fulfilled under time pressure with high accuracy.

Another way of dealing with complexity is to provide anchor examples. Building upon the work by Fastenmeier and Gstalter (2007), Paxion, Galy, and Berthelon (2014) stated that low density traffic flow on a straight motorway should count as a simple situation, while a moderate density traffic flow on a rural road with a few curves would be a moderately complex situation and a busy city road with many curves would be a very complex situation. For other combinations of these features, for instance high density traffic flow on a motorway, it is not specifically stated which category of situation complexity would be appropriate. Other attempts to classify route complexity have been made through high or low demands on information processing and vehicle handling, respectively (Patten, Kircher, Östlund, Nilsson, \& Svenson, 2006), for instance high/high (demands on information processing/demands on vehicle handling) complexity when driving within city centre environments, high/low or low/high complexity at intersections regulated by road signs or at signalised intersections, and low/low complexity driving unhindered in urban and rural areas and on motorways.

Anchor examples can also be shown to the participants in the form of video clips, as reported in a workload study by Schweitzer and Green (2007). In their study two video clips of forward road scenes, with the set anchor workload rating of 2 and 6, i.e. light and heavy traffic, respectively, were shown to the participants. After practicing, the participants were asked to rate other video clips of forward road scenes within the interval of 1 to 10 , in relation to the anchors.

Some simulator studies varied traffic flow and presence of lane change (Teh, Jamson, Carsten, \& Jamson, 2014) or buildings, oncoming vehicles etc. (Horberry et al., 2006) to create situations of more or less complexity. In other simulator studies, speed has counted as a factor contributing to the complexity of the situation. Examples are the three situations of driving on straight roads with essentially unvaried speed, approaching intersections where a stop should be made, and overtaking a slower vehicle, studied by Cantin, Lavallière, Simoneau, and Teasdale (2009). 
Nunes and Recarte (2004), on the other hand, used a three-point scale for rating traffic complexity from video recordings of car driving. The scale was defined as 0 , meaning that there are no vehicles or one vehicle visible, but very far away; 1 meaning that there is one vehicle visible ahead but that there is no significant action involved such as overtaking or being overtaken and there is no lane change; and 2 meaning that at least two vehicles are visible or that the driver is changing lanes or performing other more complex manoeuvres.

Another way of recognising complexity is to ask the participants, i.e. to employ road-user subjective rating. That speed is related to complexity was acknowledged by de Craen, Twisk, Hagenzieker, Elffers, and Brookhuis (2008), who presented photographed traffic scenes to participants and asked them to state their preferred driving speed for each scene. For each photo there was another, almost identical one, differing in one detail, increasing the complexity of the traffic scene. The participants could only look at one photo at a time and were not given the opportunity to go back. The paper does not explicitly state which details are considered to increase the complexity. However, from the cases revealed, a pedestrian walking close by the road on a traffic island, and a cyclist in the same lane looking over his or her shoulder are some examples.

Efforts have been made to rate complexity more implicitly while driving, exemplified by Hulse, Dingus, Fischer, and Wierwille (1989) who used a nine-point subjective rating scale for visual attentional demand rating when driving on a road. The rating should be given at the beginning of each roadway segment and was triggered by an experiment leader in the vehicle. The scale was linked to the drivers' ability to look away from the roadway, where 1 represented the lowest level of attentional demand and was defined as "Can look away from roadway for long periods, possibly 4 secs. or more. (Frequent and long duration looks away are possible.)", whereas 5 was defined as "Can look away from roadway for intervals of 1 to 1.5 secs., but no longer. (Looks away must be followed by quick return to roadway.)" and 9 represented the highest level of attentional demand and was defined as "Cannot look away from roadway for even a brief glance. (Total visual attention required by roadway.)" Besides the ability to look away from the roadway, the participants were also instructed to consider the type of roadway, the possibility of unanticipated traffic and the effects of intersections and interactions with other vehicles in their subjective rating.

\section{Summary and development of complexity classification}

Although classification of road traffic situations can be done according to Fastenmeier and Gstalter (2007), it is difficult to include all possible road designs and layouts and traffic flow constellations. The interaction between the components of this type of rating is on an aggregate level and not easily apparent. Use of anchor examples allow for more dynamic situations but are still limited to situations similar to the examples used and are therefore not applicable in all contexts. Rating the traffic complexity only does not acknowledge the margins that the road user has for adaptation and can be used in more static surroundings such as simulator settings. All these ways to classify complexity are in various degrees limited to a certain pre-defined setting.

The subjective rating scale by Hulse et al. (1989) was used directly on road users in traffic and was based on attentional demands, which is important for adaptation. In the attempts to code complexity in this thesis, a scale similar to Hulse et al. (1989) has been used, but for video analysis (Nygårdhs, Ahlström, Ihlström, \& Kircher, 2018). This means that the 
participants do not rate the complexity in any way, but that this is done subsequently from the video data, by the experimenters. While looking at the video, driver speed is a factor that contributes to the rating. Whereas the nine-point scale used by Hulse et al. (1989) contained three pre-defined benchmarks, at the lowest and the highest score, and the one in the middle, the aim here was to specify complexity for all points of the scale to reduce uncertainty.

Additionally, to facilitate similar classification between experimenters, too many steps should not be included. This resulted in four complexity levels categorized in Table 3 and used in Paper II and III. The advantages are that speed is a factor integrated within the rating, that the complexity level is not subjectively rated by the participant and that the rating scale is easy to understand and apply. The complexity level is also independent of subjective workload.

Table 3. Complexity levels used by expert rater to classify traffic situations from video.

\begin{tabular}{ll}
\hline Complexity level & $\begin{array}{l}\text { Time possible to close eyes or look away from } \\
\text { road }\end{array}$ \\
\hline 0 & $>3 \mathrm{~s}$ \\
1 & $1-3 \mathrm{~s}$ \\
2 & $<1 \mathrm{~s}$ \\
3 & Not possible \\
\hline
\end{tabular}

\subsubsection{System acceptance scale}

The system acceptance scale (van der Laan, Heino, \& de Waard, 1997) was developed for measuring driver acceptance of new technology and was used in Study IV to assess how cyclists experienced a countdown to green system (see Figure 9). The nine items of the scale load onto two subscales, the usefulness scale and the satisfying scale, both ranging from -2 (totally negative) to +2 (totally positive). The scale is simple and quick to use and is well established as a standard for measuring user acceptance of systems in traffic.

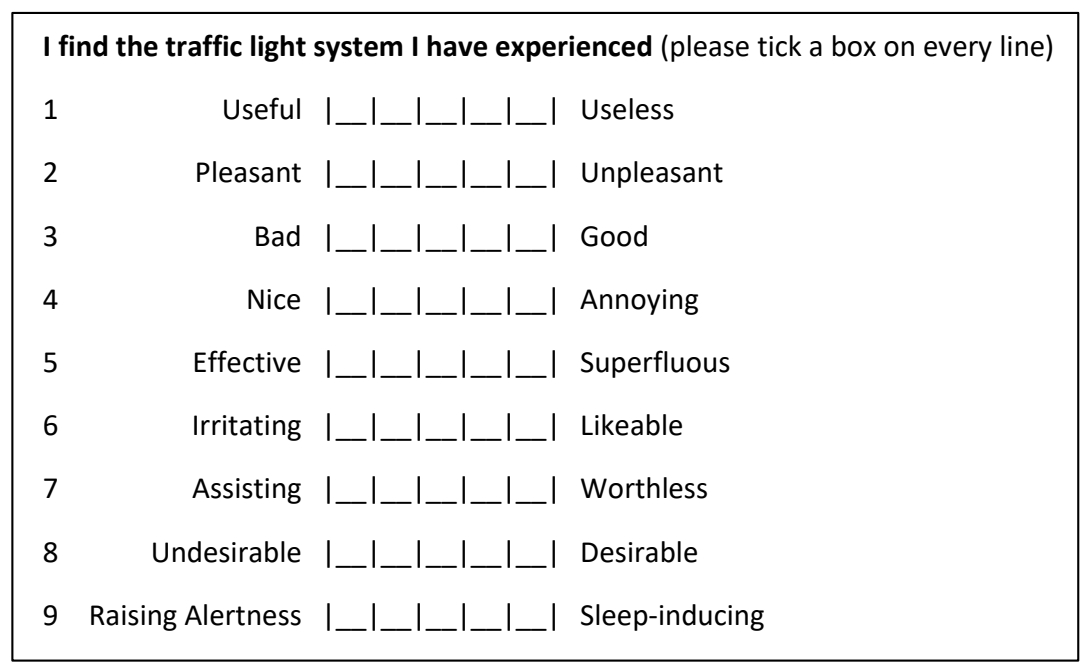

Figure 9. The system acceptance scale used in Paper IV. Adapted from van der Laan et al. (1997). 


\subsection{Discussion of methods}

As pointed out above, different research settings as well as methods were applied in the studies included in this thesis. Study I was conducted in a simulator while the other three studies were conducted in real traffic. The difference between Study I and the subsequent studies is primarily a result of the fact that fast manipulation of static infrastructure is expensive and potentially dangerous to carry out in real traffic, and the fact that the situation of interest in Study I, driving a car at night on rural roads, can be simulated with a sufficient degree of realism. However, investigating people's behaviour in their everyday life in simulators or laboratory settings is in general inappropriate because it is impossible to evoke all aspects of adaptive behaviour in such settings. Therefore, it is crucial to have a realistic setting when studying these phenomena and semi-controlled studies offer a plausible way forward. Study II had the aim of investigating road-user strategies and was hence conducted as a semi-controlled field study in real traffic, as was Study III, which examined how roaduser roles affected adaptation in a natural setting.

In traffic, visual sampling is one of the main sources available for information intake. Although eye tracking as a method has its limitations both in terms of technical issues and of what conclusions can be drawn about attention, it is the best measure accessible. It is impossible to know what the participants are thinking without asking them, but if they are asked, their natural behaviour is disturbed and the result will not be accurate. In studies II, III, and IV, data from eye tracking were used for analysing visual sampling, and for studies II and IV it was possible to examine if requirements based on the MiRA theory were fulfilled.

Acknowledging the fact that the traffic situation is an important determinant for human performance, and hence adaptation, there is a need to describe complexity in traffic in a comparable manner. Different approaches have formerly been used for complexity classification. While some of them aim to classify complexity from road and traffic features taking the researcher's point of view, others provide anchor examples from which other situations should be classified by participants. Anchor examples are still limited because there are uncertainties in how to interpret other situations. Asking the participants to make a roaduser subjective rating of complexity while driving is another approach. However, an objective comparison between different participants in different situations cannot be made. Hence, complexity classification according to Table 3 was made from videos for investigating the possible influence of complexity on glance behaviour in studies II and III. Although the classification was new and untested, it was considered necessary to try an approach allowing for all kinds of environments and situations that can happen in real traffic, considering the real traffic setting used in the studies. The simplicity of the complexity classification with only four categories allowed for a rather time-effective rating over interesting situations.

For Study II, the NASA-RTLX scale was adapted for the specific road-user category (cyclists) and used for apprehending the subjective experience of different parts of the route. Although the scale uses a retrospective approach, it was here considered acceptable because of the need for a measure of workload that did not interfere with the cyclists' natural behaviour but could still be compared between participants. It was further used as a complement to observational measures, which were the main measures in this study.

Introduction of a new roadside piece of equipment in traffic in Study IV prompted subjective system evaluation in addition to the observational measures. The system acceptance scale was 
chosen to have a simple and easy measure giving an overall opinion of how the cyclists as a whole perceived the new system. A disadvantage is that the subjective opinion is given in retrospect and may be influenced by the fact that the participant knows that the study is about this specific equipment and may e.g. be overly positive in the presence of the experimenter. To avoid this, the experimenter stated specifically that he or she was not involved with the roadside piece of equipment construction or installation and that the interest was to know what the participants really thought about the system. In addition, the system acceptance scale was preceded by other, open, questions concerning the participants' opinion of the system.

Summing up, different study settings as well as data capturing methods have their benefits and drawbacks. To illuminate the complex subject of road-user adaptation in the traffic environment, a battery of methods is necessary. The methods that exist today will be refined and new methods are constantly being developed, in the search for better understanding of human behaviour. In the next chapter studies utilizing the methods mentioned here are presented. 


\section{EMPIRICAL STUDIES}

The studies included in this thesis examine adaptive behaviour in traffic from various perspectives and they each contribute to the understanding of road user adaptation. In Figure 10 an overview of the included papers (each corresponding to a study) and their focus is presented.

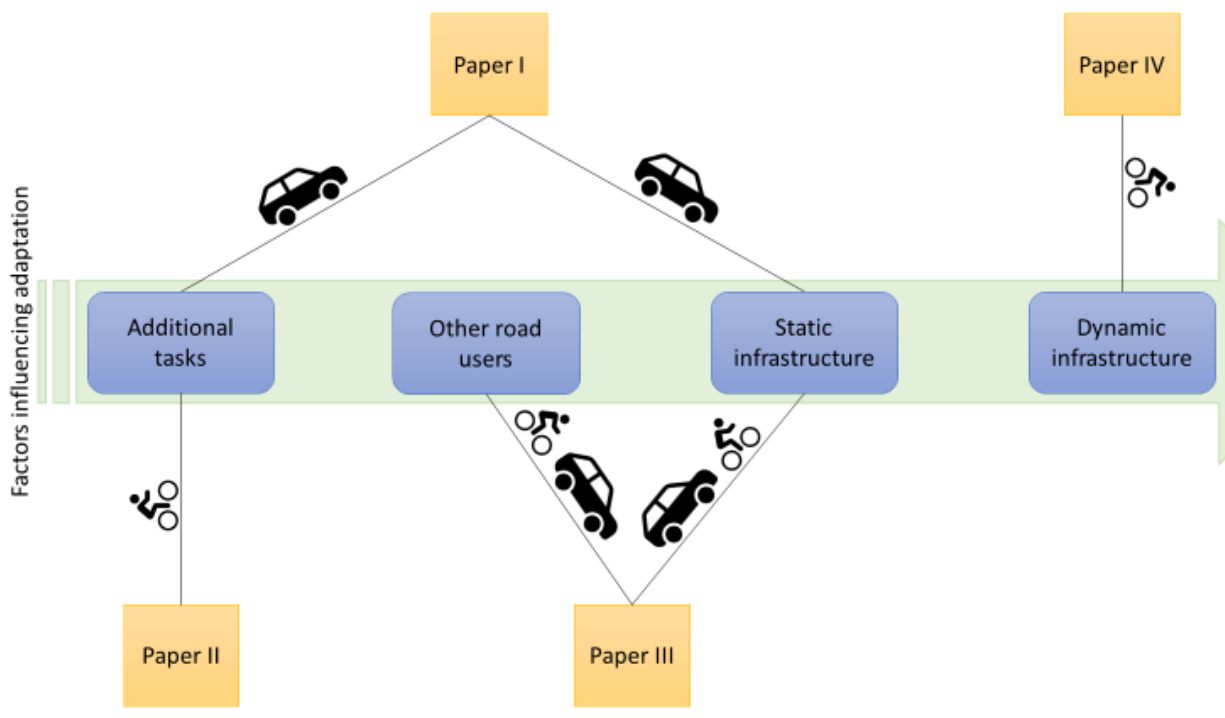

Figure 10. Rough overview of papers, how they are related, and which road-user types are studied in each paper.

Additional tasks are hence studied in Paper I and Paper II, while other road users are studied in Paper III, static infrastructure in Paper I and Paper III, and dynamic infrastructure in Paper IV. Paper I uses car driver participants, while Paper II and Paper IV uses cyclists, and both car drivers and cyclists participate in the study reported in Paper III.

- Study I was conducted as a controlled study in a moving-base car simulator, and was financed by a co-operation between the national road keepers of the Nordic countries, called NMF. The main aim was to investigate how different delineator post configurations affected driver speed. Paper I is based on this study and was published in Accident Analysis and Prevention, 2014.

- Study II was a semi-controlled field study with cyclist participants, carried out within the research programme "A strong research environment in the field of non-motorised vulnerable road users", financed by the research fund of the insurance company Länsförsäkringar. The main aim of the study was to explore cyclists' adaptation strategies when interacting with text messages in real traffic. Paper II reports this study and was published in Cognition, Technology \& Work, 2018.

- Study III was a semi-controlled field study with cyclists and drivers, financed by the partnership programme FFI (Strategic vehicle research and innovation). The main aim was to investigate what trade-offs can be observed when driving and cycling in the same traffic environment and if the road-user role that a person is most familiar with 
influences adaptation. Paper III is based on this study and was published in European Transport Research Review, 2020.

- Study IV was a before-after field study with cyclist participants, carried out within the EU project Xcycle (H2020 - 635975). The main aim was to examine cyclists' adaptive behaviour towards a countdown timer to green traffic light. The results of the study are reported in Paper IV, which has been submitted to an international journal.

Each study above is presented below including aim, method and main results. In addition, the contribution of each paper is stated.

\subsection{Paper I. The effect of different delineator post configurations on driver speed in night-time traffic: A driving simulator study}

The aim of the study was to investigate how different delineator post configurations affect driver speed in night-time traffic. The potential speed effect of introducing an additional task was also investigated.

The following predictions were made:

- Presence of delineator posts lead to increased driver speed compared to absence of delineator posts on the whole road stretch and in curves.

- Given that there are delineator posts present continuously on the road, driver speed is dependent on the spacing between them.

- Drivers reduce their speed in connection to an additional task.

- There is an interaction between presence of an additional task and presence of delineator posts, in terms of driver speed.

To investigate the predictions, a controlled car simulator study presenting the task of nighttime driving on a rural road was conducted. The only visual cues were road markings and road delineators, see Figure 11.

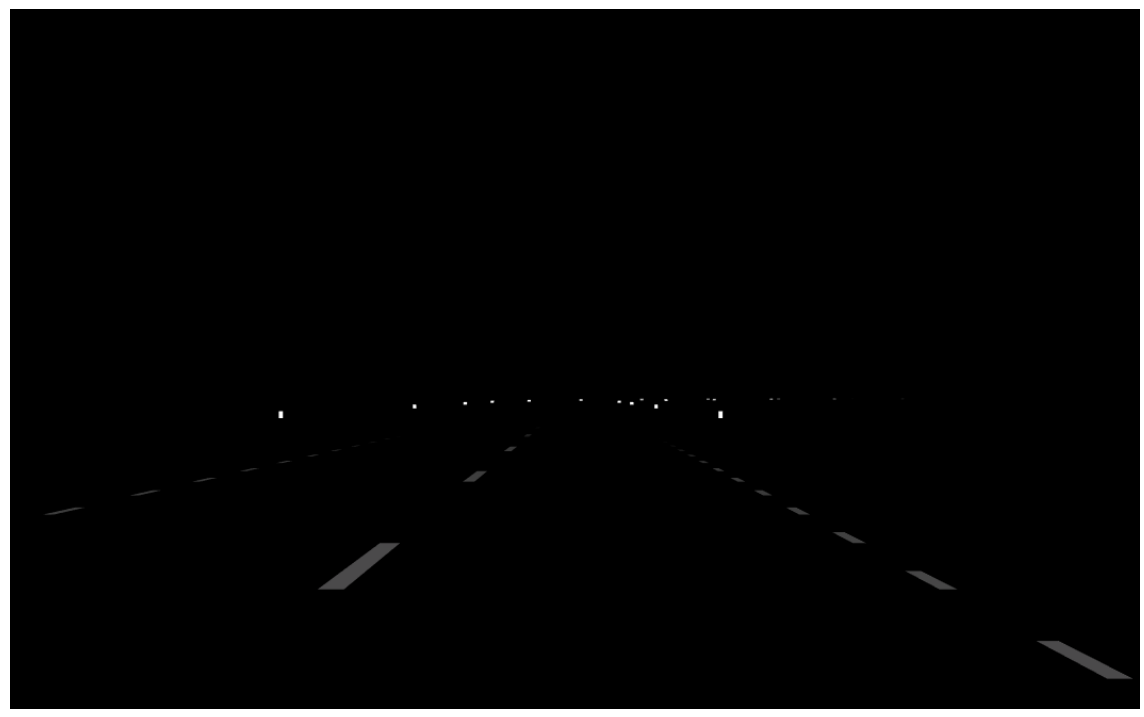

Figure 11. An example view from the driver's position in the simulator study. Source: VTI/Björn Blissing. 
Seven road delineator configurations were tested, where each differed from the others in the distance between the road delineators in at least one of the following road segments: on straight road stretches, before/after a curve, in curves with large radius, or in curves with small radius.

An additional visual distraction task, previously developed within the EU project HASTE (Jamson \& Merat, 2005), was used and shown on a touch screen inside the simulator car, see Figure 12. The task was to look at the screen for any arrow pointing upwards and if so, push the button YES, and else push NO.
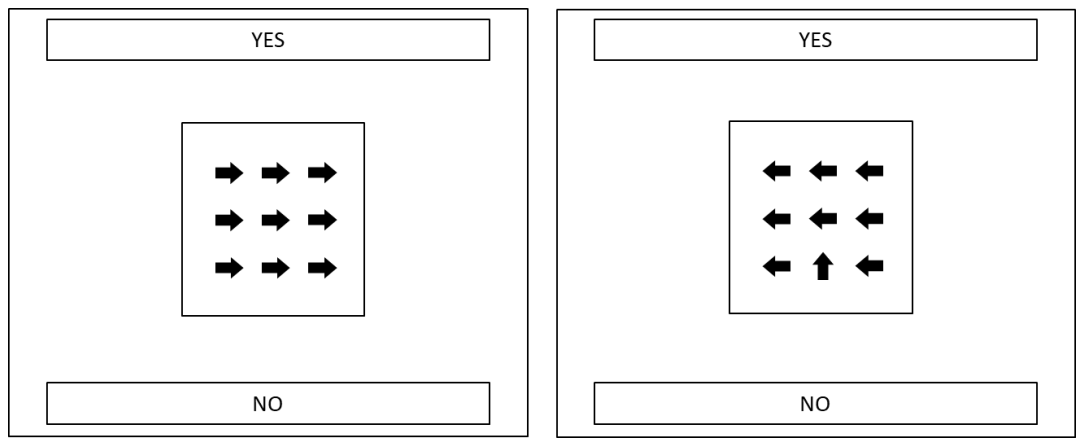

Figure 12. Two examples of the principle of the additional task used in the simulator study. To the left, the correct answer is $N O$, since no arrow is pointing upwards. To the right, the correct answer is YES, since there is an arrow pointing upwards.

A road stretch of $6 \mathrm{~km}$ including six curves was driven for each road delineator configuration, first without any additional task and then with the additional task appearing four times for each configuration. The configurations were counterbalanced to the extent possible given the limited number of participants. Data from fourteen drivers were analysed.

The results from Paper I show that absence of delineator posts lead to reduced speed. However, if there are delineator posts continuously present along the road, driver speed is essentially the same, regardless of the distance between the delineator posts. The results also imply that using more compact spacing of posts in curves with small radius as compared to in curves with a larger radius, could potentially reduce driver speed in curves with small radius. The speed reducing effect of an additional task only existed where the task was initiated, i.e. before a curve but not in or after the curve.

The outcome of the study was that:

- Presence of delineator posts did lead to increased driver speed compared to absence of delineator posts seen over the whole road stretch as well as in curves with a large radius. However, the same was not true in curves with a small radius.

- Given that there are delineator posts present continuously along the road, driver speed did depend on the spacing between them before and in curves but not after curves.

- Drivers did reduce their speed in connection to an additional task where it was initiated, i.e. before curves, but not in or after the curves.

- There was no interaction between presence of an additional task and presence of delineator posts, in terms of driver speed either before, in or after curves. 


\subsubsection{Contribution of Paper I}

Paper I contributes by examining the effect of static infrastructure in road users' speed adaptation. It gives empirical examples of how road users adapt to visual guidance, suggesting that above a certain level of visual guidance, more detailed information does not have any effect on driver speed adaptation in non-complex situations. Situations that are more demanding (infrastructural or cognitive demands) seem to entail maintained safety margins by decreased driver speed. In more demanding situations, there are implications that more detailed information about the increased complexity leads to proactive adaptations according to the visual information.

Paper I also contributes by showing that a visual system-paced (initiated by someone else) additional task introduced before an upcoming complex situation, led to (reactive) speed adaptation in connection with the task, but that there was no added contribution of the additional task in the subsequent complex situation.

\subsection{Paper II. Bicyclists' adaptation strategies when interacting with text messages} in urban environments

The aims of the study were to investigate how cyclists adapt their traffic behaviour when texting and listening to music in a complex urban environment, and if they compensate enough to maintain safe traffic behaviour.

Forty-one cyclists participated in a semi-controlled study, using their own bicycle and smartphone in real traffic. A head-mounted eye tracker was used throughout the study, where each cyclist travelled two laps completing a total of $6 \mathrm{~km}$ divided into six road segments. For one of the laps, the cyclist was asked to listen to some audio of their choice via ear buds connected to his or her mobile phone. On three of the segments, a text message containing a question was sent to the cyclist. The cyclist was supposed to handle these messages as he or she normally would have done, if not being part of a study. The influence on attention was examined using measures based on static minimum attention requirements, while the complexity of the situations was accounted for by complexity classification according to Table 3, and workload was approached by requesting the cyclist to fill out a NASA-RTLX scale after each segment.

The results from Paper II show that listening to self-chosen audio through ear-buds while cycling did not affect workload, speed, SMS interaction or attention significantly. Seven different adaptive behaviours were identified when cycling and receiving a text message: The text messages were either ignored, handled when the destination was reached, handled by the cyclist making a specific stop to deal with the message, handled at a red light, read but not answered while cycling, read with a delayed answer while cycling, or read and answered in direct sequence while cycling. Figure 13 illustrates these behaviours and the outcomes of each behaviour. 


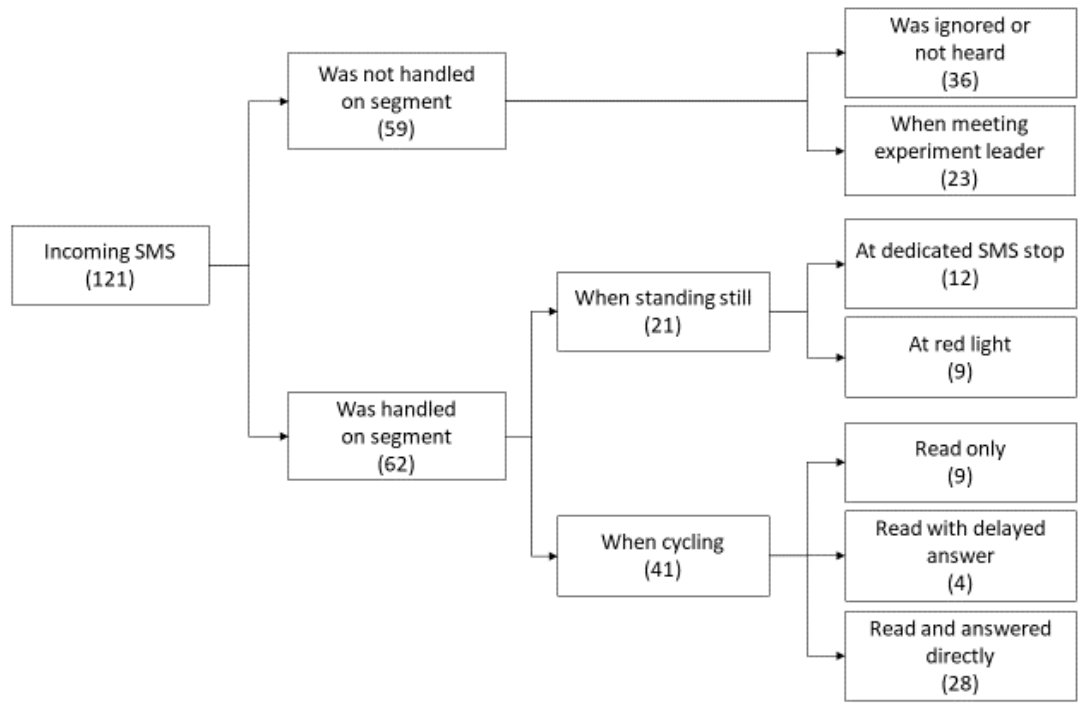

Figure 13. SMS interactions. Total number of outcomes in parenthesis.

Individual cyclists applied different personal strategies for dealing with incoming text messages. Half of the cyclists sometimes read or replied to a message while cycling. One fourth of the cyclists never interacted with their phones before reaching their destination. The remaining quarter of the cyclists sometimes stopped before reaching their destination to interact with their phones, either by making a dedicated SMS stop or by taking the opportunity to deal with the text message while waiting for green at a traffic light, but they never interacted with their phone while cycling. There were no differences in the duration of glances towards the phone between the different complexity levels when interacting with the phone. Generally, the cyclists managed to integrate SMS interactions with their cycling behaviour. Nevertheless, there were two occasions when necessary attention criteria were violated in connection with texting.

\subsubsection{Contribution of Paper II}

Paper II contributes by giving empirical examples of adaptive behaviours in connection to additional tasks in an authentic road traffic setting. The tasks included both a system-paced (initiated by someone else) and a self-paced (initiated by the road user) component. How additional tasks are executed in a real-world setting was exemplified and discussed.

The paper suggested that road users have a personal strategy with respect to the maximum complexity of interaction they accept, and that the interaction can be modified according to the current circumstances. Almost half of the road users sometimes performed the systempaced component of the additional task while cycling and many of those (39\%) performed the self-paced component while cycling too.

Paper II contributes to methodology in adaptation research by showing how eye tracking and the MiRA theory can be used for examining the effects that text messages have on attention in a complex real traffic setting. It further contributes to theory by exemplifying that the comfort zone is subjective while the safety zone is objective and that the comfort zone is not always 
smaller but may in fact be larger than the safety zone. (In this case, the adaptation object was probably misinterpreted.)

\subsection{Paper III. Trade-offs in traffic: does being mainly a car driver or a cyclist affect adaptive behaviour while driving and cycling?}

The aim of the study was to investigate observable trade-offs when adapting to other road users and the infrastructure as a cyclist and as a car driver in the same traffic environment. The influence of the road-user role that the person was most familiar with (cyclist or car driver) was also examined.

Twenty-three participants, whereof twelve regular cyclists who seldom drove a car (character cyclists) and eleven regular drivers who seldom cycled (character drivers), participated in a semi-controlled study in real traffic. All participants were equipped with a head-mounted eye tracker and travelled a specified route in an urban environment twice, once while cycling using their own bicycle and once while driving a car. The car route was equal to the cycling route but extended in the end. The participants were instructed to behave as they normally would have, if not being part of a study. The influence of main road-user role and current road-user role on observable adaptive behaviour was studied in intersections of different types (mixed traffic/separate paths, signalised/unsignalised) using measures based on glance behaviour and video data, while complexity was classified according to Table 3 . The extended control model was used as a framework for predicting adaptation.

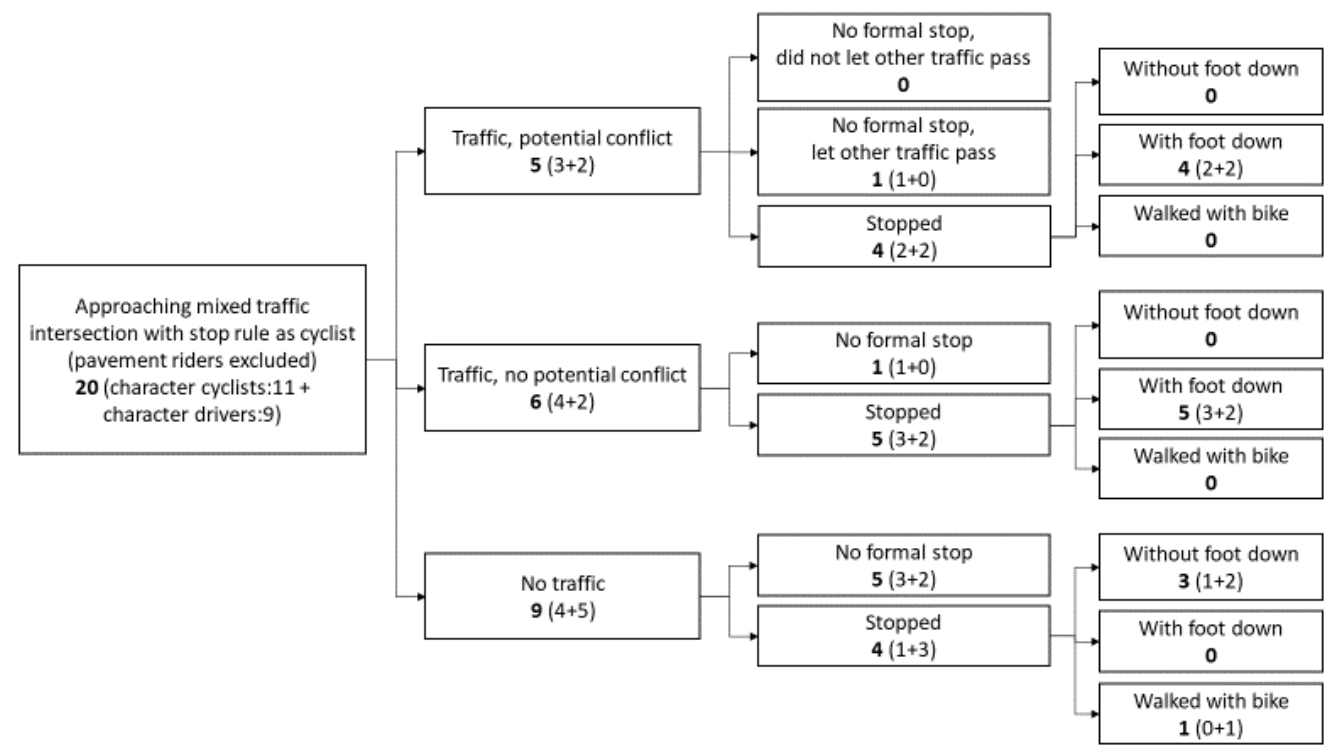

Figure 14. Actions when cycling in mixed traffic at the intersection with stop rule. Result in total (number of outcomes for character cyclists + number of outcomes for character drivers).

The study revealed trade-offs in relation to rule-following, safety, efficiency and physical comfort. The results from Paper III show that adaptive behaviour is not governed by whether the road user is a regular cyclist or a regular car driver, but of the current road-user role and the demands for that role in the current situation. Cycling in a mixed traffic intersection with stop rule, different actions are performed by different persons, according to the traffic 
situation (see Figure 14): If there was no traffic, about equally many stopped as did not stop formally, while if there was traffic, the majority made a formal stop, irrespective of whether there was a potential conflict or not.

Driving a car at the same intersection the participants stopped to a larger degree, irrespective of current situation in terms of potential conflicts in the intersection (see Figure 15).

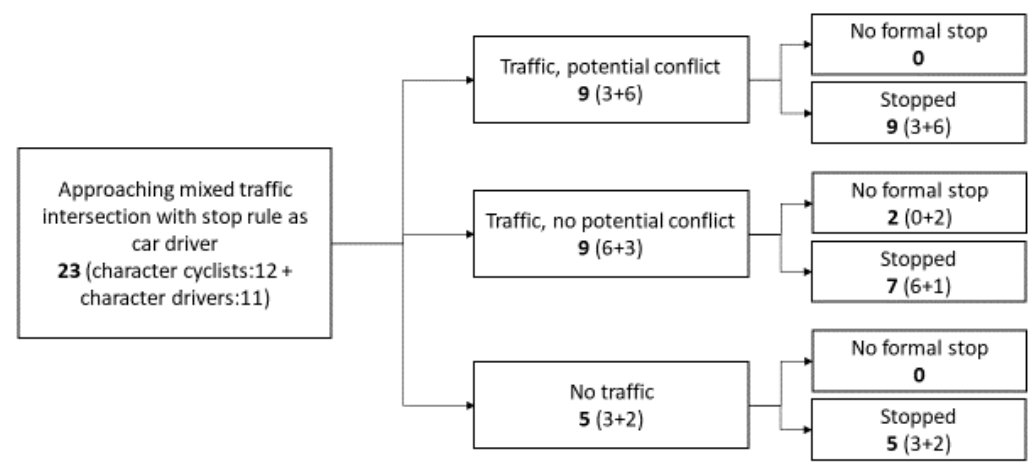

Figure 15. Stopping behaviour when driving in mixed traffic at the intersection with stop rule. Result in total (number of outcomes for character cyclists + number of outcomes for character drivers).

Cycling in a signalised intersection, over $80 \%$ looked over their shoulder before passing the intersection at green signal, for their own safety. Driving in the same intersection and turning right, all but one driver looked for vulnerable road users (VRUs) from behind before turning, and all drivers with an approaching VRU yielded to the VRU.

In an intersection where the cycle path was separated and situated on the right hand side of the car path, the side road to the right was checked significantly more in the current role as cyclist than as car driver. When cycling, there was no difference regarding looking into a side-road to the right between a mixed traffic intersection and an intersection where there were separated paths for cyclists and car drivers. However, significantly fewer drivers looked into a side-road to the right when approaching the intersection with separated paths, compared to in the mixed traffic intersection.

The highest complexity levels involved the highest gaze change frequency and the lowest number of glances to non-relevant objects. Whether the participants were in their most familiar role or not did not influence the results.

\subsubsection{Contribution of Paper III}

Paper III contributes to methodology in adaptation research by using the same participants in both familiar and more unfamiliar road-user roles in real traffic and gives empirical examples of adaptive behaviour with respect to other road users, both potential and present, from observations of two road-user roles.

Paper III further contributes by showing that the effect of main road-user role was overruled by the effect of the current road-user role and the demands and opportunities for that role. The study generated hypotheses suggesting that current prerequisites, in terms of environment, complexity and vehicle, determine the capacity for action related to adaptive behaviour. 
The importance of the situational demands for comfort has been discussed and exemplified. The paper showed that the propensity to stop at an intersection where the stop rule applies, was primarily affected by the stop sign when driving a car but that while cycling, the tendency to stop appeared to be more associated with presence of other road users in the intersection. This has implications for the comfort zone, because breaking the cyclist's flow is more discomforting compared to that of a car driver.

\subsection{Paper IV. Cyclists' adaptation to a countdown timer to green traffic light: a before-after field study}

This paper aimed to examine cyclists' adaptation to a countdown timer (CDT) to green traffic light, and if the adaptation had any detrimental effects on crucial information intake. ECOM was used as a structure for setting up hypotheses on observable cyclist behaviour and the MiRA theory was used for defining attention targets.

Twenty-six cyclists participated in a before-after study with a within-group design. In baseline, each participant was equipped with a head-mounted eye tracker and cycled with his or her own bicycle, also equipped with cameras, four times towards the same signalised intersection in real traffic with the traffic light to the left of the cycle path. There was also an experiment leader cycling behind the participant, filming the traffic environment. After baseline, a countdown timer to green traffic light was installed at the intersection on the righthand side of the cycle path. The treatment study was conducted a year after baseline, using the same procedure.

The results of the study indicate that cyclists look for and use the information presented to them on a CDT showing the remaining time left to green traffic light. In general, the information was more used for their own efficiency and comfort than for safety, at least in the rule-based sense. The start-up delay times were reduced with the CDT, but the number of redlight violations seemed to increase. Overall attention to necessary targets was similar in baseline and treatment. Cyclists adapted their speed to the information of the CDT to try to avoid coming to a complete stop. Pedalling behaviour indicated that without the CDT, cyclists prepared to stop more than with the CDT. One participant stated that the CDT was beneficial for keeping the flow because of other road users' adaptation to it. The cyclists in general found the CDT quite useful but thought it could be improved, with the most common improvement suggestion to place the CDT and the traffic light on the same side of the cycle path.

Figure 16 shows the distribution of glances in relation to the distance from the intersection in baseline and treatment, respectively. It can be observed that the glances to the CDT are taken from glances towards the traffic light. The same pattern is noted during the last two seconds before setting off after a stop, see Figure 17. 

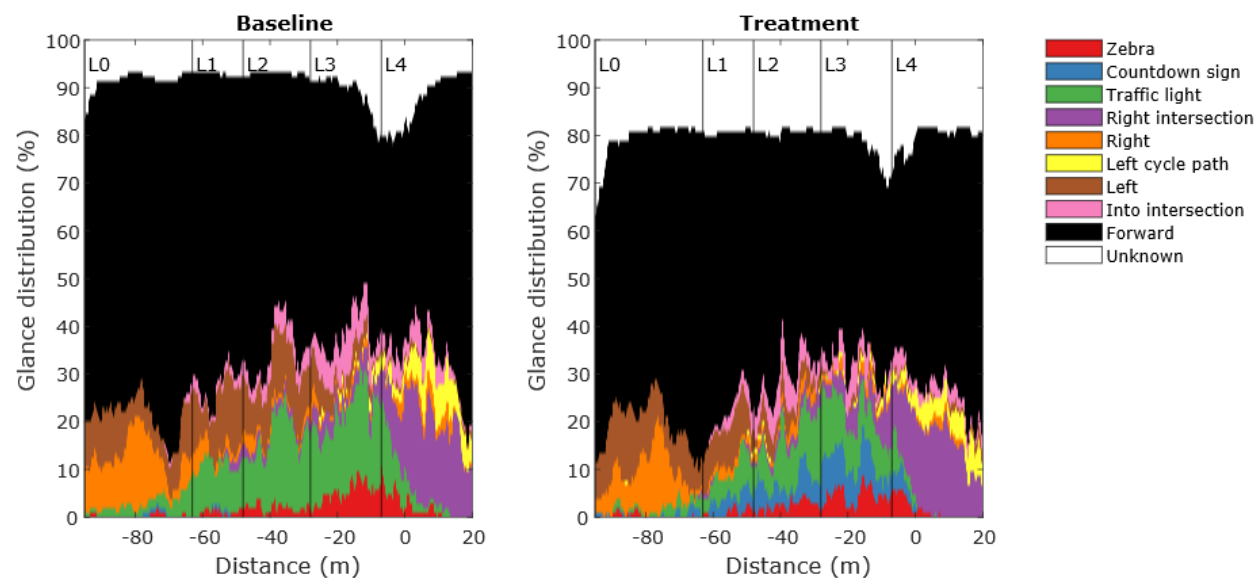

Figure 16. Glance distribution in relation to distance from intersection. Glances when standing still excluded.
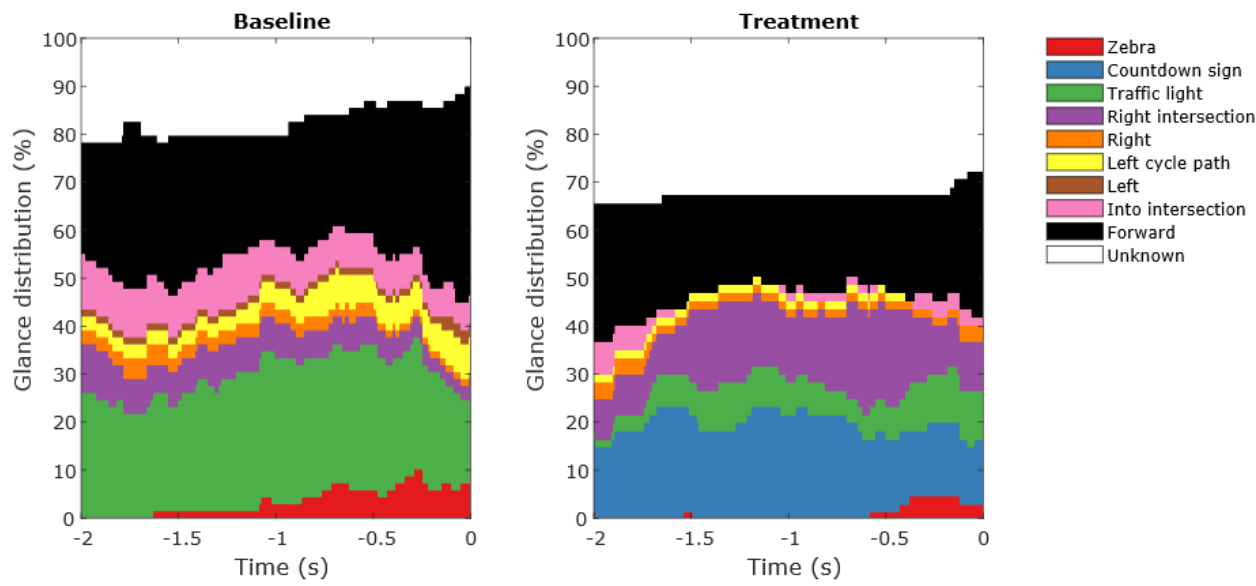

Figure 17. Glance distribution during the last $2 \mathrm{~s}$ before starting to cycle after having stopped at red light.

During the last two seconds before moving after a stop, neither the traffic light nor the CDT was monitored in about half of the cases both in baseline and in treatment. For the cases in treatment where glances to either the traffic light or the CDT were observed, the largest share was to the CDT only.

\subsubsection{Contribution of Paper IV}

Paper IV contributes by assessing adaptive behaviours related to a dynamic infrastructure system. The added detailed information given by the system was appreciated by the road users and used in addition to the standard information system.

The findings of Paper IV suggest that road users strive to stay within the comfort zone using the available means of detailed predictive information. Examining adaptive behaviour towards a CDT for cyclists in addition contributes to the applied field since studies in this area have been very few. 


\subsection{Methodological considerations}

In this thesis, the primary unit of analysis is individual road users, not overall behavioural adaptation of road users as a collective. The advantage is that the same road user can be examined in different situations, and individual adaptive behaviours can be studied in response to changes in visual guidance, vehicle, with or without an additional task, with or without a support system.

None of the studies performed within this work incorporated all interesting aspects to consider. Instead, they complement each other in digging into the subject of road user adaptation. While the controlled study has its advantages of varying an interesting factor while keeping other aspects constant, the ecological validity is higher in the semi-controlled studies. On the other hand, all kinds of circumstances can influence behaviour and since it is important to compare relevant things, the analysis becomes more complicated. Then again, the ecological validity is larger when behaviours are performed "in the wild" which goes for all field studies in this thesis: In a natural setting it should be kept in mind that taking chances in the study equals taking chances in real traffic and this may cause fines and, even worse, injuries or death.

There are numerous ways of designing additional tasks that are intended to correspond to real tasks in traffic that are not immediately related to operating the vehicle. In this thesis two extremes were given; one was totally made up and would never happen in a natural setting, and the other was a commonly occurring task in real traffic. The advantage of using the invented task was that it was equally unknown to all participants, so that there were no biased interactions. This task was a system-paced task which was given to all participants at the same position for causing a distraction from the driving task that needed both perceptual and motoric attention. The other, more natural, additional task was probably more familiar in traffic to some participants and less to some. The basis for using this task was to detect naturally occurring adaptive behaviours in relation to an ecologically valid task.

In Study IV a full year passed between baseline and treatment. During this time span, outside of the study, the approach to the studied intersection was renewed. The most apparent changes were the colour of the cycle path (changing from red to dark grey) and that there was lane separation for cyclists' turning right in baseline but not in treatment. Although it cannot be ruled out that these changes have had an effect, for instance in where cyclists turning right position themselves to the right of the cycle path, the probability of behaviour change in relation to the introduction of the CDT is estimated as low.

Some additional issues with real-world resemblance in the studies are given here:

- In the simulator study, the exact level of the speed is not to be considered as on the road, but speed differences between delineator configurations should be correct. A validation study on a real road (Rajamäki, Luoma, \& Rämä, 2013) was carried out after the simulator study with four of the seven road delineator configurations. This study could not verify the results from the simulator, which might be explained by varying weather and road surface conditions during the two months that the study was conducted.

- Conducting a simulator study, motion sickness is an issue affecting who will participate, both when recruiting people and when the study is conducted. Although this is a restriction on whose data is collected, this was not perceived as a major 
problem of the study here where different visual guidance features should be compared by means of driver speed.

- Participants in all the three field studies carried eye tracking glasses. Due to the large sidepieces, it is possible that the gaze behaviour was supplemented with more head movements than if the participants would not have worn them. However, all participants were affected equally in all conditions and the information gathered by visual sampling is considered unlikely to change by the restrictions of the eye tracking equipment.

- The field study with mainly car drivers vs. mainly cyclists whose task was to cycle and drive a car along a predefined route is considered quite ecologically valid, since what differed from normal riding and driving was the presence of an observer and wearing eye tracking glasses. In the driving condition, however, the car was unfamiliar to the participants.

- The field study with cyclists riding through the same intersection four times per participation occasion, with one year in between, cannot simply be assumed to be free of familiarity issues. The participants were chosen based on their recurring cycling in the area and therefore familiarity with the intersection was high. Familiarity with the CDT in the treatment phase varied though. However, when comparing the first lap with the other laps, no differences in either the time on approach or stopping duration were noted. Therefore, different experiences with the CDT were neglected in the analyses. 


\section{THEORETICAL AND EMPIRICAL IMPLICATIONS}

From theory on adaptation, attention and behavioural models, adaptation in the road traffic environment can be viewed as the road user setting the safety margins of the comfort zone according to his or her present state and capability. Adaptation can however only be measured in terms of perceivable adaptive behaviour, which is reported in the papers of this thesis and further discussed below. Adaptive behaviour is shown in the adjustments made to have large enough subjective safety margins, i.e. as perceived by the road user. Proactive adaptive behaviours are applied if the road user predicts that the margins will be too short otherwise, while reactive adaptive behaviours are employed when the subjective safety margins are already too short.

Behavioural models depict adaptations in different ways. In common for several of the models is that adaptive behaviour can be viewed as the adjustments made to maintain safety margins of the comfort zone. Here, the comfort zone is defined by its subjective safety margins when they are sufficiently large for a feeling of comfort. The margins differ depending on how close to the subjective safety zone boundary it is comfortable to be for different functional control variables, in line with the perspective of Summala (2007) described in 3.2.9. The safety margins and the comfort zone depend on what state the road user is currently in. Road user state depends on the internal and external factors that may influence adaptation, where being in a hurry and driving through a non-complex road environment can allow for decreased safety margins, whereas being well-rested, driving on icy roads and carrying a load that needs to be handled with extra care may lead to increased safety margins. Note that in both cases, the road user operates within the comfort zone, as long as he or she feels comfortable.

Not only driver state but also the capability of the driver matters for setting the safety margins. A person experiencing low capability can set the margins larger than a person experiencing high capability of conducting the task. For instance, inexperience with a certain vehicle, route or system can increase the safety margins. It is important to acknowledge that these are subjective, and not actual safety margins. Even though a driver thinks that he or she has set the safety margins so that there is extra space for taking decisions on a non-familiar route, these may still not suffice for the driver to handle a demanding situation without loss of control.

Figure 18 shows a conceptual model of how comfort zone, discomfort zone, adaptive behaviour and subjective safety margin are linked together for a road user within his or her comfort zone. While the objective safety margin (or rather margins, in different directions) always follows the road user, the subjective safety margin(s) is not considered by the road user as more than sufficiently large, as long as he or she is within the comfort zone. 


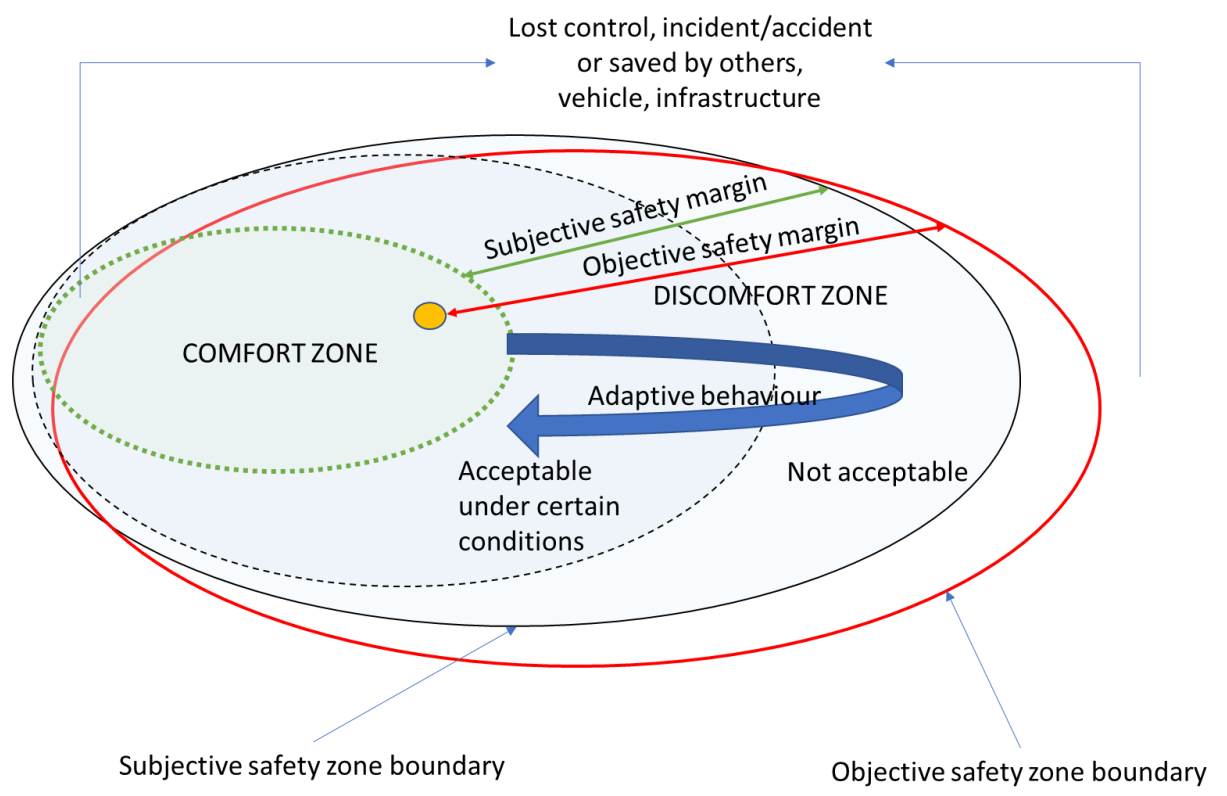

Figure 18. Conceptual model showing relations between comfort zone, discomfort zone, subjective and objective safety margins and adaptive behaviour for a road user (depicted by a yellow circle) within the comfort zone.

The boundaries of the comfort zone and of the subjective safety zone continuously change in time and space, according to external and internal factors. External factors are attributed to the context and present situation, whereas internal factors include the capability, internal state, emotions and feelings, personal strategy and goals that the road user has. If ECOM is applied to this, the setting of safety margins for the comfort zone is seen as a combination of more steady conscious strategies decided upon in the higher layers of ECOM, and more instantaneous decisions that may be either conscious or nonconscious and carried out in the lower layers of ECOM, related to the present context, but also to internal factors that are not a part of ECOM. When the road user is outside the comfort zone the subjective safety margins are shorter. This can be acceptable under certain conditions, i.e. with extra motives (Bärgman et al., 2015; Näätänen \& Summala, 1976). Näätänen and Summala (1976) proposed six categories of extra motives: Goals set for the trip or during it, emotions (in a traffic situation or external to traffic), behavioural models (e.g. norms among the road user's social group), showing off and the need to prove oneself, hedonistic objectives (pleasure of driving) and, finally, risk for risk's sake. Although there might be such extra motives, there is also a personal limit concerning how small the road user is willing to let the subjective safety margin be. This is here called the non-acceptable part of the discomfort zone and it is an area which the road user would never enter deliberately. The predictive processing framework (Lupyan \& Clark, 2015) is useful for understanding the constant interactions between predictions made both in higher and lower layers of ECOM and the corresponding prediction errors. As illustrated in the figure, there can be a discrepancy between the subjective and objective safety zones. This is not apparent to the road user until predictions are evidently incorrect. If outside of the objective safety zone boundary, control is lost and an unplanned outcome will occur, which can range from a skid to a fatal crash, depending on the vehicle, other traffic and surrounding infrastructure. 

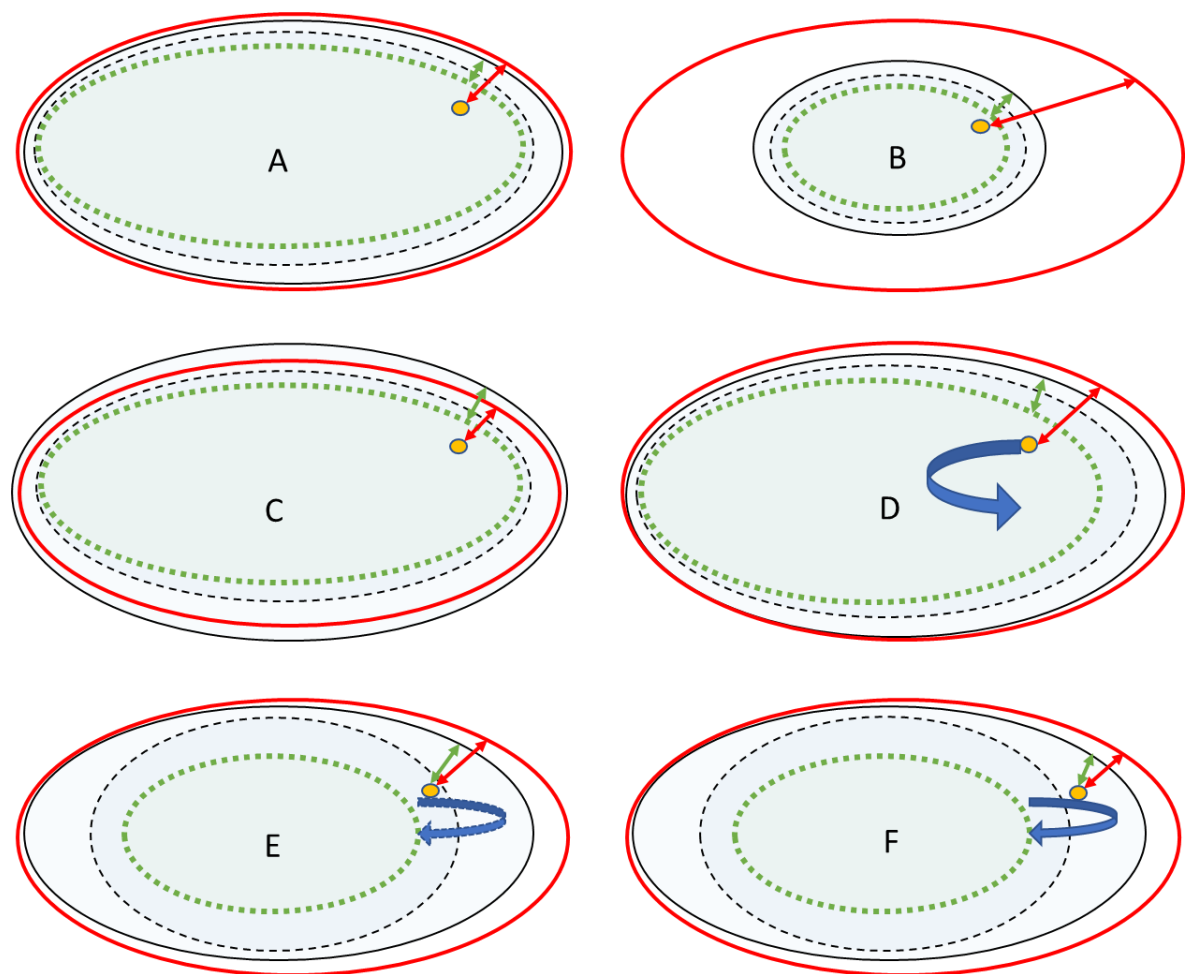

Figure 19. A-F illustrate different traffic situations. A: Small objective safety margin. B: Large objective safety margin. C: The subjective safety margin exceeds the objective safety margin. D: Proactive behaviour is performed to stay within the comfort zone. E: Road user in the acceptable part of the discomfort zone. F: Road user in the non-acceptable part of the discomfort zone.

Figure 19 exemplifies how the conceptual model is affected by different traffic situations. In A, the road user utilises the capacity of the traffic system as the comfort zone boundary is close to the subjective as well as objective safety zone boundary. In B, on the other hand, the subjective safety zone is much smaller than the objective safety zone, e.g. when a driver thinks that the road surface is slippery and drives with extreme caution when in fact it is not. In $\mathrm{C}$, a situation is illustrated that is more hazardous than the road user thinks, e.g. due to a combination of icy roads and bad tyres. D illustrates proactive adaptations made by the road user to an anticipated situation to stay within the comfort zone, such as a cyclist stopping before initiating a call. As soon as a functional control variable is not within its acceptable range, the feeling of comfort is lost, and the comfort zone boundary is exceeded as illustrated in $\mathrm{E}$ and $\mathrm{F}$. In $\mathrm{E}$, the road user is within the acceptable part of the discomfort zone and may choose to stay there under certain conditions, or to perform adaptive behaviour to return to the comfort zone. The road user can also act proactively, to avoid the non-acceptable part of the discomfort zone. The road user in $\mathrm{F}$ has entered the non-acceptable part of the safety zone, for instance as a result of experiencing visual impairment from glare, and adaptive behaviour is performed to increase the safety margin. 


\subsection{Road-user adaptation in response to static infrastructure}

The results in Paper I show that presence or absence of road delineators affects adaptation in terms of speed behaviour more than the exact distance between the delineators. When the visual guidance is adequate, more detailed information does not affect the subjective safety margins because the road user is already within the comfort zone and the overall feeling of comfort remains. The substantial speed reduction related to absence of road delineators can be interpreted as the visual information being insufficient for accurate prediction of the future path given the current speed. Adaptive behaviour is then adopted to return to the comfort zone where the driver feels in control of the situation and the safety margins are satisfactory. The study by Kallberg (1993), where driver speeds increased on roads with low but not with high geometric standard when road delineators were introduced, also supports this: When predictions of the future path are experienced as hard but turn out easier, drivers may have extended their comfort zone in relation to the current infrastructure. On roads with a higher geometrical standard, more detailed visual guidance does not influence the predictions to any larger extent, and they are already good enough for the driver to perform within the comfort zone.

There are implications that drivers make proactive adaptations to upcoming curves by reducing their speed more to curves ahead with a small radius compared to curves with a large radius, given that the distance between the road delineators is smaller in the curves with small radius than in those with large radius. This implies that a way to make it easier for drivers to perceive that there is a sharp curve ahead, and hence to adapt their speed appropriately, is to place road delineators more densely together in those curves than in milder ones. This probably triggers bottom-up attention which makes them more aware of the objective safety margins by way of road boundaries, which in turn makes them adjust their subjective safety margins to stay within the comfort zone. The speeds in curves with smaller radii were always lower than in curves with larger radii, which means that reactive speed adaptations when the driver has already entered the curve also occur, when the boundaries of the comfort zone are exceeded.

Findings from Paper II and Paper IV revealed that not all the necessary attention requirements in intersections were attended to. One reason for this could be that the zones for attention requirements are wrong. Another could be that the eye tracking measure is not adequate. As previously stated, eye tracking is not an exhaustive measure for attention, not even for visual input, and leaves non-visual cues, such as audio, neglected. When cycling in open air, both visual and audible information is mostly present. However, audible information can guide visual sampling and hence, if hearing a threat (i.e. a prediction error, according to the predictive processing theory) the focus of the eyes can move towards the source to sample more information. If no threat is heard, however, the foveal attention of the eyes may not change, so that the person is not considered attentive from an observer perspective. In the case that the attention requirements were implemented properly, and the eye tracking was adequate, then the observed inattention can have consequences for traffic safety. If a road user is inattentive to the necessary attention requirements, this can be due to a mismatch between the subjective and objective safety margins and can have severe consequences for his or her own safety and that of others. In a situation studied in Paper II a participant seemed to have mistaken the green traffic light for cars as the one for cyclists and went on to cross the intersection, negotiating with a car turning right as a result. In the conceptual model in 
Figure 18 this is a case of lost control where the cyclist was saved by others and had to make new predictions from bottom-up stimuli due to the right-turning car, leading to adjusted subjective safety margins.

Other adaptations in relation to the static infrastructure include riding on the pavement along a mixed traffic road in Study III. Although it is prohibited to ride a bicycle on the pavement, some people still did so rather than using the road. At least three possible alternatives for this behaviour can be discerned: 1) The cyclist does not know that he or she is supposed to use the road. 2) The cyclist trades rule-following for perceived safety. 3) The cyclist trades rulefollowing for efficiency. For the first alternative, information and clarity of the infrastructure should help to diminish confusion. For the last two alternatives, which may in fact apply simultaneously, the cyclist knows that it is not legal, but experiences that the (safety) loss of riding in mixed traffic or (efficiency) gain of using the pavement surpasses the lawful behaviour. This is in accordance with the efficiency-thoroughness trade-off (ETTO) principle, in which a continuous trade-off between efficiency and thoroughness are made depending on the main concerns for the moment (Hollnagel, 2012). The cyclist may feel that his or her safety margins cannot be made satisfactorily large on the road, hence being pushed into the discomfort zone. Due to different perceptions and motives for different persons, some people act within the acceptable part of the discomfort zone and stay on the road, while others ride on the pavement to increase the subjective safety margins. Changes in the infrastructure can affect the comfort zone. Going from a cycle path to a mixed traffic road might either decrease the comfort zone, increase it or leave it unaffected, depending on the individual and other situational demands. For some persons, the increased space given by a road in relation to a cycle path increases the comfort zone and the road may be preferable and perceived as more efficient. Some road users may be indifferent to the variation in infrastructure and stay in their comfort zone, while others feel that they are being pushed out of it. This is supported by (Ihlström, Henriksson, \& Kircher, submitted) in their finding that cyclists who feel uncomfortable sharing the road with motorized traffic either choose to ride on the pavement or continue to ride on the mixed traffic road, e.g. because they do not want to behave illegally. In this thesis this is interpreted as extra motives in line with Näätänen and Summala (1976).

In Study III, it was also found that the setting and context, i.e. the situational demands, affect adaptation. That the specific situational demands affect coping behaviour in traffic has previously been recognized by e.g. Hennessy and Wiesenthal (1997). Situational demands include those represented by both infrastructure and traffic. While the infrastructure sets the arena in which behaviour can be performed, it also gives the road user expectations of the future path and traffic. These expectations, which are also influenced by current regulations, affect how the road user prepares for an upcoming situation. If the road user feels discomfort due to the predictions being uncertain, he or she can adapt, for instance by slowing down, increasing the time available for acquiring information to improve the prediction and hence return to the comfort zone. If the road user is within the comfort zone but has wrong expectations, adaptive behaviour towards an upcoming situation may be inappropriate. This has e.g. been shown in a simulator study by Martens and Fox (2007), where repeated exposure to an intersection lead to certain expectations, leaving a change in the priority situation unnoticed by the participants. 


\subsection{Road-user adaptation in response to dynamic infrastructure}

Paper IV revealed several adaptive behaviours in relation to the traffic light and the CDT. In general, cyclists used the dynamic infrastructure to be effective and to avoid discomfort proactively. With the traffic light only, at red they stopped pedalling early to avoid the effort of coming to a complete stop and continued to roll and pedal when the traffic light was green. The physical effort of stopping and starting over also breaks the riding flow, which is often not preferred (Broach, Dill, \& Gliebe, 2012). It seems that the more detailed information given by the CDT led to better predictions and allowed for the cyclists to continue pedalling to a larger extent, while still being within the comfort zone in anticipation of the green traffic light without having to stop. Cyclists adapted to the CDT by searching for and taking in information from it and using it for improved predictions in their speed adjustment. If a stop was inevitable, then the CDT was used for predictions and hence efficiency in terms of reducing start-up delays but there were also cases of red-light violations. These effects have also been shown in relation to CDTs showing the remaining time left to green for car drivers (Chiou \& Chang, 2010; Islam, Hurwitz, \& Macuga, 2016; Liu \& Kircher, 2018; Wenbo, Zhaocheng, Xi, \& Feifei, 2013; Yuan, Zhang, \& Lei, 2009). This can be interpreted as the subjective safety margins being large enough for the road user to move while expecting green signal, in relation to the discomfort of frustration with unnecessary waiting time or, at least for cyclists, of having to travel within a crowd, which could be the result of waiting a bit longer. These perceptions are individual but also context-related since they can vary depending on traffic and familiarity with the intersection and traffic light. For the kind of dynamic infrastructure examined here, i.e. two information sources concerning the same circumstance, but on different levels of detail, the cyclists applied visual time-sharing. Using this strategy, the more detailed information of the CDT contributes to the prediction of the traffic light, which formally decides when to go and hence needs to be checked. By prediction, the road user controls that the safety margins are large enough for comfort.

\subsection{Road-user adaptation in response to additional tasks}

Results from Paper I show that when drivers received an additional task before a curve ahead, they slowed down before the curve, but there was no speed reduction due to the additional task in or after the curve. This implies that the drivers were proactive in the sense that they tried to deal with the additional task before the curve and reduced their speed then, so that they didn't have to deal with the demands of the curve at the same time as the additional task. This can be a strategy to keep within the comfort zone, or at least within the acceptable part of the discomfort zone, in more complex situations. Other simulator studies (OviedoTrespalacios, Haque, King, \& Washington, 2017) support this, showing that drivers who had to engage continuously in an additional task (a mobile phone conversation) when driving chose a lower speed driving along a curved road compared to when they did not have any additional task.

In Paper II, listening to a self-chosen audio with ear-buds while cycling did neither affect the cyclists' experienced workload, which varied on low levels, nor their speed. The possibility that listening while cycling could have had an impact on speed if experienced workload had involved larger variations cannot be excluded since this could have affected the comfort zone. Furthermore, with experimental control of the volume level and content of the audio, listening has been reported to impair cyclists' response to other auditory signals (see de Waard, Edlinger, \& Brookhuis, 2011). Hence, the results in Paper II indicate that if cyclists can 
decide for themselves, they choose a level of volume and a content that they are able to listen to without exceeding the boundaries of their comfort zone.

The empirical material supports the claim that comfort zones differ between individuals, because the cyclists in Paper II applied different strategies for dealing with incoming text messages on an individual level. The maximum complexity of interaction can be consciously decided upon as a personal strategy, while the interaction in a given situation is highly context specific. When the additional task is announced, the road user may not feel that attending to the task is as important as efficiency of the trip and as a result keeps on cycling without attending to it. If the cyclist is forced to stop and wait, for instance at a traffic light, the efficiency cannot be influenced by the cyclist without violating the rules, and other goals or tasks can emerge as important, such as attending to the text message. Given that the cyclist feels comfortable with this, this is carried out within the comfort zone. If the context changes, e.g. by the traffic lights turning green, and this is noted, the efficiency goal can rise again, and the road user may feel that he or she is pushed into the discomfort zone unless continuing cycling. Either the cyclist finalises the interaction while in the acceptable part of the discomfort zone or decides to abandon the task in favour of the efficiency goal.

For cyclists who do not feel that the cycling efficiency goal is dominant, additional tasks can have higher priority and a location can be chosen where the comfort zone is intact, by making a dedicated stop. Alternatively, the individual can incorporate the task within the personal comfort zone while cycling by controlling factors such as speed and choosing an appropriate context for interaction. This way, the additional task is integrated within the cycling task and the subjective safety margins can be maintained. The adaptive behaviour of reading a text message with a delayed answer while cycling implies that the cyclist could read the message in a certain environment or situation but waited for a better opportunity before replying, which requires both perceptual and motoric skills. If the cyclist is within the comfort zone in a given context, the decision to check the text message could be taken. While cycling and reading the message, the cyclist may feel that he or she is pushed into the discomfort zone, either because of the added demands of the reading task or of changing context, or both, possibly making predictions of the future path insufficiently precise for comfort. Then the answering of the text message is postponed to when the cyclist has returned to the comfort zone, where the subjective safety margins are sufficient, i.e. when the cyclist estimates that the current situation allows for interacting with the additional task within the comfort zone or at least within the part of the discomfort zone that is acceptable under certain conditions.

\subsection{Road-user adaptation in response to other road users}

The results from Paper III demonstrated that cyclists showed different adaptive behaviours in relation to presence of other traffic in a mixed traffic intersection with stop rule. The major part of the cyclists stopped formally if there was traffic in the intersection, irrespective of whether there was a potential conflict or not. This was not the case if they did not encounter any traffic, where about half of the cyclists did not make a formal stop. Presence of other road users, i.e. basically the relevance of the stop rule, appears to be an important determining factor of rule compliance for cyclists. The behaviour was related to the road-user role, because traffic in the intersection did not lead to that much different adaptive behaviours when driving a car, since most made a formal stop, irrespective of traffic situation. This difference between driving a car and riding a bicycle can have various reasons. One could be the more formal rules that are associated with driving a car and reflected in that the fines are 
higher for neglecting the stop sign with a motorised vehicle than with a bicycle (at least in Sweden, where the study was conducted). Another could be the different physical setting that is related to the different types of vehicles: at the stop line a cyclist is situated closer to the intersection and has a more unobstructed view from higher up compared to a car driver. In addition, the physical effort of stopping and starting over is higher when cycling than when driving and is more important to avoid for a cyclist than for a driver.

As previously noted (in Section 6.1), some cyclists rode on the pavement on the mixed traffic section and one possible explanation of this behaviour might be that avoiding motorised traffic is perceived as safer than sharing the road. Pavement cycling is further investigated in (Ihlström et al., submitted) where the phenomenon is considered as rational in mixed traffic when infrastructure is unclear. Since the safety margins need to be large enough for the road user to be within the boundaries of the comfort zone, in this case the comfort of the cyclist is clearly affected by the infrastructural setting and the eventuality of motorised traffic in the same lane. For the majority of cyclists who used the mixed traffic road for cycling, it is not clear whether this was within their comfort zone or not. If it was not, then there might be extra motives to have a feeling of discomfort, in accordance with the term of Näätänen and Summala (1976). The most reasonable ones here are goals set for the trip ("obey the rules"), emotions (fear of reprisals) and norms ("we do not use the pavement for cycling").

Paper III also revealed that cyclists going straight and car drivers turning right in a signalised intersection adapted to each other. From an individual perspective, the situational demands, in terms of presence, intention and relative speed of the other, expected time until red and the restriction of the regulations seemed to determine who went first. All these aspects are inferred by the individual, and the future course of events predicted. Although the regulations state that drivers should yield to cyclists in this situation, most of the cyclists checked that they were given right of way before passing the intersection. This behaviour can be interpreted as a way to check and maintain the safety margins of the comfort zone, i.e. to perform proactive adaptive behaviour according to the description in the beginning of this chapter. In addition, an individual road user can affect the objective safety margins of other road users. If the light is green for right-turning vehicles and for cyclists going straight ahead, a car driver can slow down or stop well before the intersection, increasing the objective safety zone for a crossing cyclist. On the other hand, the objective and subjective safety margins can both be decreased by a car driver driving close to a crossing cyclist. Conversely, a crossing cyclist can affect the (objective and subjective) safety margins of a car driver. Renner and Johansson (2006) emphasise that the capacity for coordination, i.e. adaptation between road users, in traffic should be enhanced. This would mean that it should be easier for road users to maintain each other's safety margins. The most obvious example of adaptation between road users was found at an intersection in Study II, where a cyclist was saved by a car driver when the cyclist's prediction in retrospect was wrong and the subjective safety zone exceeded the limits of the objective safety zone. 


\section{GENERAL DISCUSSION AND CONCLUSION}

The theoretical frameworks that are included in this thesis are synthesized by defining adaptation in the road traffic setting in relation to the road user's subjective safety margins and comfort zone. In addition, adaptive behaviour is perceived as how the adaptation is operationalised, and hence is observable from an outside perspective. All studies examine factors affecting adaptive behaviour in the road traffic environment. The major theoretical contribution of this thesis is the development of the conceptual model of comfort zone in Chapter 6 that describes when and why adaptive behaviour in traffic occurs. In this view, proactive adaptive behaviours are employed in the light of predictions made by the road user of upcoming situations that would otherwise result in too small safety margins. Reactive adaptive behaviours are, on the other hand, performed when the current traffic situation already provides too small safety margins. Adaptations can occur proactively in the comfort zone, proactively or reactively in the acceptable part of the discomfort zone, and reactively in the non-acceptable part of the discomfort zone.

Examples of adaptive behaviours of road users in response to static and dynamic infrastructure, additional tasks and other road users, have been demonstrated. In general, these correspond well with the concept of the comfort zone where the road users have a feeling of comfort as long as their subjective safety margins are sufficiently large, but that adaptations are carried out when these margins are exceeded or are predicted to be exceeded. The results illustrate that the subjective safety margins can extend beyond the objective safety zone. It is indeed possible that the subjective safety zone can be smaller than the objective safety zone, e.g. depending on experienced capability, but this was not shown in this work.

According to the often-used definition of the comfort zone (Engstrom \& Ljung Aust, 2011; Ljung Aust \& Engström, 2011; Panero, 2018), a feeling of discomfort leads to adaptive behaviours. Unless this feeling does not have to reach consciousness, I tend to disagree. There are adjustments carried out within the tracking layer of ECOM all the time, such as small corrections of steering and speed, which are not necessarily deliberated but performed automatically.

The subjective safety margins of the comfort zone are set in accordance with both the road user's capabilities and his or her personal strategies. The strategies involve trade-offs between goals, which are evident in ECOM where one goal can be suspended for a while, to the advantage of another. Support for this perspective was given by the resulting interactions connected to the ecologically valid additional task. The invented additional task vividly called for attention and needed to be handled within a certain time limit regardless of the road user's current driving task. The ecologically valid additional task did not call for attention acutely, and the road user could decide to neglect it or choose an appropriate location for handling the task. Considering that executing the natural additional task while moving did not cause any delay, the locations were probably chosen deliberately and not at random.

Another examined phenomenon was how the invented additional task, which can be seen as an externally paced adaptation object, led to reactive adaptive behaviour in terms of speed reduction, that was only present in connection to the task initiation. The effect of the adaptive behaviour was not prolonged further, i.e. the speed reduction caused by the additional task did not affect the total speed reduction in connection to the complexity of the static infrastructure ahead. Hence, people tend to get rid of the task and shift focus to the next task, and static 
infrastructure affects behaviour more than an additional task. The infrastructure will affect comfort, and possibly safety margins, in a more tangible way because the physical environment is changed, as opposed to the additional task which affects cognitive comfort.

Information level of detail for static and dynamic infrastructure was investigated in the thesis in Paper I and Paper IV. It appears that if the (top-down) predictions are correct, the road user is within the comfort zone, and more detailed information about visual guidance does not alter the behaviour. However, if the future path is more uncertain and adaptive behaviour is needed to maintain safety margins, then people use more detailed information available, consciously or non-consciously, to carry out proactive adaptations.

Complexity affects the capacity for action related to adaptive behaviour. When the situational demands (complexity levels) are highest, predictions need to be verified more thoroughly (comfort zone margins need to be maintained) and road users focus more on taking in relevant information by changing their gaze more frequently and neglecting non-relevant objects (Paper III). Furthermore, people have different personal strategies with respect to the maximum complexity of interaction with an additional task that they accept (Paper II). If the situational demands are too high, focus is not shifted to an additional task until demands are lower. Only a few interactions were conducted at the highest complexity level in Study II and for the other complexity levels, there was no difference in glance duration towards the adaptation object. A hypothesis is that additional tasks are handled when the road user thinks that his or her capacity to handle the task is sufficient considering the current complexity, whilst fitting with the personal strategy (see also de Waard, 1996).

The external demands make up the structure for how the individual can and will act to keep the safety margins sufficiently large. This work has contributed by acknowledging that external demands in traffic are imposed by the current road-user role, which contains a certain type of vehicle and infrastructure setting. In addition, these factors determine the available options for adaptive behaviour. This is in line with situated cognition which emphasises the importance of the context in which actions are carried out (Lave \& Wenger, 1991; Suchman, 1993; Suchman, 1987). From the perspective taken here, the actual behaviour performed is a matter of predictions made by the road user, personal strategy and capability, i.e. also of the internal processes. The capability depends on the means available and it should be acknowledged that when cycling or driving, the individual does not act alone, but all the time together with (and restricted to) the vehicle. Using the description by Hollnagel and Woods (2005), the two components of person and vehicle form one of the smallest aggregations of a joint cognitive system, a JCS. Another smallest aggregation of a JCS is that of two persons working together, which could be interpreted in traffic as two road users adapting to each other, since adaptive behaviour towards other road users is not an isolated issue, but an interaction that depends on the adaptive behaviour of the other part or parts. Coordination between road users is indeed crucial, but is an aspect that is often neglected in road-user models (Renner \& Johansson, 2006). Nonetheless, the emphasis of this dissertation is on the single road user, and how he or she adapts in relation to various factors affecting adaptation, here called adaptation objects. Hence, although it is an important area to investigate in traffic research, road-user coordination as such is outside of the scope of this work. Adaptations in traffic are not perceived as going on inside the individual only and detached from the rest of the world. Instead, the adaptation is performed within a certain context, with external and internal demands and prerequisites attached to it. In this thesis, the unit of analysis is the 
individual while the vehicle, infrastructure, other road users and additional tasks are viewed as contextual factors.

The same person can have different comfort zones depending on the current road-user role, not only depending on the overall strategy of the individual, but also on the trade-offs that are made in connection to the available means of transportation and the corresponding effort. This can clarify why more formal rules are broken when cycling than when driving. The rules are not broken without distinction, rather the functional rules, with the overarching goal of no accidents, are followed. There are numerous ways of explaining why drivers do not break the rules to the same extent. One reason might be that regulations are often formed from a driver perspective. Another could be that the fines are higher for driver violations, and a third might be physical restrictions with no option to go to the side if something happens. The vehicle and the infrastructure hence form the options. The bicycle offers another physical setting for the cyclist and at the stop position at an intersection, the cyclist is closer to the intersection and the eyes are positioned higher up from the ground, allowing for a better overview of the situation. If the situational demands are such that they allow for a better prediction of relevant future events, such as traffic and traffic signals, the road user will use this information to achieve his or her goals. If the context, such as current infrastructure and signage, presents an uncertainty in relation to the existence of and/or what could be expected from other traffic, the road user strives to minimize this uncertainty, either by changing the situational demands (e.g. pavement riding) or by increasing the information intake. For adaptation objects in general, the current and predicted situational demands together with the internal state, strategy and capability, determine what adaptation is carried out.

Although external factors are included in ECOM, by situation assessment in the monitoring and tracking layers (Hollnagel, 2016b), ECOM does not explicitly state the role of internal factors. The internal factors are described by goals, targets, plans, objectives and current understanding, but the prerequisites for determining the goals, such as emotions and feelings, are not visible in the model. Instead, these are accounted for in the conceptual model in Chapter 6, based on the multiple comfort zone model. The conceptual model acknowledges that there can be a part of the zone outside of the comfort zone that the road user can be willing to accept under certain conditions but that there is also a certain boundary which will never be exceeded voluntarily. Adaptive behaviours can be performed proactively, as a result of predictions, and reactively, when the subjective safety margins are not large enough for experienced comfort.

In the view of theory and the results of the studies reported within this thesis, the surface of what adaptation and adaptive behaviours in traffic are, has begun to be scratched. The results reported call for other studies to be carried out to develop the understanding further. In this sense, the number of participants, means of transportation, participant cohort and methods used could be increased or developed. There are also other possible aspects that could influence road-user behaviour apart from static and dynamic infrastructure, other road users and additional tasks, such as one's own vehicle, internal factors, policies and legislation. Future work could include how adaptive behaviour is influenced by internal factors such as being in a hurry, habit, waiting for an important telephone call or emotions such as anger. To impose those internal factors naturally is however difficult and more knowledge is needed. Every factor examined in this thesis could also be examined in other ways, for example the number of additional tasks used in the studies here was limited, and there could be numerous 
more, possibly affecting adaptive behaviours in other ways. The same reasoning goes for both static and dynamic infrastructure, which could have very different visualisations. "Other road users" is a factor that varied naturally in the studies, but that could be varied systematically in future studies, e.g. encountering pedestrians, buses, motorcycles etc. In addition, other roaduser roles than passenger car drivers and cyclists, such as pedestrians, could be studied to investigate adaptive behaviours and to see if the results in other roles would differ. Pedestrians have even more degrees of freedom than cyclists but is a very heterogeneous group, including all ages and all physical abilities and disabilities.

From this thesis as a starting point, revealing adaptive behaviour in different applications and settings from the individual perspective of a road user, supplementary studies can be made for scrutinising adaptation in traffic further. One interesting area of research would be the coordination of road users, when they perceive and adapt to each other. What determines the interactions? How can this be studied in real traffic circumstances? Improved traffic infrastructure and perhaps special regulations for cyclists could be developed and evaluated to facilitate road-user effectiveness and comfort while mitigating violations.

Neither ECOM nor the predictive processing framework seems to be perfectly aimed for examining adaptive behaviour, because of their lack of internal factors such as emotions etc., but ECOM was found useful for setting up hypotheses on adaptive behaviour covering various aspects, and for understanding adaptation in relation to behavioural models. The results of this work could be used for developing road user models that incorporate the comfort zone of the road user, as affected by the internal state, along with top-down and bottom-up processes.

To conclude, road-user behaviour should not be dismissed as typical of the individual and his or her character but rather be understood in relation to the prerequisites of the current roaduser role, i.e. the vehicle and infrastructure available. When designing and planning for infrastructure, the needs of all road-user roles should be regarded. Improved traffic infrastructure and perhaps differentiated regulations for different road-user roles should be developed and evaluated to support road-user effectiveness and comfort while mitigating violations. To facilitate for road users to stay within their comfort zone, it should be easy to make correct predictions while striving for personal goals of the trip. When the road user is within the comfort zone, the subjective safety margins are sufficient for comfort and there is an extra capacity for unexpected events. Hence, infrastructure design should be adapted to the road user, to facilitate adaptive behaviours. 


\section{REFERENCES}

Adell, E., Nilsson, A., \& Kircher, K. (2014). Cyclists' use of mobile IT in Sweden - usage and selfreported behavioural compensation. Paper presented at the International Cycling Safety Conference 2014, Gothenburg, Sweden.

Ajzen, I. (1985). From intentions to actions: A theory of planned behavior. In J. Kuhl \& J. Beckmann (Eds.), Action control (pp. 11-39): Springer, Berlin, Heidelberg.

Anttila, V., \& Luoma, J. (2005). Surrogate in-vehicle information systems and driver behaviour in an urban environment: A field study on the effects of visual and cognitive load. Transportation Research Part F: Traffic Psychology and Behaviour, 8(2), 121-133.

Avineri, E., Shinar, D., \& Susilo, Y. O. (2012). Pedestrians' behaviour in cross walks: the effects of fear of falling and age. Accident Analysis \& Prevention, 44(1), 30-34.

Benmimoun, M., Pütz, A., Zlocki, A., \& Eckstein, L. (2013). euroFOT: Field operational test and impact assessment of advanced driver assistance systems: Final results. Paper presented the Proceedings of the FISITA 2012 World Automotive Congress.

Blanchard, R. A., \& Myers, A. M. (2010). Examination of driving comfort and self-regulatory practices in older adults using in-vehicle devices to assess natural driving patterns. Accident Analysis \& Prevention, 42(4), 1213-1219.

Broach, J., Dill, J., \& Gliebe, J. (2012). Where do cyclists ride? A route choice model developed with revealed preference GPS data. Transportation Research Part A: Policy and Practice, 46(10), 1730-1740.

Bärgman, J., Smith, K., \& Werneke, J. (2015). Quantifying drivers' comfort-zone and dread-zone boundaries in left turn across path/opposite direction (LTAP/OD) scenarios. Transportation Research Part F: Traffic Psychology and Behaviour, 35, 170-184.

Cantin, V., Lavallière, M., Simoneau, M., \& Teasdale, N. (2009). Mental workload when driving in a simulator: Effects of age and driving complexity. Accident Analysis \& Prevention, 41(4), 763771.

Carsten, O. (2013). Early theories of behavioural adaptation. In C. M. Rudin-Brown \& S. L. Jamson (Eds.), Behavioural adaptation and road safety: Theory, evidence and action (pp. 23-34). Boca Raton, Florida: CRC Press.

Carsten, O. (2014). Introduction to the special section: Can workload take the strain? Cognition, Technology \& Work, 16, 285-287. doi:https://doi.org/10.1007/s10111-014-0280-4

Charlton, J. L., Oxley, J., Fildes, B., Oxley, P., Newstead, S., Koppel, S., \& O’Hare, M. (2006). Characteristics of older drivers who adopt self-regulatory driving behaviours. Transportation Research Part F: Traffic Psychology and Behaviour, 9(5), 363-373.

Charlton, S. G., \& Starkey, N. J. (2013). Driving on familiar roads: Automaticity and inattention blindness. Transportation Research Part F: Traffic Psychology and Behaviour, 19, 121-133.

Chiou, Y.-C., \& Chang, C.-H. (2010). Driver responses to green and red vehicular signal countdown displays: Safety and efficiency aspects. Accident Analysis \& Prevention, 42(4), pp 1057-1065.

Clark, A. (2016). Surfing uncertainty. Prediction, action, and the embodied mind. United States of America: Oxford University Press.

Corbetta, M., \& Shulman, G. L. (2002). Control of goal-directed and stimulus-driven attention in the brain. Nature Reviews. Neuroscience, 3, 201-215. doi:10.1038/nrn755

Damasio, A. R. (1996). The somatic marker hypothesis and the possible functions of the prefrontal cortex. Philosophical Transactions of the Royal Society of London. Series B: Biological Sciences, 351(1346), 1413-1420.

de Craen, S., Twisk, D. A., Hagenzieker, M. P., Elffers, H., \& Brookhuis, K. A. (2008). The development of a method to measure speed adaptation to traffic complexity: Identifying novice, unsafe, and overconfident drivers. Accident Analysis \& Prevention, 40(4), 1524-1530.

de Raedt, R., \& Ponjaert-Kristoffersen, I. (2000). Cognitive/neuropsychological functioning and compensation related to car driving performance in older adults. In T. Rothengatter \& R. D. 
Huguenin (Eds.), Traffic and transport psychology: theory and application: proceedings of the ICTTP 2000 (pp. 267-274). Berne, Switzerland: Elsevier.

de Waard, D. (1996). The measurement of drivers' mental workload. Haren, The Netherlands: The Traffic Research Centre VSC, University of Groningen.

de Waard, D., Edlinger, K., \& Brookhuis, K. (2011). Effects of listening to music, and of using a handheld and handsfree telephone on cycling behaviour. Transportation Research Part F: Traffic Psychology and Behaviour, 14(6), 626-637.

de Waard, D., \& Lewis-Evans, B. (2014). Self-report scales alone cannot capture mental workload. Cognition, Technology \& Work, 16(3), 303-305.

Donges, E. (1978). A two-level model of driver steering behavior. Human Factors, 20(6), 691-707.

Dozza, M., Schindler, R., Bianchi-Piccinini, G., \& Karlsson, J. (2016). How do drivers overtake cyclists? Accident Analysis \& Prevention, 88, 29-36.

Engstrom, J., \& Ljung Aust, M. (2011). Adaptive behavior in the simulator: Implications for active safety system evaluation. In D. L. Fisher, M. Rizzo, J. Caird, \& J. D. Lee (Eds.), Handbook of driving simulation for engineering, medicine, and psychology. Boca Raton, FL United States: CRC Press.

Erke, A., Sagberg, F., \& Hagman, R. (2007). Effects of route guidance variable message signs (VMS) on driver behaviour. Transportation Research Part F, 10(6).

Fastenmeier, W., \& Gstalter, H. (2007). Driving task analysis as a tool in traffic safety research and practice. Safety Science, 45(9), 952-979.

Findlay, J. M., \& Gilchrist, I. D. (2003). Visual selection, covert attention and eye movements. In Active vision: The psychology of looking and seeing (pp. 35-54). New York: Oxford University Press.

Fitch, G., Grove, K., Hanowski, R., \& Perez, M. (2014). Compensatory behavior of drivers when conversing on a cell phone: Investigation with naturalistic driving data. Transportation Research Record: Journal of the Transportation Research Board (2434), 1-8.

Fuller, R. (2000). The task-capability interface model of the driving process. Recherche - Transports Sécurité, 66, 47-57. doi:https://doi.org/10.1016/S0761-8980(00)90006-2

Fuller, R. (2005). Towards a general theory of driver behaviour. Accident Analysis \& Prevention, 37, 461-472. doi:10.1016/j.aap.2004.11.003

Fuller, R., McHugh, F., \& Pender, S. (2008). Task difficulty and risk in the determination of driver behaviour. European Review of Applied Psychology, 58(1), 13-21.

Gibson, J. J., \& Crooks, L. E. (1938). A theoretical field-analysis of automobile-driving. The American journal of psychology, 51(3), 453-471.

Hart, S. G. (2006). NASA-task load index (NASA-TLX); 20 years later. In Proceedings of the human factors and ergonomics society annual meeting (Vol. 50, pp. 904-908): Sage Publications Sage CA: Los Angeles, CA.

Hart, S. G., \& Staveland, L. E. (1988). Development of NASA-TLX (Task Load Index): Results of Empirical and Theoretical Research. In P. Hancock \& N. Meshkati (Eds.), Human mental workload (pp. 139-183). Amsterdam: North Holland.

Helland, A., Lydersen, S., Lervåg, L.-E., Jenssen, G. D., Mørland, J., \& Slørdal, L. (2016). Driving simulator sickness: impact on driving performance, influence of blood alcohol concentration, and effect of repeated simulator exposures. Accident Analysis \& Prevention, 94, 180-187.

Hennessy, D. A., \& Wiesenthal, D. L. (1997). The relationship between traffic congestion, driver stress and direct versus indirect coping behaviours. Ergonomics, 40(3), 348-361.

Hennessy, D. A., \& Wiesenthal, D. L. (1999). Traffic congestion, driver stress, and driver aggression. Aggressive Behavior: Official Journal of the International Society for Research on Aggression, 25(6), 409-423.

Hertzum, M., Hansen, K. D., \& Andersen, H. H. (2009). Scrutinising usability evaluation: does thinking aloud affect behaviour and mental workload? Behaviour \& Information Technology, 28(2), 165-181. 
Ho, A. M., Phelan, R., Mizubuti, G. B., Murdoch, J. A., Wickett, S., Ho, A. K., . . Gilron, I. (2018). Bias in before-after studies: narrative overview for anesthesiologists. Anesthesia \& Analgesia, 126(5), 1755-1762.

Hollnagel, E. (2003). Context, cognition and control. In Y. Waern (Ed.), Co-operative process management: Cognition and information technology (pp. 27-52). Boca Raton, FL: CRC Press.

Hollnagel, E. (2012). The ETTO principle as ETTOing-or Occam's Razor redux. Paper presented at the Human Factors: a view from an integrative perspective. Presented at the Human Factors and Ergonomics Society Europe Chapter Annual Meeting, Toulouse, France.

Hollnagel, E. (2016a). Contextual Control Model (COCOM). Retrieved from http://erikhollnagel.com/ideas/cocom.html

Hollnagel, E. (2016b). Extended Control Model (ECOM). Retrieved from http://erikhollnagel.com/ideas/ecom.html

Hollnagel, E., Nåbo, A., \& Lau, I. V. (2003). A systemic model for driver-in-control. Paper presented at the the Second International Driving Symposium on Human Factors in Driver Assessment, Training and Vehicle Design, Park City, Utah.

Hollnagel, E., \& Woods, D. D. (2005). Joint cognitive systems: Foundations of cognitive systems engineering: CRC Press.

Horberry, T., Anderson, J., Regan, M. A., Triggs, T. J., \& Brown, J. (2006). Driver distraction: The effects of concurrent in-vehicle tasks, road environment complexity and age on driving performance. Accident Analysis \& Prevention, 38(1), 185-191.

Hulse, M. C., Dingus, T. A., Fischer, T., \& Wierwille, W. W. (1989). The influence of roadway parameters on driver perception of attentional demand. Advances in industrial ergonomics and safety $I, 451,456$.

Hyman Jr, I. E., Sarb, B. A., \& Wise-Swanson, B. M. (2014). Failure to see money on a tree: inattentional blindness for objects that guided behavior. Frontiers in psychology, 5, 356.

Ihlström, J., Henriksson, M., \& Kircher, K. (submitted). Immoral and irrational cyclists? Exploring the practice of cycling on the pavement.

Islam, M. R., Hurwitz, D. S., \& Macuga, K. L. (2016). Improved driver responses at intersections with red signal countdown timers. Transportation Research Part C: Emerging Technologies, 63, pp 207-221.

Itti, L., \& Koch, C. (2001). Computational modelling of visual attention. Nature Reviews. Neuroscience, 2, 194-203.

Jagacinski, R. J., \& Flach, J. M. (2003). Control theory for humans: Quantitative approaches to modeling performance. Mahwah, New Jersey: Lawrence Erlbaum Associates, Inc., Publishers.

James, W. (1890). Principles of Psychology. Holt, New York.

Jamson, A. H., \& Merat, N. (2005). Surrogate in-vehicle information systems and driver behaviour: Effects of visual and cognitive load in simulated rural driving. Transportation Research Part F: Traffic Psychology and Behaviour, 8(2), 79-96.

Johnson, D. M. (2005). Introduction to and review of simulator sickness research. (Research Report 1832). Fort Rucker, AL: U.S. Army Research Institute for the Behavioral and Social Sciences.

Kallberg, V.-P. (1993). Reflector Posts - Signs of Danger? Transportation research record, 1403, 57-66.

Kircher, K., \& Ahlstrom, C. (2017a). Evaluation of methods for the assessment of attention while driving. Accident Analysis \& Prevention. doi:https://doi.org/10.1016/i.aap.2017.03.013

Kircher, K., \& Ahlstrom, C. (2017b). Minimum required attention: a human-centered approach to driver inattention. Human Factors, 59(3), 471-484.

Kircher, K., Eriksson, O., Forsman, Å., Vadeby, A., \& Ahlstrom, C. (2017). Design and analysis of semicontrolled studies. Transportation Research Part F: Traffic Psychology and Behaviour, 46, 404-412.

Koch, C. (2004). The quest for consciousness. A neurobiological approach. United States of America: Roberts \& Company Publishers.

Kolasinski, E. M. (1995). Simulator Sickness in Virtual Environments. (ARI Technical Report 1027). Alexandria, VA: U.S. Army Research Institute for the Behavioral and Social Sciences. 
Land, M. F. (2006). Eye movements and the control of actions in everyday life. Progress in Retinal and Eye Research, 25, 296-324. doi:10.1016/j.preteyeres.2006.01.002

Lave, J., \& Wenger, E. (1991). Situated learning: Legitimate peripheral participation. Cambridge, United Kingdom: Cambridge university press.

Lee, D. N. (1980). The optic flow field: The foundation of vision. Philosophical Transactions of the Royal Society of London. B, Biological Sciences, 290(1038), 169-179.

Liu, Z., \& Kircher, K. (2018). Comparison of a time-and a speed-based traffic light assistance system. Cognition, Technology \& Work, 20(1), 93-103.

Ljung Aust, M., \& Engström, J. (2011). A conceptual framework for requirement specification and evaluation of active safety functions. Theoretical Issues in Ergonomics Science, 12(1), 44-65.

Lupyan, G., \& Clark, A. (2015). Words and the world: Predictive coding and the language-perceptioncognition interface. Current Directions in Psychological Science, 24(4), 279-284.

Martens, M. H., \& Fox, M. R. (2007). Do familiarity and expectations change perception? Drivers' glances and response to changes. Transportation Research Part F: Traffic Psychology and Behaviour, 10(6), 476-492.

McCambridge, J., Witton, J., \& Elbourne, D. R. (2014). Systematic review of the Hawthorne effect: new concepts are needed to study research participation effects. Journal of clinical epidemiology, 67(3), 267-277.

McCauley, M. E. (1984). Research issues in simulator sickness: Proceedings of a workshop: National Academies.

Michon, J. A. (1979). Dealing with danger. Retrieved from http://www.jamichon.nl/jam writings/1979 dealing with danger.pdf

Michon, J. A. (1985). A critical view of driver behavior models: What do we know, what should we do? In L. Evans \& R. C. Schwing (Eds.), Human behavior and traffic safety (pp. 485-520). New York: Plenum Press.

Miller, G., Galanter, E., \& Pribram, K. (1960). Plans and the structure of behavior. New York, NY, US: Henry Holt and Co. In.

Most, S. B., Scholl, B. J., Clifford, E. R., \& Simons, D. J. (2005). What you see is what you set: Sustained inattentional blindness and the capture of awareness. Psychological Review, 112(1), 217-242. doi:10.1037/0033-295X.112.1.217

Neisser, U. (1976). Cognition and reality: Principles and implications of cognitive psychology. New York, the United States of America: W.H. Freeman and Company.

Nunes, L. M., \& Recarte, M. A. (2004). Speed, traffic complexity and visual performance. A study on open road. Paper presented at the Traffic and transport psychology: Theory and application. Proceedings of the ICTTP 2004.

Nygren, T. E. (1991). Psychometric properties of subjective workload measurement techniques: Implications for their use in the assessment of perceived mental workload. Human Factors, 33(1), 17-33.

Nygårdhs, S., Ahlström, C., Ihlström, J., \& Kircher, K. (2018). Bicyclists' adaptation strategies when interacting with text messages in urban environments. Cognition, Technology \& Work, 20(3), 377-388. doi:10.1007/s10111-018-0478-y

Näätänen, R., \& Summala, H. (1976). Road-user behavior and traffic accidents. Amsterdam: NorthHolland Publishing Company.

OECD. (1990). Behavioural adaptations to changes in the road transport system. Paris: Organization for Economic Co-operation and Development.

Oviedo-Trespalacios, O., Haque, M. M., King, M., \& Washington, S. (2017). Effects of road infrastructure and traffic complexity in speed adaptation behaviour of distracted drivers. Accident Analysis \& Prevention, 101, 67-77.

Panero, G. (2018). Drivers' comfort zone boundaries when overtaking pedestrians Analysis of naturalistic driving and field test data. Politecnico di Torino, Italy \& Chalmers university of technology, Sweden, (Master's thesis 2018:66) 
Patten, C. J., Kircher, A., Östlund, J., Nilsson, L., \& Svenson, O. (2006). Driver experience and cognitive workload in different traffic environments. Accident Analysis \& Prevention, 38(5), 887-894.

Paxion, J., Galy, E., \& Berthelon, C. (2014). Mental workload and driving. Frontiers in psychology, 5, 1344.

Prokop, T., Schubert, M., \& Berger, W. (1997). Visual influence on human locomotion modulation to changes in optic flow. Experimental brain research, 114(1), 63-70.

Raichle, M. E. (2010). Two views of brain function. Trends in cognitive sciences, 14(4), 180-190.

Rajamäki, R., Luoma, J., \& Rämä, P. (2013). Effects of delineator post density on vehicle speed, lateral position and driver acceptance. Espoo: VTT Technical Research Centre of Finland. VTT Technology, No. 132.

Rasmussen, J. (1983). Skills, rules, and knowledge; signals, signs, and symbols, and other distinctions in human performance models. IEEE transactions on systems, man, and cybernetics(3), 257266.

Reid, G. B., \& Nygren, T. E. (1988). The subjective workload assessment technique: A scaling procedure for measuring mental workload. In Advances in psychology (Vol. 52, pp. 185-218): Elsevier.

Renner, L., \& Johansson, B. (2006). Driver coordination in complex traffic environments. Paper presented at the Proceedings of the 13th Eurpoean conference on Cognitive ergonomics: trust and control in complex socio-technical systems.

Rensink, R. A. (2009). Attention: Change blindness and inattentional blindness. In W. Banks (Ed.), Encyclopedia of Consciousness (Vol. 1). New York: Elsevier.

Roscoe, A. H. (1984). Assessing pilot workload in flight. Bedford, United Kingdom: Royal Aircraft Establishment.

Rudin-Brown, C., \& Jamson, S. (Eds.). (2013). Behavioural adaptation and road safety: Theory, evidence and action. Boca Raton, FL: CRC Press.

Schweitzer, J., \& Green, P. (2007). Task acceptability and workload of driving city streets, rural roads, and expressways: Ratings from video clips.

Simon, H. A. (1956). Rational choice and the structure of the environment. Psychological Review, 63(2), 129.

Snyder, A. Z., \& Raichle, M. E. (2012). A brief history of the resting state: the Washington University perspective. Neuroimage, 62(2), 902-910.

Son, J., Lee, Y., \& Kim, M.-H. (2011). Impact of traffic environment and cognitive workload on older drivers' behavior in simulated driving. International Journal of Precision Engineering and Manufacturing, 12(1), 135-141.

Stanney, K. M., \& Kennedy, R. S. (2010). Simulation sickness: ed Boca Raton, Florida: CRC Press.

Suchman, L. (1993). Response to Vera and Simon's situated action: A symbolic interpretation. Cognitive Science, 17(1), 71-86.

Suchman, L. A. (1987). Plans and situated actions: The problem of human-machine communication. Cambridge, United Kingdom: Cambridge university press.

Summala, H. (1988). Risk control is not risk adjustment: The zero-risk theory of driver behaviour and its implications. Ergonomics, 31(4), 491-506.

Summala, H. (2005). Traffic psychology theories: towards understanding driving behaviour and safety factors. Paper presented at the International Conference of Traffic and Transport Psychology.

Summala, H. (2007). Towards understanding motivational and emotional factors in driver behaviour: Comfort through satisficing. In Modelling driver behaviour in automotive environments (pp. 189-207): Springer.

Swedish Transport Administration. (n.d., 2020-01-15). Det här är Nollvisionen. Retrieved from https://www.trafikverket.se/resa-och-trafik/Trafiksakerhet/det-har-ar-nollvisionen/

te Velde, A. F., van der Kamp, J., Barela, J. A., \& Savelsbergh, G. J. (2005). Visual timing and adaptive behavior in a road-crossing simulation study. Accident Analysis \& Prevention, 37(3), 399-406. 
Teh, E., Jamson, S., Carsten, O., \& Jamson, H. (2014). Temporal fluctuations in driving demand: The effect of traffic complexity on subjective measures of workload and driving performance. Transportation Research Part F: Traffic Psychology and Behaviour, 22, 207-217.

Trafikanalys. (2017). The Swedish national travel survey 2015-2016. (Statistik 2017:13). Sveriges officiella statistik.

van der Laan, J. D., Heino, A., \& de Waard, D. (1997). A simple procedure for the assessment of acceptance of advanced transport telematics. Transportation Research Part C: Emerging Technologies, 5, 1-10.

Vavryn, K., \& Winkelbauer, M. (2004). Braking performance of experienced and novice motorcycle riders-results of a field study. Paper presented at the International Conference on Transport and Traffic Psychology.

Wenbo, S., Zhaocheng, H., Xi, X., \& Feifei, X. (2013). Exploring impacts of countdown timers on queue discharge characteristics of through movement at signalized intersections. Procedia-Social and Behavioral Sciences, 96, pp 255-264.

Wilde, G. J. (1982). The theory of risk homeostasis: implications for safety and health. Risk analysis, 2(4), 209-225.

Wilde, G. J. S. (2001). Target Risk 2. A New Psychology of Safety and Health. What works? What doesn't? And why... Toronto, Canada: PDE Publications.

Wolfe, B., Dobres, J., Rosenholtz, R., \& Reimer, B. (2017). More than the Useful Field: Considering peripheral vision in driving. Applied Ergonomics, 65, 316-325. doi:http://dx.doi.org/10.1016/i.apergo.2017.07.009

Yarbus, A. L. (1967). Eye movements during perception of complex objects. In Eye movements and vision (pp. 171-211). Boston, MA: Springer.

Yuan, L., Zhang, Q., \& Lei, Z. (2009). Impact of Traffic Signal Countdown Displays on Driver Behaviors. In International Conference on Transportation Engineering 2009 (pp. 4176-4179): American Society of Civil Engineers.

Zijlstra, F., \& van Doorn, L. (1985). The construction of a scale to measure perceived effort. Delft: Delft University of Technology.

Åkerstedt, T., Peters, B., Anund, A., \& Kecklund, G. (2005). Impaired alertness and performance driving home from the night shift: a driving simulator study. Journal of sleep research, 14(1), 17-20. 


\section{Papers}

The papers associated with this thesis have been removed for copyright reasons. For more details about these see:

http://urn.kb.se/resolve?urn=urn:nbn:se:liu:diva-164952 

Department of Computer and Information Science

Linköpings universitet

\section{Dissertations}

\section{Linköping Studies in Science and Technology Linköping Studies in Arts and Science \\ Linköping Studies in Statistics \\ Linköping Studies in Information Science}

Linköping Studies in Science and Technology

No 14 Anders Haraldsson: A Program Manipulation System Based on Partial Evaluation, 1977, ISBN 917372-144-1.

No 17 Bengt Magnhagen: Probability Based Verification of Time Margins in Digital Designs, 1977, ISBN 91-7372157-3.

No 18 Mats Cedwall: Semantisk analys av processbeskrivningar i naturligt språk, 1977, ISBN 91- 7372168-9.

No 22 Jaak Urmi: A Machine Independent LISP Compiler and its Implications for Ideal Hardware, 1978, ISBN 91-7372-188-3.

No 33 Tore Risch: Compilation of Multiple File Queries in a Meta-Database System, 1978, ISBN 91- 7372-232-4.

No 51 Erland Jungert: Synthesizing Database Structures from a User Oriented Data Model, 1980, ISBN 917372-387-8.

No 54 Sture Hägglund: Contributions to the Development of Methods and Tools for Interactive Design of Applications Software, 1980, ISBN 91-7372-404-1.

No 55 Pär Emanuelson: Performance Enhancement in a Well-Structured Pattern Matcher through Partial Evaluation, 1980, ISBN 91-7372-403-3.

No 58 Bengt Johnsson, Bertil Andersson: The HumanComputer Interface in Commercial Systems, 1981, ISBN 91-7372-414-9.

No 69 H. Jan Komorowski: A Specification of an Abstract Prolog Machine and its Application to Partial Evaluation, 1981, ISBN 91-7372-479-3.

No 71 René Reboh: Knowledge Engineering Techniques and Tools for Expert Systems, 1981, ISBN 91-7372489-0.

No 77 Östen Oskarsson: Mechanisms of Modifiability in large Software Systems, 1982, ISBN 91- 7372-527-7.

No 94 Hans Lunell: Code Generator Writing Systems, 1983, ISBN 91-7372-652-4.

No 97 Andrzej Lingas: Advances in Minimum Weight Triangulation, 1983, ISBN 91-7372-660-5.

No 109 Peter Fritzson: Towards a Distributed Programming Environment based on Incremental Compilation, 1984, ISBN 91-7372-801-2.

No 111 Erik Tengvald: The Design of Expert Planning Systems. An Experimental Operations Planning System for Turning, 1984, ISBN 91-7372- 805-5.

No 155 Christos Levcopoulos: Heuristics for Minimum Decompositions of Polygons, 1987, ISBN 91-7870133-3.

No 165 James W. Goodwin: A Theory and System for NonMonotonic Reasoning, 1987, ISBN 91-7870-183-X.

No 170 Zebo Peng: A Formal Methodology for Automated Synthesis of VLSI Systems, 1987, ISBN 91-7870-225-9.

No 174 Johan Fagerström: A Paradigm and System for Design of Distributed Systems, 1988, ISBN 91-7870301-8.
No 192 Dimiter Driankov: Towards a Many Valued Logic of Quantified Belief, 1988, ISBN 91-7870-374-3.

No 213 Lin Padgham: Non-Monotonic Inheritance for an Object Oriented Knowledge Base, 1989, ISBN 917870-485-5.

No 214 Tony Larsson: A Formal Hardware Description and Verification Method, 1989, ISBN 91-7870-517-7.

No 221 Michael Reinfrank: Fundamentals and Logical Foundations of Truth Maintenance, 1989, ISBN 917870-546-0.

No 239 Jonas Löwgren: Knowledge-Based Design Support and Discourse Management in User Interface Management Systems, 1991, ISBN 91-7870-720-X.

No 244 Henrik Eriksson: Meta-Tool Support for Knowledge Acquisition, 1991, ISBN 91-7870-746-3.

No 252 Peter Eklund: An Epistemic Approach to Interactive Design in Multiple Inheritance Hierarchies, 1991, ISBN 91-7870-784-6.

No 258 Patrick Doherty: NML3 - A Non-Monotonic Formalism with Explicit Defaults, 1991, ISBN 917870-816-8.

No 260 Nahid Shahmehri: Generalized Algorithmic Debugging, 1991, ISBN 91-7870-828-1.

No 264 Nils Dahlbäck: Representation of DiscourseCognitive and Computational Aspects, 1992, ISBN 91-7870-850-8.

No 265 Ulf Nilsson: Abstract Interpretations and Abstract Machines: Contributions to a Methodology for the Implementation of Logic Programs, 1992, ISBN 917870-858-3.

No 270 Ralph Rönnquist: Theory and Practice of Tensebound Object References, 1992, ISBN 91-7870-873-7.

No 273 Björn Fjellborg: Pipeline Extraction for VLSI Data Path Synthesis, 1992, ISBN 91-7870-880-X.

No 276 Staffan Bonnier: A Formal Basis for Horn Clause Logic with External Polymorphic Functions, 1992, ISBN 91-7870-896-6.

No 277 Kristian Sandahl: Developing Knowledge Management Systems with an Active Expert Methodology, 1992, ISBN 91-7870-897-4.

No 281 Christer Bäckström: Computational Complexity of Reasoning about Plans, 1992, ISBN 91-7870-979-2.

No 292 Mats Wirén: Studies in Incremental Natural Language Analysis, 1992, ISBN 91-7871-027-8.

No 297 Mariam Kamkar: Interprocedural Dynamic Slicing with Applications to Debugging and Testing, 1993, ISBN 91-7871-065-0.

No 302 Tingting Zhang: A Study in Diagnosis Using Classification and Defaults, 1993, ISBN 91-7871-0782.

No 312 Arne Jönsson: Dialogue Management for Natural Language Interfaces - An Empirical Approach, 1993, ISBN 91-7871-110-X.

No 338 Simin Nadjm-Tehrani: Reactive Systems in Physical Environments: Compositional Modelling and Framework for Verification, 1994, ISBN 91-7871-237-8. 
Bengt Savén: Business Models for Decision Support and Learning. A Study of Discrete-Event Manufacturing Simulation at Asea/ABB 1968-1993, 1995, ISBN 91-7871-494-X.

No 375 Ulf Söderman: Conceptual Modelling of Mode Switching Physical Systems, 1995, ISBN 91-7871-5164.

No 383 Andreas Kågedal: Exploiting Groundness in Logic Programs, 1995, ISBN 91-7871-538-5.

No 396 George Fodor: Ontological Control, Description, Identification and Recovery from Problematic Control Situations, 1995, ISBN 91-7871-603-9.

No 413 Mikael Pettersson: Compiling Natural Semantics, 1995, ISBN 91-7871-641-1.

No 414 Xinli Gu: RT Level Testability Improvement by Testability Analysis and Transformations, 1996, ISBN 91-7871-654-3.

No 416 Hua Shu: Distributed Default Reasoning, 1996, ISBN 91-7871-665-9.

No 429 Jaime Villegas: Simulation Supported Industrial Training from an Organisational Learning Perspective - Development and Evaluation of the SSIT Method, 1996, ISBN 91-7871-700-0.

No 431 Peter Jonsson: Studies in Action Planning: Algorithms and Complexity, 1996, ISBN 91-7871-7043.

No 437 Johan Boye: Directional Types in Logic Programming, 1996, ISBN 91-7871-725-6.

No 439 Cecilia Sjöberg: Activities, Voices and Arenas: Participatory Design in Practice, 1996, ISBN 91-7871728-0.

No 448 Patrick Lambrix: Part-Whole Reasoning in Description Logics, 1996, ISBN 91-7871-820-1.

No 452 Kjell Orsborn: On Extensible and Object-Relational Database Technology for Finite Element Analysis Applications, 1996, ISBN 91-7871-827-9.

No 459 Olof Johansson: Development Environments for Complex Product Models, 1996, ISBN 91-7871-855-4.

No 461 Lena Strömbäck: User-Defined Constructions in Unification-Based Formalisms, 1997, ISBN 91-7871857-0.

No 462 Lars Degerstedt: Tabulation-based Logic Programming: A Multi-Level View of Query Answering, 1996, ISBN 91-7871-858-9.

No 475 Fredrik Nilsson: Strategi och ekonomisk styrning En studie av hur ekonomiska styrsystem utformas och används efter företagsförvärv, 1997, ISBN 91 7871-914-3.

No 480 Mikael Lindvall: An Empirical Study of Requirements-Driven Impact Analysis in Object-Oriented Software Evolution, 1997, ISBN 91-7871-927-5.

No 485 Göran Forslund: Opinion-Based Systems: The Cooperative Perspective on Knowledge-Based Decision Support, 1997, ISBN 91-7871-938-0.

No 494 Martin Sköld: Active Database Management Systems for Monitoring and Control, 1997, ISBN 91 7219-002-7.

No 495 Hans Olsén: Automatic Verification of Petri Nets in a CLP framework, 1997, ISBN 91-7219-011-6.

No 498 Thomas Drakengren: Algorithms and Complexity for Temporal and Spatial Formalisms, 1997, ISBN 91 7219-019-1.

No 502 Jakob Axelsson: Analysis and Synthesis of Heterogeneous Real-Time Systems, 1997, ISBN 91-7219-035-3.
No 503 Johan Ringström: Compiler Generation for DataParallel Programming Languages from Two-Level Semantics Specifications, 1997, ISBN 91-7219-045-0.

No 512 Anna Moberg: Närhet och distans - Studier av kommunikationsmönster i satellitkontor och flexibla kontor, 1997, ISBN 91-7219-119-8.

No 520 Mikael Ronström: Design and Modelling of a Parallel Data Server for Telecom Applications, 1998, ISBN 91-7219-169-4.

No 522 Niclas Ohlsson: Towards Effective Fault Prevention - An Empirical Study in Software Engineering, 1998, ISBN 91-7219-176-7.

No 526 Joachim Karlsson: A Systematic Approach for Prioritizing Software Requirements, 1998, ISBN 917219-184-8.

No 530 Henrik Nilsson: Declarative Debugging for Lazy Functional Languages, 1998, ISBN 91-7219-197-X.

No 555 Jonas Hallberg: Timing Issues in High-Level Synthesis, 1998, ISBN 91-7219-369-7.

No 561 Ling Lin: Management of 1-D Sequence Data - From Discrete to Continuous, 1999, ISBN 91-7219-402-2.

No 563 Eva L Ragnemalm: Student Modelling based on Collaborative Dialogue with a Learning Companion, 1999, ISBN 91-7219-412-X.

No 567 Jörgen Lindström: Does Distance matter? On geographical dispersion in organisations, 1999, ISBN $91-$ 7219-439-1.

No 582 Vanja Josifovski: Design, Implementation and Evaluation of a Distributed Mediator System for Data Integration, 1999, ISBN 91-7219-482-0.

No 589 Rita Kovordányi: Modeling and Simulating Inhibitory Mechanisms in Mental Image Reinterpretation - Towards Cooperative HumanComputer Creativity, 1999, ISBN 91-7219-506-1.

No 592 Mikael Ericsson: Supporting the Use of Design Knowledge - An Assessment of Commenting Agents, 1999, ISBN 91-7219-532-0.

No 593 Lars Karlsson: Actions, Interactions and Narratives, 1999, ISBN 91-7219-534-7.

No 594 C. G. Mikael Johansson: Social and Organizational Aspects of Requirements Engineering Methods - A practice-oriented approach, 1999, ISBN 91-7219-541$\mathrm{X}$

No 595 Jörgen Hansson: Value-Driven Multi-Class Overload Management in Real-Time Database Systems, 1999, ISBN 91-7219-542-8.

No 596 Niklas Hallberg: Incorporating User Values in the Design of Information Systems and Services in the Public Sector: A Methods Approach, 1999, ISBN 917219-543-6.

No 597 Vivian Vimarlund: An Economic Perspective on the Analysis of Impacts of Information Technology: From Case Studies in Health-Care towards General Models and Theories, 1999, ISBN 91-7219-544-4.

No 598 Johan Jenvald: Methods and Tools in ComputerSupported Taskforce Training, 1999, ISBN 91-7219547-9.

No 607 Magnus Merkel: Understanding and enhancing translation by parallel text processing, 1999, ISBN 91 7219-614-9.

No 611 Silvia Coradeschi: Anchoring symbols to sensory data, 1999, ISBN 91-7219-623-8.

No 613 Man Lin: Analysis and Synthesis of Reactive Systems: A Generic Layered Architecture Perspective, 1999, ISBN 91-7219-630-0. 
No 618 Jimmy Tjäder: Systemimplementering i praktiken En studie av logiker i fyra projekt, 1999, ISBN 91 7219-657-2.

No 627 Vadim Engelson: Tools for Design, Interactive Simulation, and Visualization of Object-Oriented Models in Scientific Computing, 2000, ISBN 91-7219709-9.

No 637 Esa Falkenroth: Database Technology for Control and Simulation, 2000, ISBN 91-7219-766-8.

No 639 Per-Arne Persson: Bringing Power and Knowledge Together: Information Systems Design for Autonomy and Control in Command Work, 2000, ISBN 91-7219796-X.

No 660 Erik Larsson: An Integrated System-Level Design for Testability Methodology, 2000, ISBN 91-7219-890-7.

No 688 Marcus Bjäreland: Model-based Execution Monitoring, 2001, ISBN 91-7373-016-5.

No 689 Joakim Gustafsson: Extending Temporal Action Logic, 2001, ISBN 91-7373-017-3.

No 720 Carl-Johan Petri: Organizational Information Provision - Managing Mandatory and Discretionary Use of Information Technology, 2001, ISBN 91-7373-1269.

No 724 Paul Scerri: Designing Agents for Systems with Adjustable Autonomy, 2001, ISBN 91-7373-207-9.

No 725 Tim Heyer: Semantic Inspection of Software Artifacts: From Theory to Practice, 2001, ISBN 917373-208-7.

No 726 Pär Carlshamre: A Usability Perspective on Requirements Engineering - From Methodology to Product Development, 2001, ISBN 91-7373-212-5.

No 732 Juha Takkinen: From Information Management to Task Management in Electronic Mail, 2002, ISBN 917373-258-3.

No 745 Johan Åberg: Live Help Systems: An Approach to Intelligent Help for Web Information Systems, 2002, ISBN 91-7373-311-3.

No 746 Rego Granlund: Monitoring Distributed Teamwork Training, 2002, ISBN 91-7373-312-1.

No 757 Henrik André-Jönsson: Indexing Strategies for Time Series Data, 2002, ISBN 917373-346-6.

No 747 Anneli Hagdahl: Development of IT-supported Interorganisational Collaboration - A Case Study in the Swedish Public Sector, 2002, ISBN 91-7373-314-8.

No 749 Sofie Pilemalm: Information Technology for NonProfit Organisations - Extended Participatory Design of an Information System for Trade Union Shop Stewards, 2002, ISBN 91-7373-318-0.

No 765 Stefan Holmlid: Adapting users: Towards a theory of use quality, 2002, ISBN 91-7373-397-0.

No 771 Magnus Morin: Multimedia Representations of Distributed Tactical Operations, 2002, ISBN 91-7373-4217.

No 772 Pawel Pietrzak: A Type-Based Framework for Locating Errors in Constraint Logic Programs, 2002, ISBN 91-7373-422-5.

No 758 Erik Berglund: Library Communication Among Programmers Worldwide, 2002, ISBN 91-7373-349-0.

No 774 Choong-ho Yi: Modelling Object-Oriented Dynamic Systems Using a Logic-Based Framework, 2002, ISBN 91-7373-424-1.

No 779 Mathias Broxvall: A Study in the Computational Complexity of Temporal Reasoning, 2002, ISBN 917373-440-3.
No 793 Asmus Pandikow: A Generic Principle for Enabling Interoperability of Structured and Object-Oriented Analysis and Design Tools, 2002, ISBN 91-7373-479-9.

No 785 Lars Hult: Publika Informationstjänster. En studie av den Internetbaserade encyklopedins bruksegenskaper, 2003, ISBN 91-7373-461-6.

No 800 Lars Taxén: A Framework for the Coordination of Complex Systems' Development, 2003, ISBN 917373-604-X.

No 808 Klas Gäre: Tre perspektiv på förväntningar och förändringar $i$ samband med införande av informationssystem, 2003, ISBN 91-7373-618-X.

No 821 Mikael Kindborg: Concurrent Comics programming of social agents by children, 2003, ISBN 91-7373-651-1.

No 823 Christina Ölvingson: On Development of Information Systems with GIS Functionality in Public Health Informatics: A Requirements Engineering Approach, 2003, ISBN 91-7373-656-2.

No 828 Tobias Ritzau: Memory Efficient Hard Real-Time Garbage Collection, 2003, ISBN 91-7373-666-X.

No 833 Paul Pop: Analysis and Synthesis of Communication-Intensive Heterogeneous Real-Time Systems, 2003, ISBN 91-7373-683-X.

No 852 Johan Moe: Observing the Dynamic Behaviour of Large Distributed Systems to Improve Development and Testing - An Empirical Study in Software Engineering, 2003, ISBN 91-7373-779-8.

No 867 Erik Herzog: An Approach to Systems Engineering Tool Data Representation and Exchange, 2004, ISBN 91-7373-929-4.

No 872 Aseel Berglund: Augmenting the Remote Control: Studies in Complex Information Navigation for Digital TV, 2004, ISBN 91-7373-940-5.

No 869 Jo Skåmedal: Telecommuting's Implications on Travel and Travel Patterns, 2004, ISBN 91-7373-935-9.

No 870 Linda Askenäs: The Roles of IT - Studies of Organising when Implementing and Using Enterprise Systems, 2004, ISBN 91-7373-936-7.

No 874 Annika Flycht-Eriksson: Design and Use of Ontologies in Information-Providing Dialogue Systems, 2004, ISBN 91-7373-947-2.

No 873 Peter Bunus: Debugging Techniques for EquationBased Languages, 2004, ISBN 91-7373-941-3.

No 876 Jonas Mellin: Resource-Predictable and Efficient Monitoring of Events, 2004, ISBN 91-7373-956-1.

No 883 Magnus Bång: Computing at the Speed of Paper: Ubiquitous Computing Environments for Healthcare Professionals, 2004, ISBN 91-7373-971-5.

No 882 Robert Eklund: Disfluency in Swedish humanhuman and human-machine travel booking dialogues, 2004, ISBN 91-7373-966-9.

No 887 Anders Lindström: English and other Foreign Linguistic Elements in Spoken Swedish. Studies of Productive Processes and their Modelling using Finite-State Tools, 2004, ISBN 91-7373-981-2.

No 889 Zhiping Wang: Capacity-Constrained Production-inventory systems - Modelling and Analysis in both a traditional and an e-business context, 2004, ISBN 9185295-08-6.

No 893 Pernilla Qvarfordt: Eyes on Multimodal Interaction, 2004, ISBN 91-85295-30-2.

No 910 Magnus Kald: In the Borderland between Strategy and Management Control - Theoretical Framework and Empirical Evidence, 2004, ISBN 91-85295-82-5. 
No 918 Jonas Lundberg: Shaping Electronic News: Genre Perspectives on Interaction Design, 2004, ISBN 9185297-14-3.

No 900 Mattias Arvola: Shades of use: The dynamics of interaction design for sociable use, 2004, ISBN 9185295-42-6.

No 920 Luis Alejandro Cortés: Verification and Scheduling Techniques for Real-Time Embedded Systems, 2004, ISBN 91-85297-21-6.

No 929 Diana Szentivanyi: Performance Studies of FaultTolerant Middleware, 2005, ISBN 91-85297-58-5.

No 933 Mikael Cäker: Management Accounting as Constructing and Opposing Customer Focus: Three Case Studies on Management Accounting and Customer Relations, 2005, ISBN 91-85297-64-X.

No 937 Jonas Kvarnström: TALplanner and Other Extensions to Temporal Action Logic, 2005, ISBN $91-$ 85297-75-5.

No 938 Bourhane Kadmiry: Fuzzy Gain-Scheduled Visual Servoing for Unmanned Helicopter, 2005, ISBN $91-$ 85297-76-3.

No 945 Gert Jervan: Hybrid Built-In Self-Test and Test Generation Techniques for Digital Systems, 2005, ISBN 91-85297-97-6.

No 946 Anders Arpteg: Intelligent Semi-Structured Information Extraction, 2005, ISBN 91-85297-98-4.

No 947 Ola Angelsmark: Constructing Algorithms for Constraint Satisfaction and Related Problems - Methods and Applications, 2005, ISBN 91-85297-99-2.

No 963 Calin Curescu: Utility-based Optimisation of Resource Allocation for Wireless Networks, 2005, ISBN 91-85457-07-8.

No 972 Björn Johansson: Joint Control in Dynamic Situations, 2005, ISBN 91-85457-31-0.

No 974 Dan Lawesson: An Approach to Diagnosability Analysis for Interacting Finite State Systems, 2005, ISBN 91-85457-39-6.

No 979 Claudiu Duma: Security and Trust Mechanisms for Groups in Distributed Services, 2005, ISBN 91-8545754-X.

No 983 Sorin Manolache: Analysis and Optimisation of Real-Time Systems with Stochastic Behaviour, 2005, ISBN 91-85457-60-4.

No 986 Yuxiao Zhao: Standards-Based Application Integration for Business-to-Business Communications, 2005, ISBN 91-85457-66-3

No 1004 Patrik Haslum: Admissible Heuristics for Automated Planning, 2006, ISBN 91-85497-28-2.

No 1005 Aleksandra Tešanovic: Developing Reusable and Reconfigurable Real-Time Software using Aspects and Components, 2006, ISBN 91-85497-29-0.

No 1008 David Dinka: Role, Identity and Work: Extending the design and development agenda, 2006, ISBN 9185497-42-8.

No 1009 Iakov Nakhimovski: Contributions to the Modeling and Simulation of Mechanical Systems with Detailed Contact Analysis, 2006, ISBN 91-85497-43-X.

No 1013 Wilhelm Dahllöf: Exact Algorithms for Exact Satisfiability Problems, 2006, ISBN 91-85523-97-6.

No 1016 Levon Saldamli: PDEModelica - A High-Level Language for Modeling with Partial Differential Equations, 2006, ISBN 91-85523-84-4.

No 1017 Daniel Karlsson: Verification of Component-based Embedded System Designs, 2006, ISBN 91-85523-79-8
No 1018 Ioan Chisalita: Communication and Networking Techniques for Traffic Safety Systems, 2006, ISBN 9185523-77-1.

No 1019 Tarja Susi: The Puzzle of Social Activity - The Significance of Tools in Cognition and Cooperation, 2006, ISBN 91-85523-71-2.

No 1021 Andrzej Bednarski: Integrated Optimal Code Generation for Digital Signal Processors, 2006, ISBN 9185523-69-0.

No 1022 Peter Aronsson: Automatic Parallelization of Equation-Based Simulation Programs, 2006, ISBN 9185523-68-2.

No 1030 Robert Nilsson: A Mutation-based Framework for Automated Testing of Timeliness, 2006, ISBN 9185523-35-6.

No 1034 Jon Edvardsson: Techniques for Automatic Generation of Tests from Programs and Specifications, 2006, ISBN 91-85523-31-3.

No 1035 Vaida Jakoniene: Integration of Biological Data, 2006, ISBN 91-85523-28-3.

No 1045 Genevieve Gorrell: Generalized Hebbian Algorithms for Dimensionality Reduction in Natural Language Processing, 2006, ISBN 91-85643-88-2.

No 1051 Yu-Hsing Huang: Having a New Pair of Glasses Applying Systemic Accident Models on Road Safety, 2006, ISBN 91-85643-64-5.

No 1054 Åsa Hedenskog: Perceive those things which cannot be seen - A Cognitive Systems Engineering perspective on requirements management, 2006, ISBN 91-85643-57-2.

No 1061 Cécile Åberg: An Evaluation Platform for Semantic Web Technology, 2007, ISBN 91-85643-31-9.

No 1073 Mats Grindal: Handling Combinatorial Explosion in Software Testing, 2007, ISBN 978-91-85715-74-9.

No 1075 Almut Herzog: Usable Security Policies for Runtime Environments, 2007, ISBN 978-91-85715-65-7.

No 1079 Magnus Wahlström: Algorithms, measures, and upper bounds for Satisfiability and related problems, 2007, ISBN 978-91-85715-55-8.

No 1083 Jesper Andersson: Dynamic Software Architectures, 2007, ISBN 978-91-85715-46-6.

No 1086 Ulf Johansson: Obtaining Accurate and Comprehensible Data Mining Models - An Evolutionary Approach, 2007, ISBN 978-91-85715-34-3.

No 1089 Traian Pop: Analysis and Optimisation of Distributed Embedded Systems with Heterogeneous Scheduling Policies, 2007, ISBN 978-91-85715-27-5.

No 1091 Gustav Nordh: Complexity Dichotomies for CSPrelated Problems, 2007, ISBN 978-91-85715-20-6.

No 1106 Per Ola Kristensson: Discrete and Continuous Shape Writing for Text Entry and Control, 2007, ISBN 97891-85831-77-7.

No 1110 He Tan: Aligning Biomedical Ontologies, 2007, ISBN 978-91-85831-56-2.

No 1112 Jessica Lindblom: Minding the body - Interacting socially through embodied action, 2007, ISBN 978-9185831-48-7.

No 1113 Pontus Wärnestål: Dialogue Behavior Management in Conversational Recommender Systems, 2007, ISBN 978-91-85831-47-0.

No 1120 Thomas Gustafsson: Management of Real-Time Data Consistency and Transient Overloads in Embedded Systems, 2007, ISBN 978-91-85831-33-3. 
No 1127 Alexandru Andrei: Energy Efficient and Predictable Design of Real-time Embedded Systems, 2007, ISBN 978-91-85831-06-7.

No 1139 Per Wikberg: Eliciting Knowledge from Experts in Modeling of Complex Systems: Managing Variation and Interactions, 2007, ISBN 978-91-85895-66-3.

No 1143 Mehdi Amirijoo: QoS Control of Real-Time Data Services under Uncertain Workload, 2007, ISBN 97891-85895-49-6.

No 1150 Sanny Syberfeldt: Optimistic Replication with Forward Conflict Resolution in Distributed Real-Time Databases, 2007, ISBN 978-91-85895-27-4.

No 1155 Beatrice Alenljung: Envisioning a Future Decision Support System for Requirements Engineering - A Holistic and Human-centred Perspective, 2008, ISBN 978-91-85895-11-3.

No 1156 Artur Wilk: Types for XML with Application to Xcerpt, 2008, ISBN 978-91-85895-08-3.

No 1183 Adrian Pop: Integrated Model-Driven Development Environments for Equation-Based Object-Oriented Languages, 2008, ISBN 978-91-7393-895-2.

No 1185 Jörgen Skågeby: Gifting Technologies Ethnographic Studies of End-users and Social Media Sharing, 2008, ISBN 978-91-7393-892-1.

No 1187 Imad-Eldin Ali Abugessaisa: Analytical tools and information-sharing methods supporting road safety organizations, 2008, ISBN 978-91-7393-887-7.

No 1204 H. Joe Steinhauer: A Representation Scheme for Description and Reconstruction of Object Configurations Based on Qualitative Relations, 2008, ISBN 978-91-7393-823-5.

No 1222 Anders Larsson: Test Optimization for Core-based System-on-Chip, 2008, ISBN 978-91-7393-768-9.

No 1238 Andreas Borg: Processes and Models for Capacity Requirements in Telecommunication Systems, 2009, ISBN 978-91-7393-700-9.

No 1240 Fredrik Heintz: DyKnow: A Stream-Based Knowledge Processing Middleware Framework, 2009, ISBN 978-91-7393-696-5.

No 1241 Birgitta Lindström: Testability of Dynamic RealTime Systems, 2009, ISBN 978-91-7393-695-8.

No 1244 Eva Blomqvist: Semi-automatic Ontology Construction based on Patterns, 2009, ISBN 978-91-7393-683-5.

No 1249 Rogier Woltjer: Functional Modeling of Constraint Management in Aviation Safety and Command and Control, 2009, ISBN 978-91-7393-659-0.

No 1260 Gianpaolo Conte: Vision-Based Localization and Guidance for Unmanned Aerial Vehicles, 2009, ISBN 978-91-7393-603-3.

No 1262 AnnMarie Ericsson: Enabling Tool Support for Formal Analysis of ECA Rules, 2009, ISBN 978-91-7393598-2.

No 1266 Jiri Trnka: Exploring Tactical Command and Control: A Role-Playing Simulation Approach, 2009, ISBN 978-91-7393-571-5.

No 1268 Bahlol Rahimi: Supporting Collaborative Work through ICT - How End-users Think of and Adopt Integrated Health Information Systems, 2009, ISBN 978-91-7393-550-0.

No 1274 Fredrik Kuivinen: Algorithms and Hardness Results for Some Valued CSPs, 2009, ISBN 978-91-7393-525-8.

No 1281 Gunnar Mathiason: Virtual Full Replication for Scalable Distributed Real-Time Databases, 2009, ISBN 978-91-7393-503-6.
No 1290 Viacheslav Izosimov: Scheduling and Optimization of Fault-Tolerant Distributed Embedded Systems, 2009, ISBN 978-91-7393-482-4

No 1294 Johan Thapper: Aspects of a Constraint Optimisation Problem, 2010, ISBN 978-91-7393-464-0.

No 1306 Susanna Nilsson: Augmentation in the Wild: User Centered Development and Evaluation of Augmented Reality Applications, 2010, ISBN 978-917393-416-9.

No 1313 Christer Thörn: On the Quality of Feature Models, 2010, ISBN 978-91-7393-394-0.

No 1321 Zhiyuan He: Temperature Aware and DefectProbability Driven Test Scheduling for System-onChip, 2010, ISBN 978-91-7393-378-0.

No 1333 David Broman: Meta-Languages and Semantics for Equation-Based Modeling and Simulation, 2010, ISBN 978-91-7393-335-3.

No 1337 Alexander Siemers: Contributions to Modelling and Visualisation of Multibody Systems Simulations with Detailed Contact Analysis, 2010, ISBN 978-91-7393317-9.

No 1354 Mikael Asplund: Disconnected Discoveries: Availability Studies in Partitioned Networks, 2010, ISBN 978-91-7393-278-3.

No 1359 Jana Rambusch: Mind Games Extended Understanding Gameplay as Situated Activity, 2010 ISBN 978-91-7393-252-3.

No 1373 Sonia Sangari: Head Movement Correlates to Focus Assignment in Swedish, 2011, ISBN 978-91-7393-1540 .

No 1374 Jan-Erik Källhammer: Using False Alarms when Developing Automotive Active Safety Systems, 2011, ISBN 978-91-7393-153-3.

No 1375 Mattias Eriksson: Integrated Code Generation, 2011, ISBN 978-91-7393-147-2.

No 1381 Ola Leifler: Affordances and Constraints of Intelligent Decision Support for Military Command and Control - Three Case Studies of Support Systems, 2011, ISBN 978-91-7393-133-5.

No 1386 Soheil Samii: Quality-Driven Synthesis and Optimization of Embedded Control Systems, 2011, ISBN 978-91-7393-102-1.

No 1419 Erik Kuiper: Geographic Routing in Intermittentlyconnected Mobile Ad Hoc Networks: Algorithms and Performance Models, 2012, ISBN 978-91-7519981-8.

No 1451 Sara Stymne: Text Harmonization Strategies for Phrase-Based Statistical Machine Translation, 2012, ISBN 978-91-7519-887-3.

No 1455 Alberto Montebelli: Modeling the Role of Energy Management in Embodied Cognition, 2012, ISBN 978-91-7519-882-8.

No 1465 Mohammad Saifullah: Biologically-Based Interactive Neural Network Models for Visual Attention and Object Recognition, 2012, ISBN 978-91-7519-838-5.

No 1490 Tomas Bengtsson: Testing and Logic Optimization Techniques for Systems on Chip, 2012, ISBN 978-917519-742-5.

No 1481 David Byers: Improving Software Security by Preventing Known Vulnerabilities, 2012, ISBN 97891-7519-784-5.

No 1496 Tommy Färnqvist: Exploiting Structure in CSPrelated Problems, 2013, ISBN 978-91-7519-711-1. 
No 1503 John Wilander: Contributions to Specification, Implementation, and Execution of Secure Software, 2013, ISBN 978-91-7519-681-7.

No 1506 Magnus Ingmarsson: Creating and Enabling the Useful Service Discovery Experience, 2013, ISBN 97891-7519-662-6.

No 1547 Wladimir Schamai: Model-Based Verification of Dynamic System Behavior against Requirements: Method, Language, and Tool, 2013, ISBN 978-917519-505-6.

No 1551 Henrik Svensson: Simulations, 2013, ISBN 978-917519-491-2.

No 1559 Sergiu Rafiliu: Stability of Adaptive Distributed Real-Time Systems with Dynamic Resource Management, 2013, ISBN 978-91-7519-471-4.

No 1581 Usman Dastgeer: Performance-aware Component Composition for GPU-based Systems, 2014, ISBN 978-91-7519-383-0.

No 1602 Cai Li: Reinforcement Learning of Locomotion based on Central Pattern Generators, 2014, ISBN 978-917519-313-7.

No 1652 Roland Samlaus: An Integrated Development Environment with Enhanced Domain-Specific Interactive Model Validation, 2015, ISBN 978-917519-090-7.

No 1663 Hannes Uppman: On Some Combinatorial Optimization Problems: Algorithms and Complexity, 2015, ISBN 978-91-7519-072-3.

No 1664 Martin Sjölund: Tools and Methods for Analysis, Debugging, and Performance Improvement of Equation-Based Models, 2015, ISBN 978-91-7519-071-6.

No 1666 Kristian Stavåker: Contributions to Simulation of Modelica Models on Data-Parallel Multi-Core Architectures, 2015, ISBN 978-91-7519-068-6.

No 1680 Adrian Lifa: Hardware/Software Codesign of Embedded Systems with Reconfigurable and Heterogeneous Platforms, 2015, ISBN 978-91-7519-0402.

No 1685 Bogdan Tanasa: Timing Analysis of Distributed Embedded Systems with Stochastic Workload and Reliability Constraints, 2015, ISBN 978-91-7519-022-8.

No 1691 Håkan Warnquist: Troubleshooting Trucks Automated Planning and Diagnosis, 2015, ISBN 97891-7685-993-3.

No 1702 Nima Aghaee: Thermal Issues in Testing of Advanced Systems on Chip, 2015, ISBN 978-91-7685949-0.

No 1715 Maria Vasilevskaya: Security in Embedded Systems: A Model-Based Approach with Risk Metrics, 2015, ISBN 978-91-7685-917-9.

No 1729 Ke Jiang: Security-Driven Design of Real-Time Embedded System, 2016, ISBN 978-91-7685-884-4.

No 1733 Victor Lagerkvist: Strong Partial Clones and the Complexity of Constraint Satisfaction Problems: Limitations and Applications, 2016, ISBN 978-91-7685856-1.

No 1734 Chandan Roy: An Informed System Development Approach to Tropical Cyclone Track and Intensity Forecasting, 2016, ISBN 978-91-7685-854-7.

No 1746 Amir Aminifar: Analysis, Design, and Optimization of Embedded Control Systems, 2016, ISBN 978-917685-826-4.

No 1747 Ekhiotz Vergara: Energy Modelling and Fairness for Efficient Mobile Communication, 2016, ISBN 978-917685-822-6.
No 1748 Dag Sonntag: Chain Graphs - Interpretations, Expressiveness and Learning Algorithms, 2016, ISBN 978-91-7685-818-9.

No 1768 Anna Vapen: Web Authentication using ThirdParties in Untrusted Environments, 2016, ISBN 97891-7685-753-3.

No 1778 Magnus Jandinger: On a Need to Know Basis: A Conceptual and Methodological Framework for Modelling and Analysis of Information Demand in an Enterprise Context, 2016, ISBN 978-91-7685-713-7.

No 1798 Rahul Hiran: Collaborative Network Security: Targeting Wide-area Routing and Edge-network Attacks, 2016, ISBN 978-91-7685-662-8.

No 1813 Nicolas Melot: Algorithms and Framework for Energy Efficient Parallel Stream Computing on Many-Core Architectures, 2016, ISBN 978-91-7685623-9.

No 1823 Amy Rankin: Making Sense of Adaptations: Resilience in High-Risk Work, 2017, ISBN 978-917685-596-6.

No 1831 Lisa Malmberg: Building Design Capability in the Public Sector: Expanding the Horizons of Development, 2017, ISBN 978-91-7685-585-0.

No 1851 Marcus Bendtsen: Gated Bayesian Networks, 2017, ISBN 978-91-7685-525-6.

No 1852 Zlatan Dragisic: Completion of Ontologies and Ontology Networks, 2017, ISBN 978-91-7685-522-5.

No 1854 Meysam Aghighi: Computational Complexity of some Optimization Problems in Planning, 2017, ISBN 978-91-7685-519-5.

No 1863 Simon Ståhlberg: Methods for Detecting Unsolvable Planning Instances using Variable Projection, 2017, ISBN 978-91-7685-498-3.

No 1879 Karl Hammar: Content Ontology Design Patterns: Qualities, Methods, and Tools, 2017, ISBN 978-917685-454-9.

No 1887 Ivan Ukhov: System-Level Analysis and Design under Uncertainty, 2017, ISBN 978-91-7685-426-6.

No 1891 Valentina Ivanova: Fostering User Involvement in Ontology Alignment and Alignment Evaluation, 2017, ISBN 978-91-7685-403-7.

No 1902 Vengatanathan Krishnamoorthi: Efficient HTTPbased Adaptive Streaming of Linear and Interactive Videos, 2018, ISBN 978-91-7685-371-9.

No 1903 Lu Li: Programming Abstractions and Optimization Techniques for GPU-based Heterogeneous Systems, 2018, ISBN 978-91-7685-370-2.

No 1913 Jonas Rybing: Studying Simulations with Distributed Cognition, 2018, ISBN 978-91-7685-348-1.

No 1936 Leif Jonsson: Machine Learning-Based Bug Handling in Large-Scale Software Development, 2018, ISBN 978-91-7685-306-1.

No 1964 Arian Maghazeh: System-Level Design of GPUBased Embedded Systems, 2018, ISBN 978-91-7685175-3.

No 1967 Mahder Gebremedhin: Automatic and Explicit Parallelization Approaches for Equation Based Mathematical Modeling and Simulation, 2019, ISBN 978-91-7685-163-0.

No 1984 Anders Andersson: Distributed Moving Base Driving Simulators - Technology, Performance, and Requirements, 2019, ISBN 978-91-7685-090-9.

No 1993 Ulf Kargén: Scalable Dynamic Analysis of Binary Code, 2019, ISBN 978-91-7685-049-7. 
No 2001 Tim Overkamp: How Service Ideas Are Implemented: Ways of Framing and Addressing Service Transformation, 2019, ISBN 978-91-7685-025-1.

No 2006 Daniel de Leng: Robust Stream Reasoning Under Uncertainty, 2019, ISBN 978-91-7685-013-8.

No 2048 Biman Roy: Applications of Partial Polymorphisms in (Fine-Grained) Complexity of Constraint Satisfaction Problems, 2020, ISBN 978-91-7929-898-2.

No 2051 Olov Andersson: Learning to Make Safe Real-Time Decisions Under Uncertainty for Autonomous Robots, 2020, ISBN 978-91-7929-889-0.

\section{Linköping Studies in Arts and Sciences}

No 504 Ing-Marie Jonsson: Social and Emotional Characteristics of Speech-based In-Vehicle Information Systems: Impact on Attitude and Driving Behaviour, 2009, ISBN 978-91-7393-478-7.

No 586 Fabian Segelström: Stakeholder Engagement for Service Design: How service designers identify and communicate insights, 2013, ISBN 978-91-7519-554-4.

No 618 Johan Blomkvist: Representing Future Situations of Service: Prototyping in Service Design, 2014, ISBN 978-91-7519-343-4.

No 620 Marcus Mast: Human-Robot Interaction for SemiAutonomous Assistive Robots, 2014, ISBN 978-917519-319-9.

No 677 Peter Berggren: Assessing Shared Strategic Understanding, 2016, ISBN 978-91-7685-786-1.

No 695 Mattias Forsblad: Distributed cognition in home environments: The prospective memory and cognitive practices of older adults, 2016, ISBN 97891-7685-686-4.

No 787 Sara Nygårdhs: Adaptive behaviour in traffic: An individual road user perspective, 2020, ISBN 978-917929-857-9.

\section{Linköping Studies in Statistics}

No 9 Davood Shahsavani: Computer Experiments Designed to Explore and Approximate Complex Deterministic Models, 2008, ISBN 978-91-7393-976-8.

No 10 Karl Wahlin: Roadmap for Trend Detection and Assessment of Data Quality, 2008, ISBN 978-91-7393$792-4$.

No 11 Oleg Sysoev: Monotonic regression for large multivariate datasets, 2010, ISBN 978-91-7393-412-1.

No 13 Agné Burauskaite-Harju: Characterizing Temporal Change and Inter-Site Correlations in Daily and Subdaily Precipitation Extremes, 2011, ISBN 978-91-7393110-6.

No 14 Måns Magnusson: Scalable and Efficient Probabilistic Topic Model Inference for Textual Data, 2018, ISBN 978-91-7685-288-0.

\section{Linköping Studies in Information Science}

No 1 Karin Axelsson: Metodisk systemstrukturering- att skapa samstämmighet mellan informationssystemarkitektur och verksamhet, 1998. ISBN 9172-19-296-8.

No 2 Stefan Cronholm: Metodverktyg och användbarhet en studie av datorstödd metodbaserad systemutveckling, 1998, ISBN 9172-19-299-2.

No 3 Anders Avdic: Användare och utvecklare - om anveckling med kalkylprogram, 1999. ISBN 91-7219606-8.
No 4 Owen Eriksson: Kommunikationskvalitet hos informationssystem och affärsprocesser, 2000, ISBN 917219-811-7.

No 5 Mikael Lind: Från system till process - kriterier för processbestämning vid verksamhetsanalys, 2001, ISBN 91-7373-067-X.

No 6 Ulf Melin: Koordination och informationssystem i företag och nätverk, 2002, ISBN 91-7373-278-8.

No 7 Pär J. Ågerfalk: Information Systems Actability - Understanding Information Technology as a Tool for Business Action and Communication, 2003, ISBN 917373-628-7.

No 8 Ulf Seigerroth: Att förstå och förändra systemutvecklingsverksamheter - en taxonomi för metautveckling, 2003, ISBN 91-7373-736-4.

No 9 Karin Hedström: Spår av datoriseringens värden Effekter av IT i äldreomsorg, 2004, ISBN 91-7373-9634.

No 10 Ewa Braf: Knowledge Demanded for Action Studies on Knowledge Mediation in Organisations, 2004, ISBN 91-85295-47-7.

No 11 Fredrik Karlsson: Method Configuration method and computerized tool support, 2005, ISBN 91-8529748-8.

No 12 Malin Nordström: Styrbar systemförvaltning - Att organisera systemförvaltningsverksamhet med hjälp av effektiva förvaltningsobjekt, 2005, ISBN 91-8529760-7.

No 13 Stefan Holgersson: Yrke: POLIS - Yrkeskunskap, motivation, IT-system och andra förutsättningar för polisarbete, 2005, ISBN 91-85299-43-X.

No 14 Benneth Christiansson, Marie-Therese Christiansson: Mötet mellan process och komponent - mot ett ramverk för en verksamhetsnära kravspecifikation vid anskaffning av komponentbaserade informationssystem, 2006, ISBN 91-8564322-X. 


\section{FACULTY OF ARTS AND SCIENCES}

Linköping Studies in Arts and Sciences No. 787, 2020

Department of Computer and Information Science (IDA]

Linköping University

SE-581 83 Linköping, Sweden

www.liu.se 